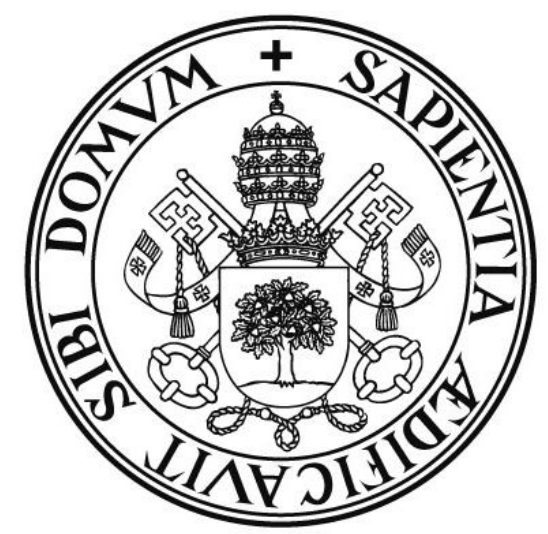

UNIVERSIDAD DE VALLADOLID

FACULTAD DE MEDICINA

DEPARTAMENTO DE CIRUGÍA, OFTALMOLOGÍA, OTORRINOLARINGOLOGÍA Y FISIOTERAPIA

TESIS DOCTORAL:

\title{
EL ESTADO DE INMUNOCOMPETENCIA DETERMINA EL PRONÓSTICO EN LOS PACIENTES SÉPTICOS
}

Presentada por Ana Fernández Urbón para optar al grado de doctora por la Universidad de Valladolid

Dirigida por: Eduardo Tamayo Gómez, Jesús Fco. Bermejo y

J. Ignacio Gómez-Herreras

Valladolid, Junio 2013 

A Álvaro y a mi familia.

"Lo que sabemos es una gota de agua; lo que ignoramos es el océano."

Isaac Newton (1642-1727). 

Dirigida por los doctores:

D. EDUARDO TAMAYO, Profesor Titular del Departamento de Cirugía, Oftalmología, Otorrinolaringología y Fisioterapia de la Facultad de Medicina de Valladolid. Especialista en Anestesiología y Reanimación.

D. JESÚS FCO. BERMEJO MARTÍN, Doctor en medicina y cirugía, especialista de Inmunología Clínica. Investigador principal de la unidad de investigación médica en infección e inmunidad -IMI- del Servicio de Microbiología en el Hospital Clínico Universitario de Valladolid-IESCYL.

D. JOSÉ IGNACIO GÓMEZ HERRERAS, Profesor asociado del Departamento de Cirugía, Oftalmología, Otorrinolaringología y Fisioterapia de la Facultad de Medicina de Valladolid. Jefe del servicio de Anestesiología y Reanimación del Hospital Clínico Universitario de Valladolid. 



\section{Universidad deValladolid}

Impreso $2 \mathrm{~T}$

\section{AUTORIZACIÓN DEL DIRECTOR DE TESIS}

(Art. 2.1. c de la Normativa para la presentación y defensa de la Tesis Doctoral en la $U V a)$

D. Eduardo Tamayo Gómez , con D.N.I. n 13087744-L, D. José Ignacio Gómez Herreras, con D.N.I. 12213549-C, profesores del departamento de Cirugía, Oftalmología y Otorrinolaringología y D. Jesús Fco. Bermejo Martín, con D.N.I.09344393C, como Directores de la tesis titulada: El estado de inmunocompetencia determina el pronóstico en los pacientes sépticos, presentada por Ana Fernández Urbón, con D.N.I. 71120488-A, alumno del programa TRASPLANTE DE ÓRGANOS Y TEJIDOS. DE LA INVESTIGACIÓN A LA CLÍNICA, impartido por el departamento de Cirugía, Oftalmología y Otorrinolaringología, autoriza la presentación de la misma, considerando que reúne todos los requisitos para la presentación, lectura y defensa de la misma.

Valladolid, de de

Los Directores de la Tesis,

Fdo.: Eduardo Tamayo Jesús Bermejo José Ignacio Gómez-Herreras. 



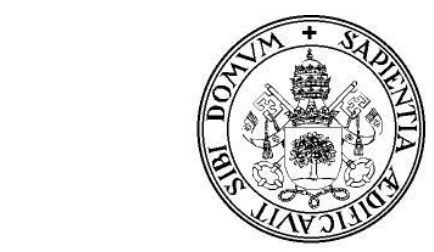

\section{Universidad deValladolid}

La presente tesis doctoral está realizada siguiendo el art. 3 de la Normativa de la UVA para la presentación y defensa de tesis doctorales por compendio de publicaciones. 



\section{AGRADECIMIENTOS}

En primer lugar quería dar las gracias a mis directores de tesis, sin los cuales este trabajo no habría sido posible.

A Eduardo Tamayo por su imprescindible asesoramiento, críticas, comentarios y sugerencias durante el desarrollo de este proyecto. Porque no cesa en su empeño por conocer mejor la fisiopatología de la sepsis. Gracias por tanta paciencia.

A Jesús Bermejo por el apoyo, entusiasmo y constancia, es admirable lo que disfruta de cada uno de los numerosos proyectos en los que se embarca.

A Jose Ignacio Gómez Herreras porque su dedicación es ejemplar y un estímulo constante para intentar ser mejor profesional cada día.

Otra persona que sin duda ha contribuido a que esta tesis sea posible es Raquel Almansa, sus consejos y aportaciones han sido fundamentales.

Debo mencionar a los facultativos del Departamento de Anestesiología y Reanimación del Hospital Clínico Universitario de Valladolid, con los que comparto tantas horas y de los que aprendo algo nuevo cada día.

Mención especial a Elena,"mi coerre", apoyo fundamental en todos estos años de formación y recogida de datos. Por saber estar ahí siempre.

Lucía y Verónica, muchas gracias por haber compartido conmigo vuestra sabiduría y buen hacer en el laboratorio.

Asimismo quiero agradecer a Sara González-Calvo su gran profesionalidad, gracias por conseguir cualquier artículo, por difícil que sea.

Tampoco quiero olvidar a mis amig@s y compañeras de promoción, que son mucho más que eso y están cuando se les necesita.

Cómo sintetizar en unas líneas el agradecimiento a mis padres y hermanos. Vuestro apoyo incondicional es el mejor estímulo para seguir esforzándome. Si algo destacaría, es el haberme inculcado la inquietud de aprender cosas nuevas. Vuestros consejos, comprensión y cariño han hecho que estemos hoy aquí.

No puedo finalizar sin hacer mención a mi familia Virgilio, Vicenta, Ana, Jose, Valeria, Samuel, Manuel, Miguel, Raquel y Jorge, por ser un ejemplo de esfuerzo, unidad y cariño.

Y como no a ti, Álvaro, ya sabes porqué. 



\section{EL ESTADO DE INMUNOCOMPETENCIA DETERMINA EL PRONÓSTICO EN LOS PACIENTES SÉPTICOS.}



ÍNDICE 



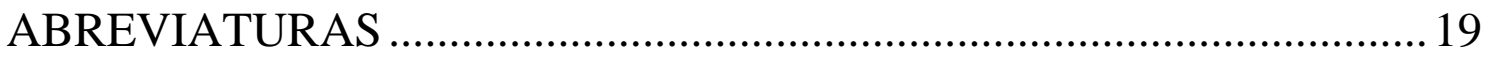

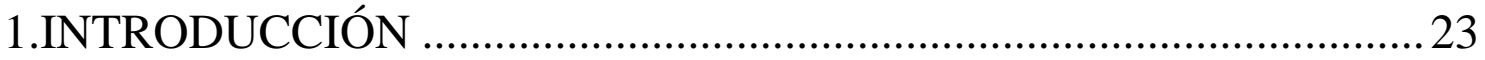

1.1-.Sepsis a través de la historia ......................................................25

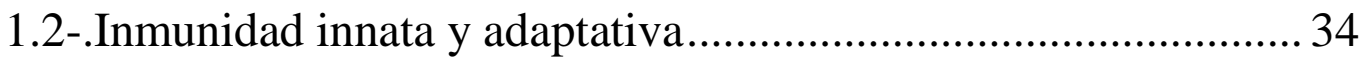

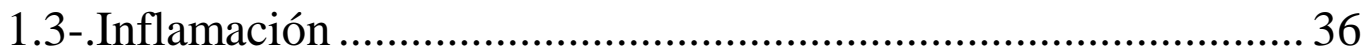

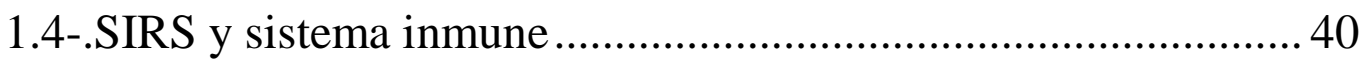

1.5-.Sepsis y sistema inmune …....................................................... 42

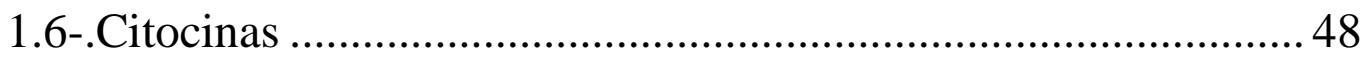

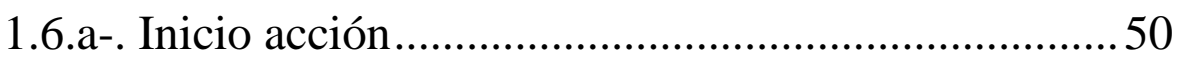

1.6.b-. Mecanismos de control ...........................................51

1.6.c-. Descripción de las principales citocinas ..................54

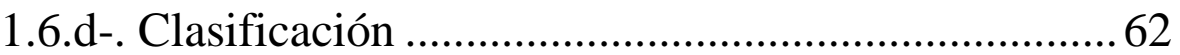

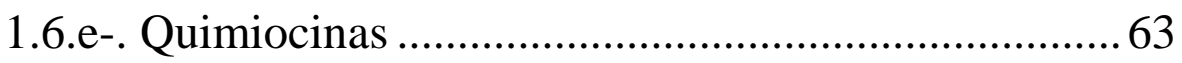

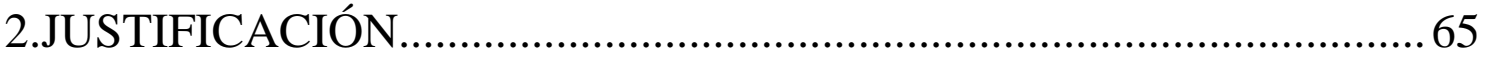

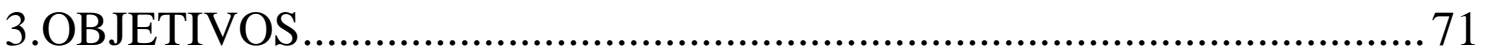

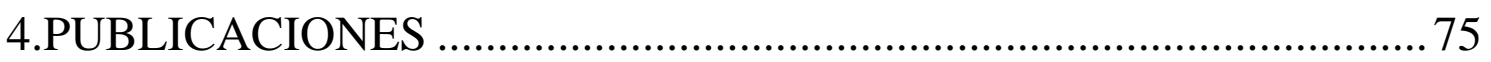

4.1. Las respuestas pro y antiinflamatorias se dan de forma simultánea desde los primeros momentos de la sepsis ..................... 77

4.2. IL-8 y predicción de mortalidad en shock séptico ........................ 87

4.3. Beneficios de subclases e isotipos de inmunoglobulinas

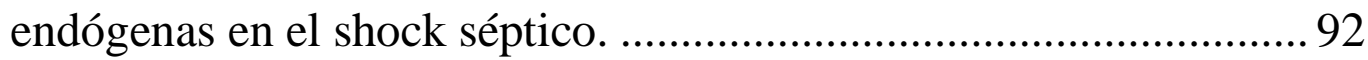

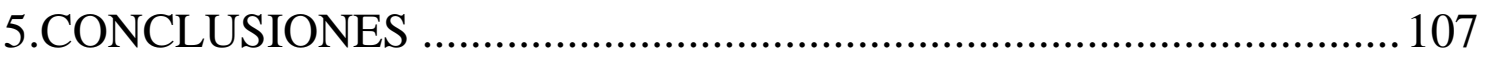

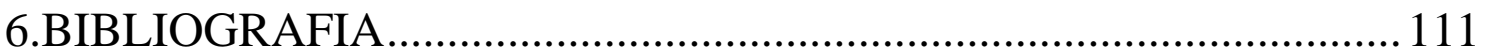

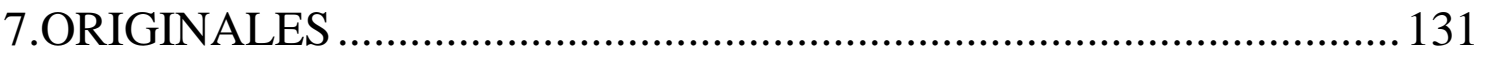



ABREVIATURAS 



$\begin{array}{ll}\text { ALI } & \text { Acute lung injury } \\ \text { AMP } & \text { Adenosín monofosfato } \\ \text { AMPc } & \text { Adenosín monofosfato cíclico } \\ \text { APACHE II } & \text { Acute physiology and chronic health evaluation } \\ \text { AUROC } & \text { Área bajo la curva ROC } \\ \text { CID } & \text { Coagulación intravascular diseminada } \\ \text { CO } & \text { Monóxido de carbono } \\ \text { CSF } & \text { Factor estimulante de colonias } \\ \text { DAMPs } & \text { Señales de alarma procedentes de las células dañadas } \\ \text { EDTA } & \text { Ácido etilendiamino tetraacético } \\ \text { G-CSF } & \text { Factor estimulador de colonias de granulocitos } \\ \text { GMP } & \text { Guanosín monofosfato } \\ \text { GMPc } & \text { Guanosín monofosfato cíclico } \\ \text { GM-SCF } & \text { Factor estimulador de colonias granulocito-macrófago } \\ \text { IC } & \text { Intervalo de confianza } \\ \text { ICAM } & \text { Moléculas de adhesión intercelulares } \\ \text { Ig } & \text { Inmunoglobulina } \\ \text { IL } & \text { Interleucina } \\ \text { IvIg } & \text { Inmunoglobulina intravenosa } \\ \text { LPS } & \text { Lipopolisacárido } \\ \text { NF-KB } & \text { Factor citosólico nuclear } \kappa B \\ \text { NO } & \text { Óxido nítrico } \\ \text { PAF } & \text { Factor activador de las plaquetas } \\ \text { PIRO } & \text { Predisposition Insult Response Organ dysfunction } \\ \text { PRR } & \text { Pattern Recognition Receptor } \\ \text { ROC } & \text { Curva característica operativa para el receptor } \\ \text { RR } & \text { Riesgo relativo } \\ \text { SIRS } & \text { Síndrome respuesta inflamatoria sistémica } \\ \text { SOFA } & \text { Sequential organ failure assessment score } \\ \text { SS } & \text { Shock séptico } \\ \text { Tc } & \text { Linfocito T citotóxico } \\ \text { TCR } & \text { receptor de la célula T } \\ \text { Th } & \text { Linfocito T helper } \\ \text { VCAM-1 } & \text { Moléculas de adhesión } \\ & \end{array}$



1.INTRODUCCIÓN 



\section{1-.SEPSIS A TRAVÉS DE LA HISTORIA}

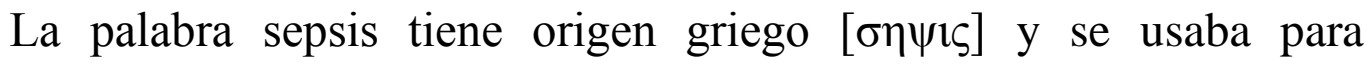
designar la descomposición de material orgánico vegetal o animal (1).

Antes de comenzar, hay que tener en cuenta que la sepsis se da como resultado de diversas infecciones que nada tienen que ver desde el punto de vista etiológico. Desde tiempos remotos existía gran interés por averiguar la causa de las infecciones que diezmaban de forma importante la población. Las primeras teorías atribuían a demonios y espíritus malignos, la autoría de las grandes epidemias (2).

El primer escrito que hace referencia a la sepsis data del 1600 a.C., es un papiro encontrado en Luxor en el 1862, copia de otro anterior datado en el 3000 a.C. y es considerado el tratado quirúrgico más antiguo (3). En esta época, la sepsis se vinculaba mayoritariamente a heridas de tipo traumático. En el papiro de Ebers (datado en el 1400 a.C.), se detallan distintos métodos encaminados a que la infección no progrese, como el uso de miel o grasa, así como la extracción de pus de las heridas (2). Hoy en día se ha constatado que los remedios egipcios disminuyen la carga bacteriana de S. Aureus y E.Colli.

Estos conocimientos fueron adoptados por los médicos griegos que se formaron en Egipto, como Herófilo (335 a.C.-280 a.C.) o Erasiato (340 a.C.-250 a.C.). El concepto de sepsis se generalizó, tanto es así que Homero hace referencia a él, en el poema XXIV de la Ilíada (4). Los griegos eran conscientes de la magnitud de este proceso, que podía conllevar compromiso sistémico: "Una única lesión, con aflujo de humor, hace que todo el cuerpo presente fiebre y el individuo pueda llegar a morir “ (5-6). Hipócrates (460-377 a.de C) propuso la teoría de que el ser humano está formado por cuatro humores fundamentales, que representaban los 
cuatro elementos (aire, agua, fuego y tierra). La salud del individuo dependía del equilibrio entre ellos (eucrasia) (7). Observó que cuando se extraía sangre de un individuo con fiebre, ésta era más oscura de lo normal (8). Lo que hoy en día sabemos que se produce debido a un aumento de la velocidad de sedimentación y de los reactantes de fase aguda, conllevando una disminución de la saturación (9-11). Para los médicos Hipocráticos la supuración podía ser beneficiosa o dañina. Esto se explica a través dos conceptos: "sepsis" que equivaldría a putrefacción (proceso dañino) y "pepsis" que se equipararía a maduración, fermentación (proceso beneficioso, parte de la evolución natural de la curación de una herida). Dependiendo de las características y procedencia de la supuración, se trataba de un proceso séptico o péptico y el pronóstico cambiaba. Era signo ominoso la ausencia total de pus, por todo esto, eran conservadores en sus métodos de curación. En este contexto se inició la asepsia y comenzaron a usar el vino y el agua hervida para lavar las heridas $(5,12)$.

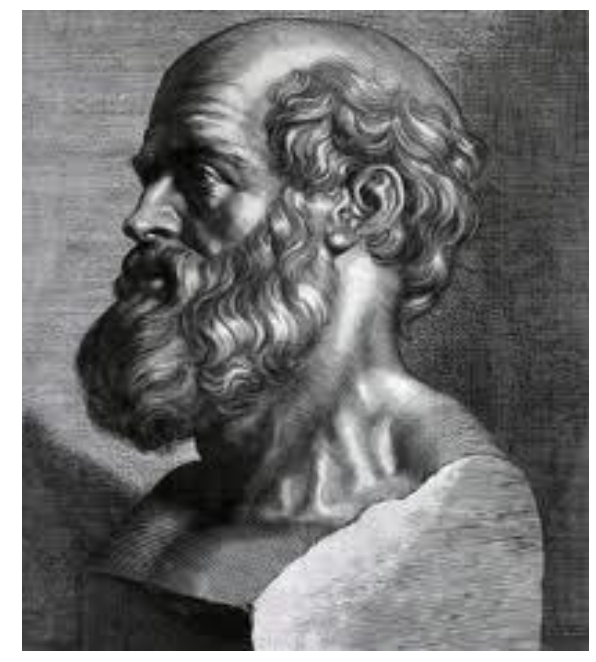

Figura1. Hipócrates.

El imperio romano recibió mucha de la sabiduría griega, usaron las mismas teorías y remedios, añadiendo alguno nuevo como el nitrato de plata (2). Galeno (131-200 a. C.) introdujo el concepto "Pus bonum et laudabile"(13-14). Lo que significaba que la formación de pus era 
beneficioso y que lo deseable era que las heridas cerraran por segunda intención, esta idea estimuló la cauterización de heridas, así, se hacían hervir los instrumentos usados para atender las lesiones de los gladiadores.

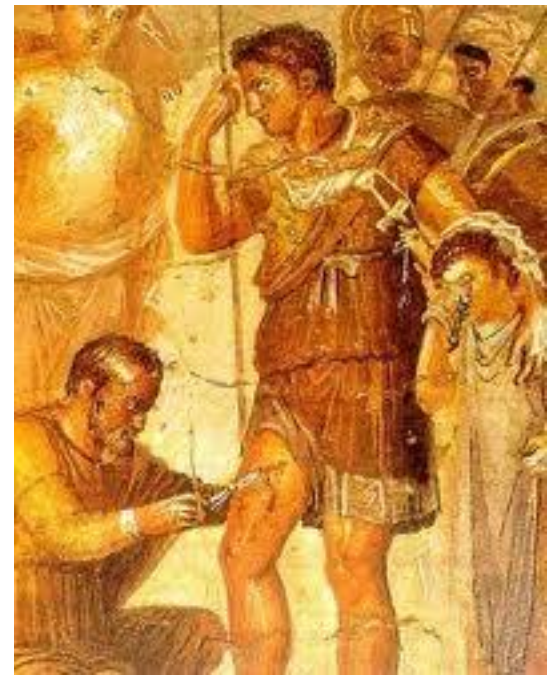

Figura 2. Galeno.

Tras el auge de la medicina romana, fueron los árabes los que recogieron el testigo, Ibn Sina, conocido como Avicena (980-1037), observó que la septicemia se acompañaba de fiebre. Durante la Edad Media, se retomó la teoría de que de la enfermedad se debía a fuerzas oscuras y la curación a lo sagrado, por lo que no hubo grandes avances en lo referente a infección. El tratamiento de la sepsis fue relegado a barberos/cirujanos en hospicios y campos de batalla (15), en este periodo el objetivo era únicamente hacer hemostasia en las heridas provocadas por espadas y flechas.

Ambroise Paré (1509-1590), ya en el Renacimiento, decidió poner fin a la cauterización indiscriminada. Durante una cruenta batalla, en la que él era el cirujano, el aceite que hervía para cauterizar las heridas se agotó y tuvo que improvisar usando turpentina y aceite de rosas. Observó que la evolución de los soldados que habían sido tratados con la turpentina y aceite de rosas era más favorable (16). 


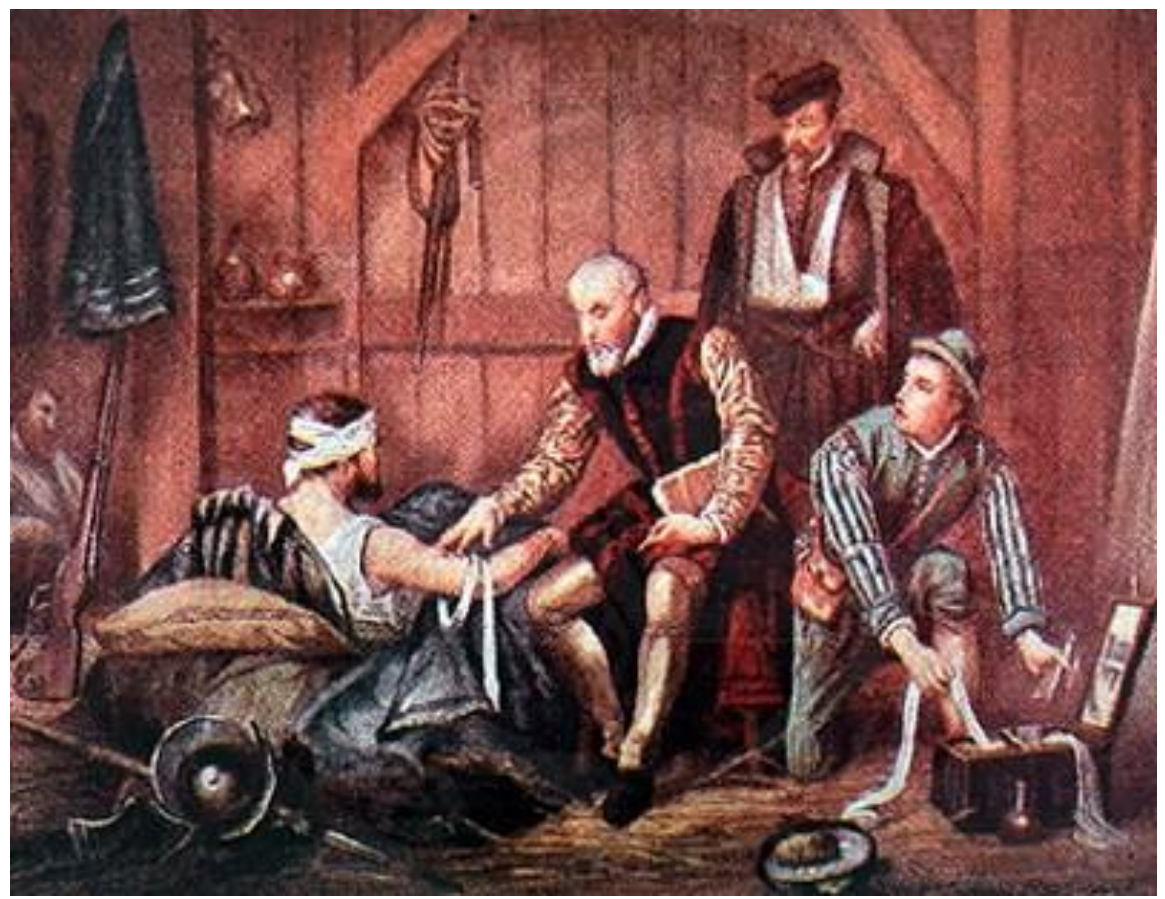

Figura 3. "Ambroise Paré treating wounded soldiers"

En esta época tan belicosa, las técnicas quirúrgicas avanzaron en gran medida así como la observación de los diferentes cuadros que sobrevenían a las heridas. En las primeras horas tras el trauma, el paciente podía morir bien por un sangrado masivo, bien por un shock que no se acompañaba de sangrado. Al principio atribuían ese shock a causas neurológicas, ya que el paciente perdía el conocimiento. Hoy en día se sabe que ese shock es secundario a una inflamación muy intensa, que tiene repercusión sistémica y que puede causar disfunción multiorgánica, aun en ausencia de infección (17). Hoy día, esta respuesta inflamatoria continúa siendo un problema, no sólo por el compromiso sistémico sino porque predispone a la infección (18-19).

De forma simultánea pero en Italia, Fracastoro (1478-1553) publicó "De Contagione et Contagiosis Morbis et Eorum Curatione", que describe lo que conocemos hoy como contagio. Aunque actualmente se le ha otorgado a su trabajo la relevancia que tiene, en su época no tuvo gran 
repercusión, fundamentalmente porque no podía demostrarse la etiología del contagio.

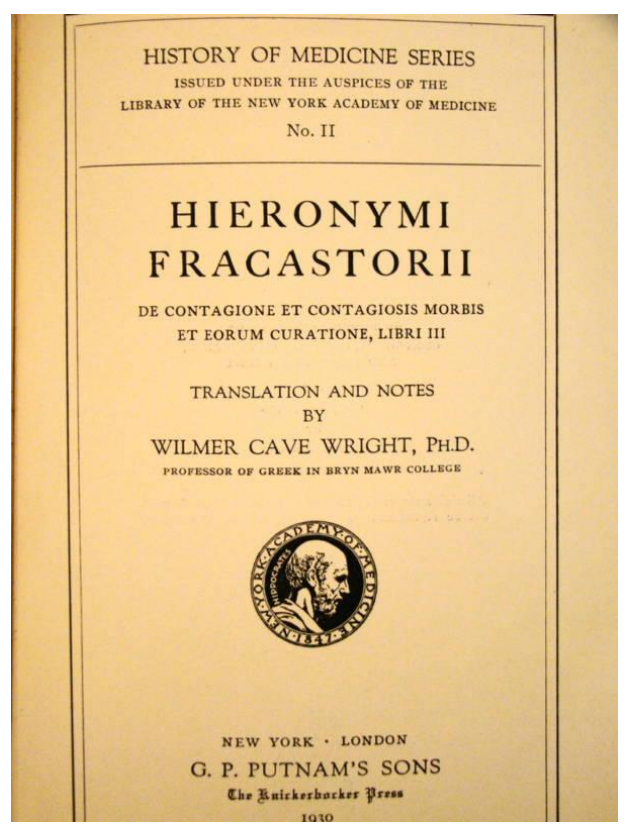

Figura 4.Traducción de 1930.

En 1752 John Pringle (1740-1780) introdujo el término anti-séptico y defendió la teoría del contagio animado como responsable de las infecciones nosocomiales. Lo que hay que tener en cuenta en este periodo histórico, es el hecho de que aunque ya existían publicaciones científicas, éstas no tenían la difusión suficiente, por lo que de forma casi simultánea, en diferentes lugares, se abordaban los mismos temas.

Hasta el siglo XIX, la amputación era la medida que se tomaba cuando el resto de tratamientos habían fracasado (20), pero Dominic Jean Larrey (1766-1842), cirujano de Napoleón Bonaparte, propuso la amputación como primera opción terapéutica. Él confiaba en disminuir la mortalidad en el campo de batalla, evitar la sepsis y el shock posttraumático y parece que lo consiguió, ya que sus tasas de supervivencia llegaron al 75\%. Durante el mismo periodo el cirujano británico George James Guthrie (1785-1856), cirujano de Wellington, describió los síntomas 
del shock séptico en soldados que participaron en la batalla de Waterloo (15).

En Austria, el obstetra Ignaz Semmelweis (1818-1865), infirió que realizar las autopsias sin guantes y a continuación atender los partos, daba como resultado la sepsis puerperal, por lo que implantó el lavado de manos, disminuyendo de forma notable la mortalidad por dicha causa $(16 \%$ a $<3 \%)$ (21-23).

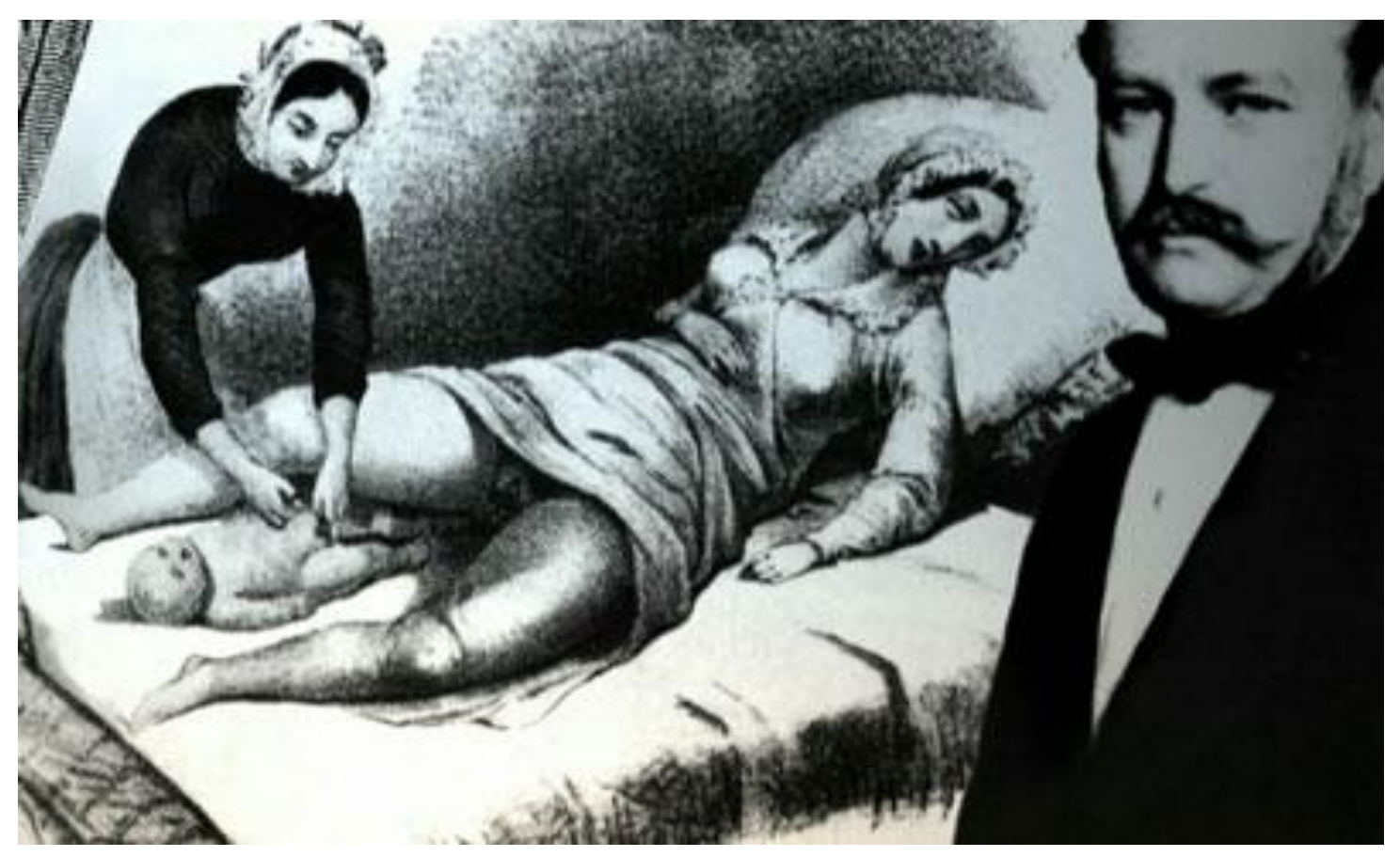

Figura 5. Ignaz Semmelweis.

Pasteur (1822-1895), sin conocer el trabajo de Semmelweis aisló el estreptococo (24), en sus trabajos comenzó a plantear la posibilidad de que los contagios se dieran a través de los microorganismos, pero no fue hasta la difusión del microscopio cuando se pudo constatar. Uno de los principales ayudantes de Virchow, Edwin Klebs (1834-1913), revisó un gran número de muestras procedentes de autopsias y encontró bacterias en casi todas ellas. A pesar de que no fue capaz de distinguir diferentes tipos, fue el primer científico que atribuyó a éstas la etiología de la sepsis (25). 


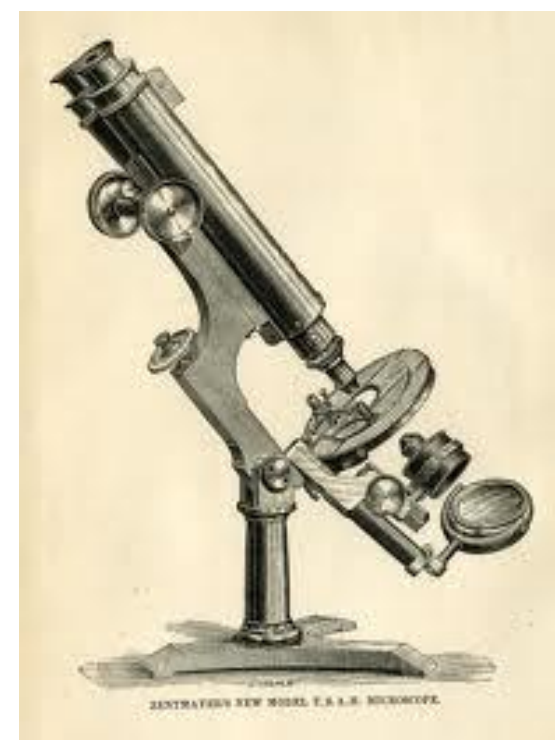

Figura 6. Microscopio 1750.

Alexander Ogston (1844-1929), que usó los métodos de Koch estableció de forma inequívoca la relación entre estafilococo, estreptococo y sepsis (25). En 1914 Hugo Schottmüller sentó las bases para la actual definición de sepsis, afirmando que la presencia de infección era parte fundamental de este cuadro clínico. Décadas después Lewis Thomas popularizó la idea de que era la propia respuesta del organismo la que estaba involucrada en dicho cuadro (26).

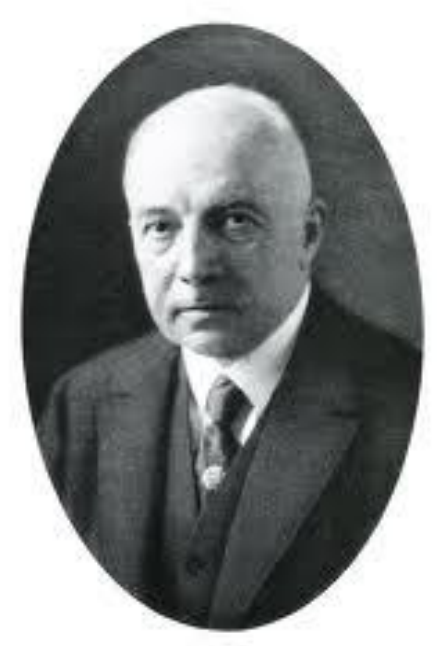

Figura 7. Hugo Schottmüller 
El descubrimiento fortuito de la penicilina por parte de Fleming en el 1929, revolucionó la forma de tratar las infecciones y le propició el premio nobel en 1945 (27).
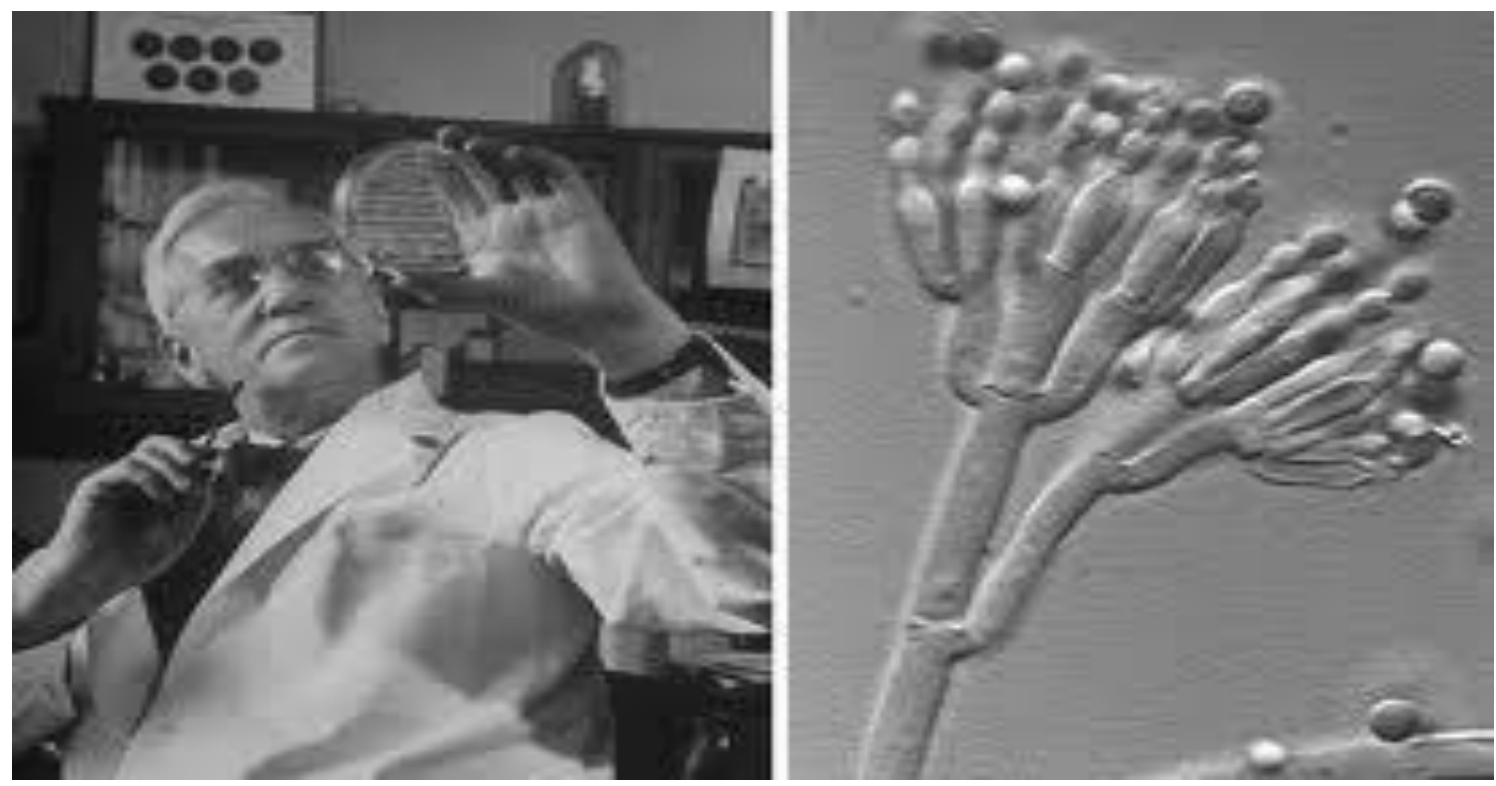

Figura 8. Alexander Fleming

En el siglo XX, la difusión mundial de la literatura médica, hace que expertos de diferentes países se hagan eco de la relevancia de la sepsis y la disparidad de criterios existentes. Con el fin de unificarlos, se realiza una conferencia de consenso en Agosto de 1991, quedando definidos y estandarizados distintos términos (28).

En la actualidad seguimos intentando profundizar en la fisiopatología de la sepsis, ya que esta entidad tiene gran repercusión, afecta a millones de personas en todo el mundo (29) y es la principal causa de mortalidad en las unidades de cuidados críticos $(28,30)$. Asimismo, su tratamiento conlleva un gasto sanitario muy importante (31-33), por ello, es objeto de estudio su fisiopatología (34-35). Cuanto mayor sea el conocimiento de los mecanismos que la desencadenan, más efectivos podrán ser los tratamientos. Hasta la fecha, las clasificaciones existentes se han centrado en la clínica y en marcadores bioquímicos, aunque las nuevas 
investigaciones van encaminadas a la tipificación de estos enfermos, ya que se ha comprobado que el sistema inmune de los pacientes más graves reacciona de forma diferente a la agresión que supone el patógeno (36-37). Así, en la última conferencia de consenso se introdujo el sistema PIRO (predisposition, insult, response, organ dysfunction), en el que se contempla que existen factores premórbidos que hacen a determinados pacientes responder de forma inadecuada a la infección (38). 


\section{2-.INMUNIDAD INNATA Y ADAPTATIVA}

El cuerpo humano tiene diversas maneras de protegerse a sí mismo. Algunas son simplemente barreras físicas como la capa de queratina que cubre la piel, otras son sustancias bioquímicas que protegen frente a una amplia variedad de microorganismos, como las lágrimas que contienen lisozimas, capaces de debilitar la pared bacteriana.

La finalidad del sistema inmune es identificar y eliminar células patógenas, además envía señales endógenas de alarma. Estas señales no sólo se envían en respuesta a la infección sino también al estrés, trauma o muerte celular no fisiológica como la necrosis (39). Para llevar a cabo su función, se vale de dos mecanismos bien diferenciados: la inmunidad innata y la adaptativa.

Inmunidad innata: sus componentes no requieren tiempo de latencia para iniciar acciones defensivas. Carece de especificidad y memoria. Es una respuesta estereotipada, independiente del antígeno y no aumenta su eficacia tras sucesivas exposiciones (40).

-Está constituida por barreras epiteliales, la inmunidad celular y humoral.

-Los elementos que integran la inmunidad celular son los linfocitos NK (Natural Killer) y los fagocitos (monocitos, macrófagos y polimorfonucleares).

-La inmunidad innata humoral la componen el sistema de complemento, lisozimas e interferones. El complemento son una serie de proteínas que median una cascada de reacciones enzimáticas que conducen a la lisis del agente invasor. 
Inmunidad adaptativa: se caracteriza porque tiene tiempo de latencia, tiene mecanismos de reconocimiento del patógeno muy específicos y posee memoria. Los responsables de llevar a cabo este tipo de respuesta son los linfocitos. Cuando el patógeno entra en el organismo la inmunidad adaptativa lo reconoce, durante la latencia linfocitos específicos amplifican su número y tras este periodo se da la respuesta efectora. Se crean anticuerpos específicos, tiene lugar una actividad citolítica y se liberan factores que activan células fagocíticas. Durante este proceso se adquiere la memoria inmunitaria (41).

Las células que llevan a cabo este tipo de respuesta son los linfocitos B y T. Ambos tipos celulares poseen en su membrana receptores capaces de reconocer el antígeno de una forma específica. Los linfocitos B son los principales encargados de la producción de anticuerpos o inmunoglobulinas (Ig). Existen 5 tipos de Igs denominadas isotipos: IgG, M, A, D y E.

Los linfocitos $\mathrm{T}$ tienen un receptor de membrana de estructura similar a las inmunoglobulinas, conocido como receptor de la célula $\mathrm{T}$ (TCR). Mediante ese receptor los linfocitos T son capaces de identificar el antígeno de forma específica. A diferencia de los linfocitos B, los linfocitos T necesitan que el antígeno sufra una serie de modificaciones antes de que lo puedan reconocer.

Existen dos tipos fundamentales de linfocitos T: los citolíticos (Tc) que son portadores de la molécula CD8 en su membrana y los cooperadores (helper, Th) que expresan CD 4. Los linfocitos Tc lisan células que presenten péptidos extraños en su membrana, por ejemplo los virus. Los linfocitos Th, como su propio nombre indica ayudan a los Tc. 


\section{3-.INFLAMACIÓN}

Se puede definir la inflamación como la respuesta no específica inicial ante la lesión tisular producida por un estímulo mecánico, químico o microbiano. Es una respuesta rápida humoral y celular, muy amplificada pero controlada, en la cual se ponen en marcha múltiples estirpes celulares.

El endotelio vascular tiene un papel fundamental en la respuesta del huésped frente a la agresión. En condiciones normales, las células endoteliales son una superficie relativamente inerte que regula el paso de sustancias desde el espacio intravascular al extravascular (42); mantiene el balance entre mecanismos procoagulantes y anticoagulantes, regula la adhesión y la migración de los leucocitos (neutrófilos), participa en la regulación del tono y crecimiento vascular y produce citocinas u otras moléculas de señales paracrinas (43). En respuesta a señales inflamatorias, como citocinas, lipopolisacáridos, productos de activación del complemento (C5a), hipoxia o radicales libres, las células endoteliales pasan a un estado de activación.

Muchas funciones homeostáticas de la vasculatura se mantienen por la señal de los nucleótidos cíclicos intracelulares. La cascada beta adrenérgica consiste en un evento mediado por receptor, que transmite una señal dentro de la célula por a través de la activación de los intermediarios de la proteína $\mathrm{G}$ y por la adenilciclasa, formando el segundo mensajero $\left(\mathrm{AMP}\right.$ cíclico, $\left.\mathrm{AMP}_{\mathrm{c}}\right)$. Éste, actuando a través de una protein-quinasa, puede fosforilar proteínas en la célula, modificando su función. El $\mathrm{AMP}_{\mathrm{c}}$ es degradado a adenosín monofosfato (AMP) por la acción de una de las diferentes fosfodiesterasas dentro de la célula. En condiciones de estrés oxidativo hay un aumento de la actividad de la fosfodiesterasa II, III y IV, con lo que rápidamente disminuyen los niveles de $\mathrm{AMP}_{\mathrm{c}}$ intracelular. El 3'5'guanosín monofosfato o GMP cíclico $\left(\mathrm{GMP}_{\mathrm{c}}\right)$ es otro segundo mensajero 
que comparte propiedades con el $\mathrm{AMP}_{\mathrm{c}}$. La guanilato ciclasa se activa para formar $\mathrm{GMP}_{\mathrm{c}}$ al unirse al óxido nítrico (NO) o al monóxido de carbono (CO), dos importantes gases biológicos con propiedades para mantener la homeostasis vascular.

Bajo condiciones hipóxicas o de isquemia, estas vías se alteran. Un descenso en el $\mathrm{AMP}_{\mathrm{c}}$ intracelular y/o un descenso en los niveles de $\mathrm{NO}$ conducen a un descenso del $\mathrm{GMP}_{\mathrm{c}}$. Este descenso de los niveles de los nucleótidos cíclicos afecta a muchas propiedades del endotelio hipóxico. Se altera la función de barrera, con lo que se produce (44):

a) aumento de la permeabilidad capilar. Debido a la retracción de las células endoteliales y al desarrollo de poros transcitoplasmáticos en dichas células, así como por efecto directo del daño causado por un trauma o por productos tóxicos liberados por los leucocitos. Esta respuesta ocurre primeramente en las vénulas postcapilares, como consecuencia se da un flujo de líquido rico en proteínas desde el espacio vascular al intersticial. De esta forma los mediadores solubles como anticuerpos llegan al lugar del daño, este aumento de permeabilidad está mediado por leucotrienos, factor activador plaquetario (FAP) e histamina (28). Todo esto provoca acúmulo de líquido en el interior de los tejidos y por tanto edema.

b) inducción de moléculas procoagulantes. Tiene como finalidad que los capilares se trombosen y que la posible agresión no pueda avanzar por el torrente sanguíneo. El mecanismo de producción es complejo y multifactorial. Se inicia con la exposición de colágeno y factor tisular en el endotelio lesionado, se suprime la expresión de trombomodulina y se produce la exocitosis de cuerpos de WeibelPalade, que contienen factor von Willebrand (favorece la adhesión de las plaquetas al endotelio). Simultáneamente hay una disminución 
de los niveles de NO y supresión del sistema fibrinolítico por parte de los fagocitos mononucleares.

c) quimiotaxis. Además de los macrófagos, otras estirpes celulares secretan citocinas y éstas a su vez atraen neutrófilos y monocitos al lugar de la agresión. Se activan leucocitos y plaquetas, con lo que se liberan proteasas y radicales libres.

d) expresión moléculas de adhesión. Proliferan tanto en la superficie del endotelio como en los leucocitos que han sido atraídos al lugar de la agresión. A través de moléculas llamadas integrinas, se conforma una unión estrecha entre ambos elementos. De esta forma, los leucocitos se fijan en el lugar dañado del endotelio. Las integrinas se expresan como resultado de la síntesis de múltiples citocinas como TNF- $\alpha$.

e) síntesis de citocinas. Se liberan citocinas y se expresan proteínas en la superficie del endotelio que favorecen reacciones inflamatorias y fenómenos trombóticos. Aunque esta respuesta es destructiva, normalmente es bien tolerada a nivel local.

f) alteración del tono vasomotor, incremento del diámetro vascular, aumento del flujo sanguíneo. Todas estas modificaciones tienen la finalidad de facilitar la llegada de los leucocitos y mediadores solubles al lugar de la agresión. Las células endoteliales y los leucocitos activan la enzima sintetasa del óxido nítrico. Las prostaglandinas son producidas por la enzima ciclooxigenasa sobre el ácido araquidónico proveniente de las membranas celulares (45). El óxido nítrico y las prostaglandinas son los responsables de la vasodilatación, cuya expresión clínica es el calor y el rubor.

El proceso de esta activación ocurre en dos fases: en la fase inmediata, los productos de degradación del complemento inician una 
respuesta rápida y corta de adhesión de los neutrófilos al endotelio. La fase tardía requiere varias horas para desarrollar nuevas proteínas, como Eselectina, moléculas de adhesión intercelulares (ICAM), que son moléculas de adhesión del neutrófilo al endotelio, e interleucina 8 (IL-8), que son expresadas por la célula endotelial en respuesta a citocinas . 


\section{4-.SIRS Y SISTEMA INMUNE}

La invasión del organismo por patógenos desencadena una respuesta inflamatoria localizada, es una respuesta fisiológica protectora, adecuadamente controlada y limitada por el organismo al lugar de la lesión. Cuando el sistema inmune falla, las bacterias o sus productos, las endotoxinas, alcanzan la circulación sistémica y una gran variedad de mediadores inflamatorios se ponen en marcha.

El Síndrome de Respuesta Inflamatoria Sistémica (SIRS) (46) (Tabla 1) es la respuesta normal del organismo a distintos tipos de agresión, ya sea aséptica, como una intervención quirúrgica o infecciosa.

Tabla 1.Criterios de SIRS (46)

SIRS = Dos o más criterios de los siguientes:

-Temperatura $<36$ ó $>38^{\circ} \mathrm{C}$.

-Frecuencia Cardíaca > 90 lpm. (47)

-Frecuencia Respiratoria > 20 rpm. ó PaCO2 $<32 \mathrm{mmHg}$.

-Recuento leucocitario > $12.000 \mathrm{~mm} 3$ ó $<4.000 \mathrm{~mm} 3$ ó > 10\% de cayados.

Cuando esta respuesta inicial (SIRS) es desmedida, la función de distintos órganos puede verse comprometida (47). Se ha constatado en diferentes estudios que el perfil inmunológico de los pacientes que desarrollan sepsis grave, son diferentes de los que únicamente desarrollan SIRS (48-51).

Las citocinas son importantes mediadores del sistema inmune. Cuando se desencadena el SIRS como respuesta a una agresión se sintetizan gran número de citocinas proinflamatorias. A veces tantas, que acaba siendo más perjudicial la producción excesiva de éstas, que el insulto primario. Este proceso ha llevado a acuñar término " tormenta de citocinas 
“ $(49,52-53)$, que alude a esta respuesta incontrolada. Se desencadena un círculo vicioso, los linfocitos producen citocinas, éstas a su vez envían señales para que las células del sistema inmune acudan al lugar de la agresión y de nuevo éstas producen más citocinas (54). El organismo comienza una reacción inflamatoria, que es capaz de autoamplificarse de forma indefinida. Esta "tormenta de citocinas" es la responsable de la disfunción orgánica y de aumentar la susceptibilidad para padecer sepsis (55).

Roger Bone (56) propuso tres estadíos:

ESTADÍO I: en respuesta a una agresión se pone en marcha un mecanismo local con mediadores destinados a la reparación del daño y reclutamiento de células del sistema inmune.

ESTADÍO II: se liberan a la circulación pequeñas cantidades de citocinas que amplifican la respuesta local, se reclutan macrófagos y plaquetas. En esta etapa se presentan los signos clínicos y de laboratorio que ponen de manifiesto la activación de la cascada inflamatoria. Se puede presentar fiebre, la hipófisis segrega hormonas relacionadas con el estrés y el hígado sintetiza reactantes de fase aguda. Esta situación se detiene cuando se produce la reparación tisular y se restaura la homeostasis. Típico ejemplo de lo que sucede en el postoperatorio.

ESTADÍO III: si la homeostasis no se reestablece comienza una respuesta sistémica masiva. La liberación de citocinas se convierte en perjudicial y los mediadores inflamatorios activan múltiples sistemas que desembocan en la pérdida de integridad microvascular y la disfunción de órganos distantes al lugar de la agresión inicial. 

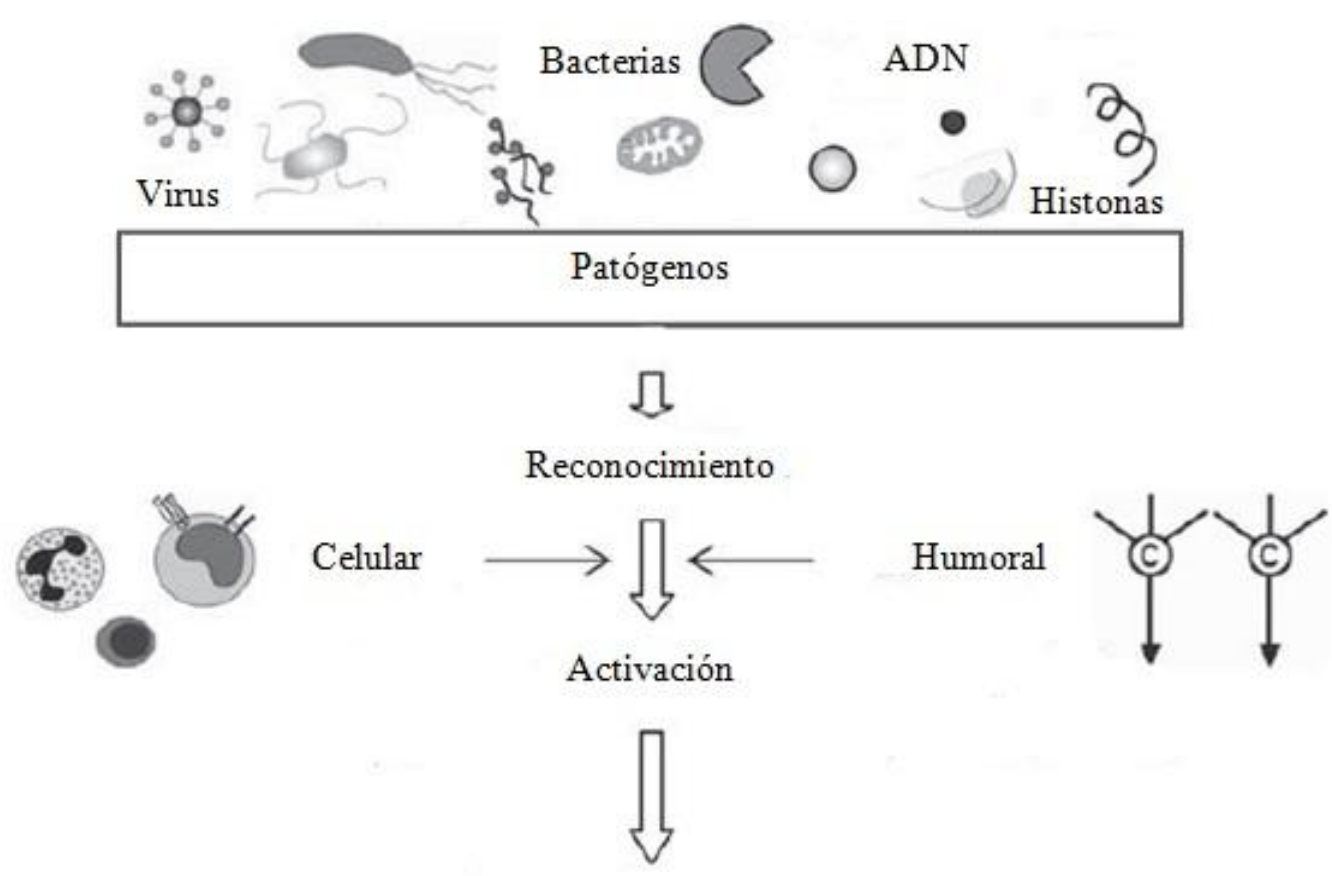

Respuesta inmune sistémica

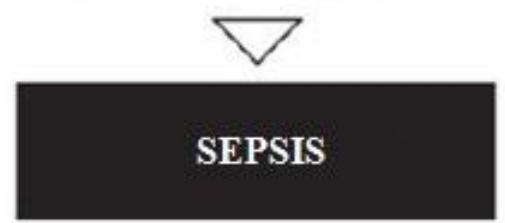

Figura 9. Activación inmunidad celular y humoral.

\section{5-.SEPSIS Y SISTEMA INMUNE}

La sepsis se define como infección documentada o sospechada en presencia de dos o más criterios de SIRS (46). En condiciones normales la infección induce una respuesta inflamatoria controlada por antagonistas antiinflamatorios. Tanto en SIRS como en sepsis se rompe el equilibrio.

La fisiopatología del SIRS y la sepsis presenta una importante relación con el sistema inmunológico innato. Ante la presencia de cualquier agresión externa, el organismo manda una serie de señales de alarma procedentes de las células dañadas (DAMPs) (57). El reconocimiento de estas señales por parte del sistema innato de inmunidad, a través de 
receptores de reconocimiento de patrones (PRR) (10), hace que se activen unos sistemas de proteasas séricas como son el complemento y la cascada de coagulación (26). Se activa la primera línea defensiva que implica la liberación de una serie de mediadores como son las quimiocinas y citocinas, así como cambios a nivel neuroendocrino.

La teoría tradicionalmente aceptada sostiene que el organismo responde al patógeno con una sobreactivación del sistema innato, mediante la activación del complemento y la síntesis de citocinas proinflamatorias, cuya finalidad es la de confinar la infección y limitar el daño tisular (54). Tras haber sido activados los macrófagos y neutrófilos producen $\mathrm{y}$ responden a las citocinas. Este ambiente proinflamatorio causa la liberación de mediadores secundarios, lo que hace que se amplifique aún más el proceso inflamatorio. El mal funcionamiento de los mecanismos reguladores durante la sepsis puede dar como resultado una pérdida de control sobre esa respuesta inflamatoria, provocando daños en el organismo. Siguiendo esta hipótesis se han intentado implantar sin éxito terapias de tipo antiinflamatorio (58-59).

Ante una agresión, las señales de alarma (DAMPs) activan al factor citosólico nuclear $\kappa \mathrm{B}(\mathrm{NF}-\kappa \mathrm{B})$, que inicia la transcripción de numerosos mediadores inflamatorios (52). Entre ellos prostaglandinas, leucotrienos, factor activador plaquetario y citocinas proinflamatorias, como IL-8. Las citocinas reclutan leucocitos al lugar de la infección. Se altera la regulación de la temperatura (induciendo fiebre o hipotermia), la resistencia y permeabilidad vasculares, la función cardiaca y el estado inotrópico del corazón. 


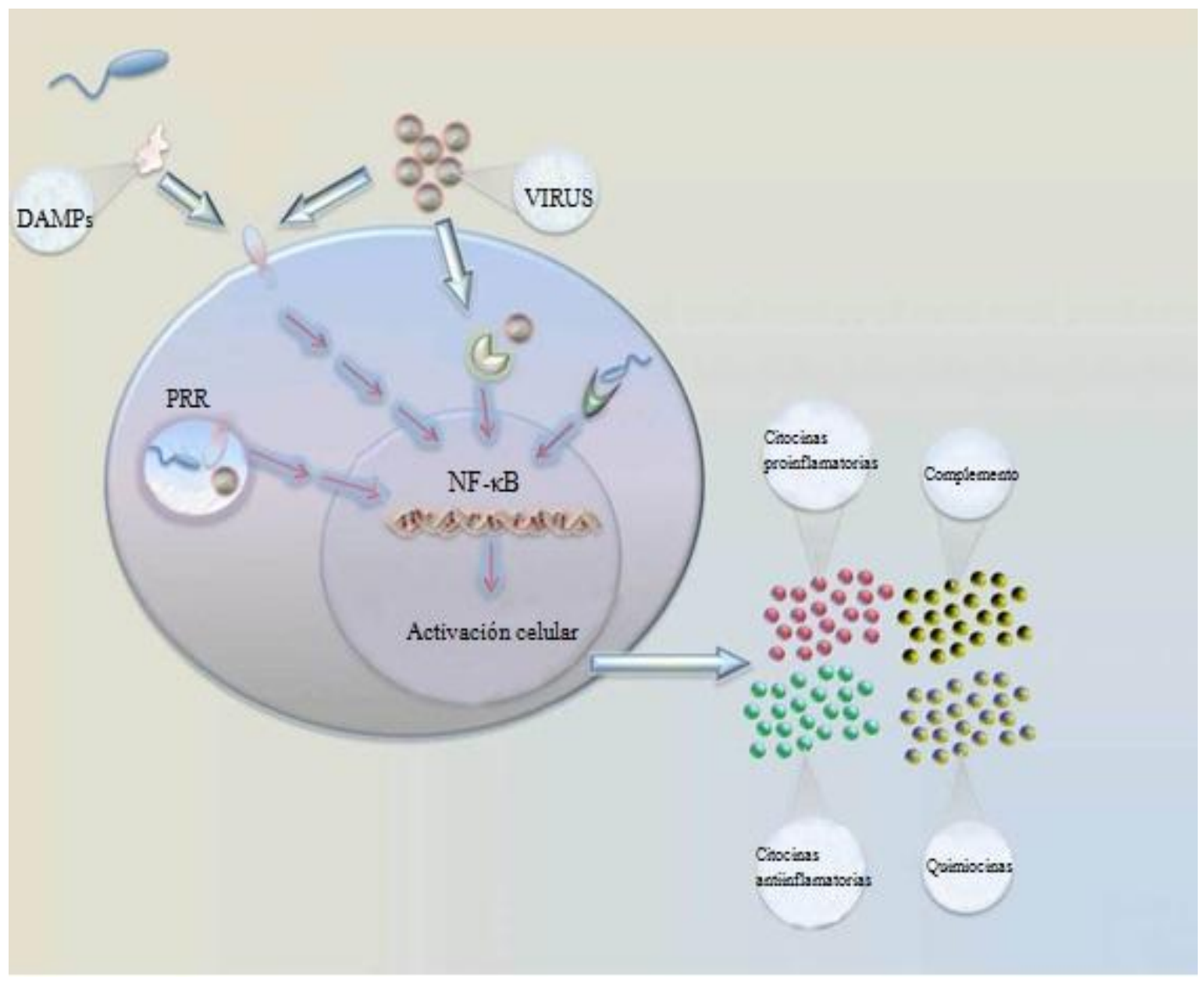

Figura 10. Activación nuclear y transcripción de mediadores.

Un factor especialmente importante es la producción local de IL-8 por parte de los fibroblastos, células endoteliales y células mononucleares en la sangre periférica; esta citocina recluta y activa leucocitos polimorfonucleares que posteriormente pueden provocar lesiones tisulares con disfunción de diferentes órganos.

La adhesión de los leucocitos y posteriormente neutrófilos al endotelio activado, es consecuencia de la actividad coordinada de selectinas, integrinas e inmunoglobulinas (60-61). Tras la adhesión los leucocitos atraviesan el endotelio y se extravasan a los tejidos, donde son atraídos hacia los patógenos por quimiotaxis. La fagocitosis puede ocurrir en presencia de oxígeno, lo que conlleva la formación de radicales libres, o 
puede llevarse a cabo en ausencia de éste, por medio de enzimas proteolíticas como la elastasa (62). El endotelio en la sepsis es disfuncionante, tanto a nivel molecular como celular (63). Desde el punto de vista molecular, existe una disminución en la disponibilidad de óxido nítrico, que repercute en la síntesis de diferentes enzimas. A nivel celular, hay una modificación de las células que lo integran debido a un aumento de la apoptosis de éstas. La microvasculatura del endotelio también presenta alteraciones, que hacen que resulte más difícil la llegada de los leucocitos al lugar de la agresión (10).

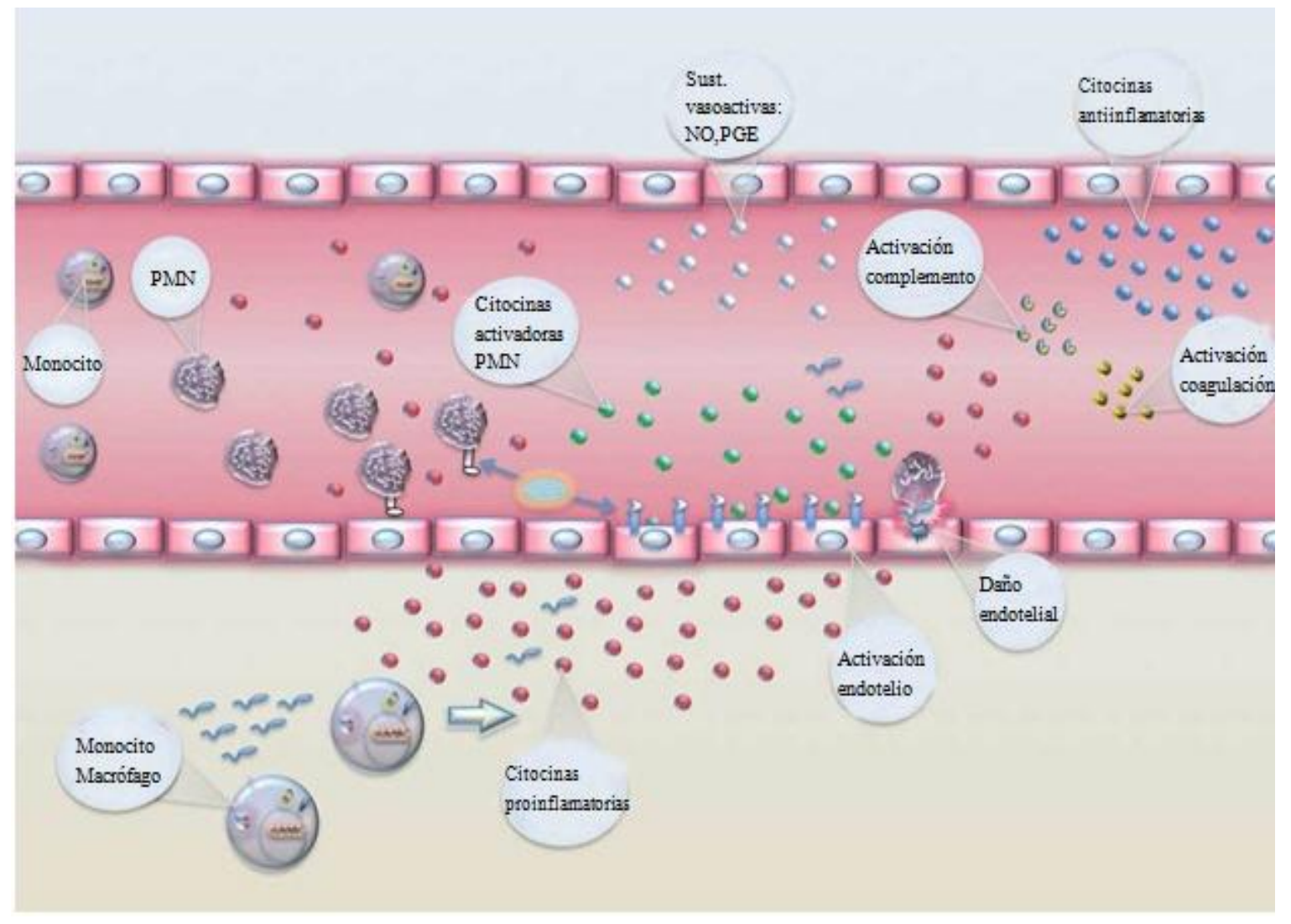

Figura 11. Activación endotelio.

La fase inicial de la sepsis se caracteriza además por la liberación de catecolaminas secundaria a la activación del sistema nervioso simpático, estimulando receptores $\alpha$ y $\beta$ expresados en las células del sistema inmune. La unión al receptor $\alpha$ tiene como principal efecto la producción de 
citocinas proinflamatorias, mientras que la unión al receptor $\beta$ deriva en liberación de citocinas antiinflamatorias (64).

Cuando finaliza la inflamación mediada por neutrófilos se produce una eliminación de los restos que es llevada a cabo por los macrófagos. Los neutrófilos terminan su ciclo con la apoptosis y en la sepsis está retardada (65-66). La apoptosis es fundamental para la resolución de la inflamación, tiene que haber un equilibrio entre el reclutamiento de neutrófilos y la eliminación de éstos del foco inflamatorio. Optimizando las defensas del huésped frente a la citotoxicidad que se genera en el proceso. Si la apoptosis está retardada la inflamación continúa perpetuándose y lesionando tejidos (67).

Los macrófagos tienen múltiples funciones en la sepsis. Algunos de los estímulos para los macrófagos son el daño tisular, la acidosis, la baja tensión de oxígeno o las moléculas proinflamatorias. La producción de citocinas y quimiocinas por los macrófagos amplía aún más la respuesta inflamatoria (68). Los monocitos circulantes parecen estar reprogramados en la sepsis para generar más mediadores antiinflamatorios (69). Esto intenta limitar el estado dañino de hiperinflamación, que por otro lado predispone al huésped a una infección secundaria $(53,70-72)$.

Estos hallazgos han llevado al acuñamiento del término CARS (síndrome de respuesta antiinflamatoria compensadora) (73), sería la respuesta del organismo al estado de hiperinflamación. El CARS desemboca en una inmunoparálisis, con disfunción de los mecanismos de señalización intracelular y disfunción del sistema adquirido de inmunidad (74), como la anergia de linfocitos T, la desactivación de macrófagos y su reducción de capacidad como presentadores de antígenos (75). Esta inmunoparálisis concordaría con el estado de inmunosupresión que se observa en los últimos estadíos de la sepsis y que hace a estos pacientes 
más susceptibles a las infecciones nosocomiales (53, 76-77). Algunas teorías apuntan que esta inmunosupresión se debe además a la imposibilidad por parte de la médula ósea de reponer las células del sistema inmune, en otras palabras es incapaz de alcanzar la homeostasis inmunológica (78).

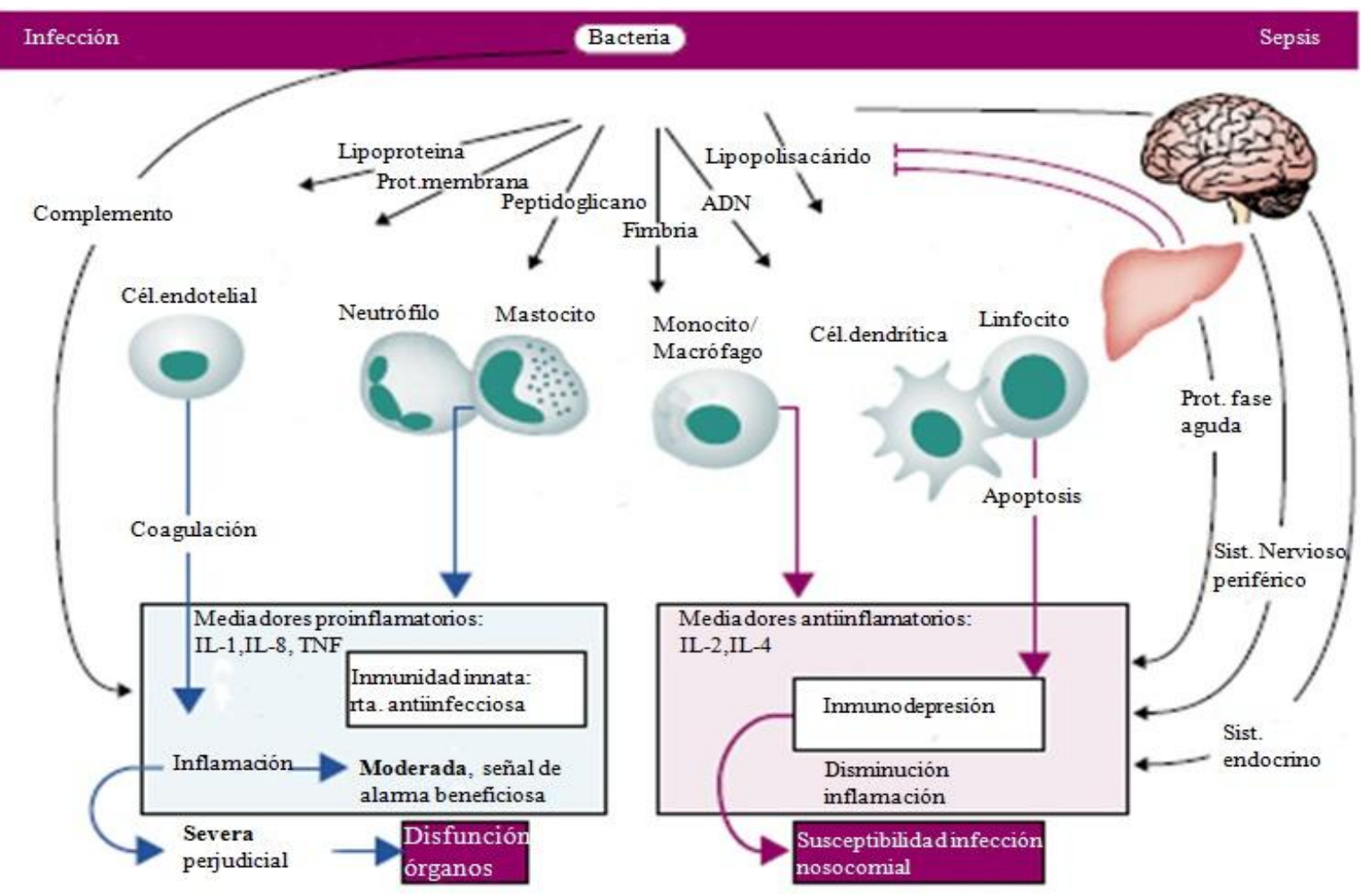

Figura 12 (67). Liberación de mediadores pro y antiinflamatorios.

Existen varias alteraciones del sistema inmune que propician un estado de inmunosupresión en la sepsis. Existe un aumento en el nivel de apoptosis de los linfocitos B y T $(67,79-80)$ y una disfunción de macrófagos y células dendríticas $(53,75,81-82)$. Esto altera la presentación de antígenos por parte de los linfocitos T.

Muchos estudios se han centrado en los mecanismos de control de la respuesta inflamatoria (83-85). Tracey et al han descrito otra modalidad de control sobre las citocinas basado en la estructura del sistema nervioso central. Éste a través del nervio vago puede modular la respuesta de la 
inmunidad innata y controlar la inflamación sistémica mediante los receptores centrales muscarínicos, iniciándose la antiinflamación $(83,86)$, la activación parasimpática libera acetilcolina, que suprime la producción de citocinas proinflamatorias. Esta acción específica de realiza por la subunidad $\alpha 7$ del receptor nicotínico de la acetilcolina $(\alpha 7 \mathrm{nAChR})$ de los macrófagos (87).

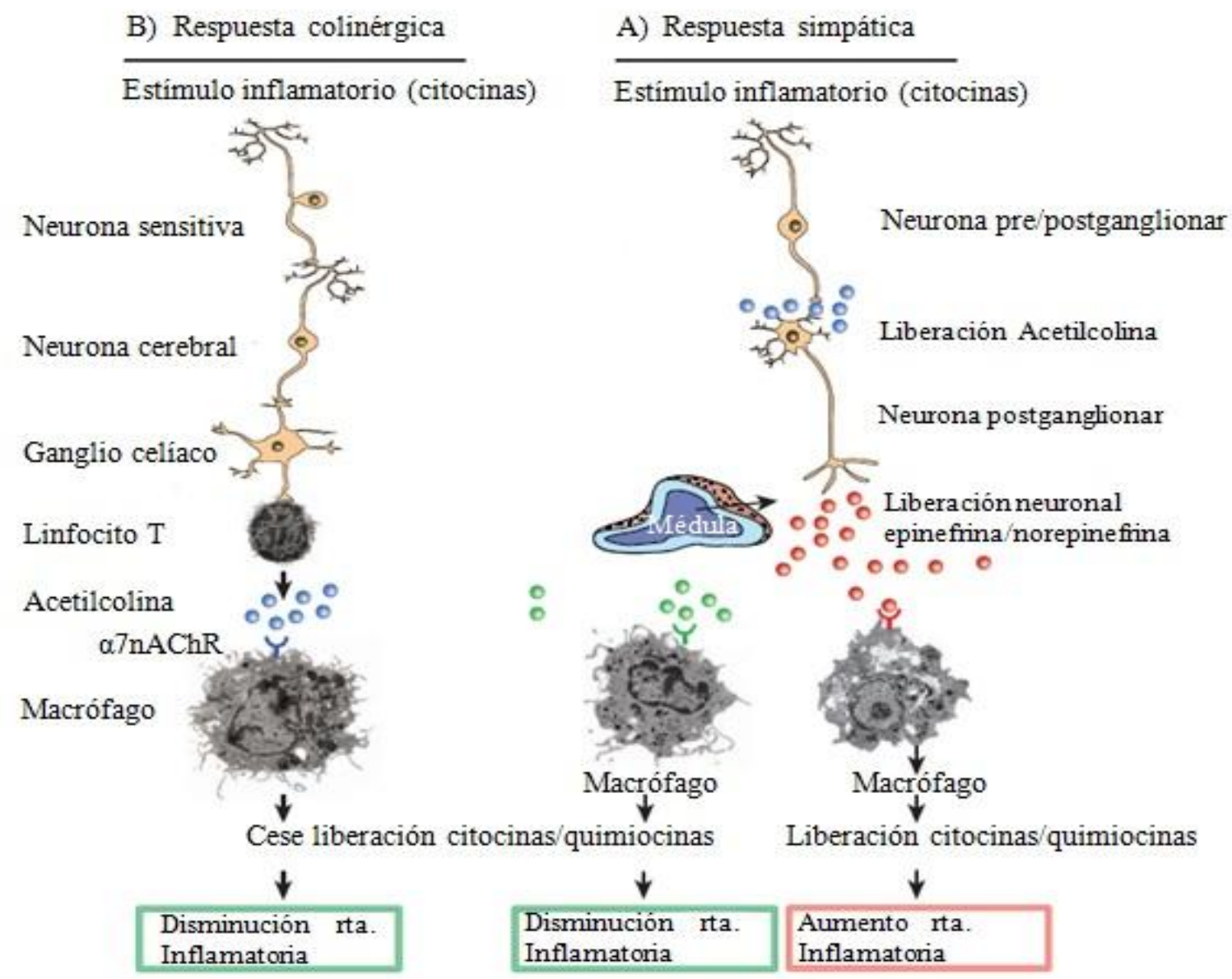

Figura 13 (19). Implicación del sistema nervioso en la liberación de citocinas.

\section{6-.CITOCINAS}

Uno de los objetivos del sistema inmune es neutralizar las agresiones externas. Para ello necesita que las células que lo integran estén conectadas 
entre sí. Tiene diversos métodos para llevar a cabo la comunicación entre dichas células, los principales son el contacto directo a través de moléculas de membrana y la síntesis de pequeñas proteínas, las citocinas.

Una de las primeras descripciones de las citocinas fue la que realizó Lindenman, que describió el interferón, en 1957 (22). Las citocinas son proteínas de bajo peso molecular generalmente glicosiladas y monoméricas. Tienen una vida media limitada, son producidas de novo cuando se lleva a cabo la agresión y sólo pueden estimular a células con receptores específicos (88). Las citocinas se sintetizan en el mismo momento en que tiene lugar la activación celular, alertando a las células que hay una respuesta inmune en marcha. Las citocinas no alertan a todas las células sino únicamente a aquellas que tienen receptores de membrana para ellas (89). La activación de estos receptores da lugar a cambios en el RNA celular y en la síntesis proteica, las citocinas actúan sobre diferentes tipos celulares, a menudo influyen en la síntesis y acción de otras citoquinas.

Son activas en concentraciones mínimas (picomolares), se diferencian de las hormonas endocrinas clásicas en que son producidas por varios tipos de células más que por órganos específicos. Ejercen efectos autocrinos y paracrinos. Su efecto se ejerce sobre todo en las células que rodean a la célula emisora (paracrino). Dentro de sus funciones además, se hallan la de regular la amplitud y duración de la respuesta inmune, reclutar células en la zona de conflicto e inducir la formación de nuevas células a partir de precursores hematopoyéticos. Regulan y modifican la maduración y crecimiento celular. Existen varios subgrupos de citocinas dependiendo de su función u origen. Así están las linfocinas, monocinas, quimiocinas, interleucinas, interferones y factores estimuladores de colonias. 
Los principales productores de citocinas son linfocitos $\mathrm{T}$ y macrófagos, que son los reguladores de la respuesta inmune tanto específica como innata. Las citocinas son producidas por los leucocitos activados, en particular los monocitos, por los fibroblastos activados y por las células endoteliales (89).

La respuesta de una célula a una determinada citocina depende de la concentración local de la citocina, del tipo de célula y de otros reguladores celulares. La mayoría son sintetizadas cuando son requeridas, no están almacenadas, salvo algunas, como el factor de crecimiento $\beta 1$ (89). La liberación de citocinas puede ser estimulada por diferentes factores como la isquemia-reperfusión, la activación del complemento, la liberación de endotoxina y por otras citocinas (90).

\section{6.a-. Inicio acción}

Cuando el patógeno entra en el organismo las células lo detectan y comienzan a sintetizar citocinas para que a su vez se activen más células y poder responder con más eficacia. La unión de la citocina a su receptor genera nuevas señales intracelulares en las que intervienen gran número de proteínas como las cinasas, que reclutan y activan factores de transcripción (STAT). Cada receptor activa un número limitado de rutas. Como consecuencia de esta activación en cadena se inducen ciertos genes. Estos genes median en la actividad de las citocinas. Éstas tienen la capacidad de ejercer más de una acción y sobre tipos diferentes de células y varias de ellas ejercen el mismo tipo de acción.

Si los microorganismos logran superar la barrera física que supone el epitelio son fagocitados por los macrófagos. La capacidad fagocítica de éstos aumenta con citocinas como INF $\gamma$, si el patógeno no puede ser 
destruido se produce un foco infeccioso. El macrófago lucha contra el patógeno de dos formas diferentes, produciendo citocinas, procesando y presentando al antígeno. Las citocinas que son secretadas en la fase aguda son TNF- $\alpha$, IL1, IL6, IL8 e IL12. Además de los macrófagos están los mastocitos que reconocen al patógenos y se degranulan secretando histamina y TNF $\alpha$. Los macrófagos tardan días en actuar mientras que los mastocitos lo hacen en segundos.

Cualquier tipo de agresión al sistema inmune produce repercusión a nivel molecular (91-94). Tanto el sistema inmune como el endocrino secretan citocinas para los que ambos tienen receptores. Cuando los tejidos están inflamados secretan IL1, activa el eje hipotálamo-hipófisissuprarrenales induciendo fiebre y sueño. Los linfocitos y macrófagos activados sintetizan opioides, sobre todo $\beta$ endorfina que son reconocidas por terminaciones nerviosas locales, mitigando el dolor en los tejidos inflamados.

\section{6.b-.Mecanismos de control}

Uno de los mecanismos de regulación que tiene el sistema inmune es que la respuesta frente al antígeno siga en activo mientras se detecte presencia del antígeno en el organismo. Mientras hay estímulo hay respuesta, pero además hay otros mecanismos en los que están implicadas las citocinas. Éstas pueden inhibir o estimular ciertos tipos de linfocitos T, así como controlar su vida media.

Linfocitos Th (mayoría CD4) se subdividen en TH1 y TH2 dependiendo de las citocinas que producen. Los TH2 son activadores de linfocitos B y los TH1 son importantes activadores de macrófagos. Si el patógeno es intracelular (TH1 inmunidad celular) se secretan IL2 e IF $\gamma$, si el patógeno es extracelular (TH2 inmunidad humoral) se secretan IL4, IL5, 
IL6 e IL10. Simultáneamente estas citocinas inhiben la proliferación y la función del tipo alternativo, es decir las citocinas producidas por el subtipo TH1 inhiben al subtipo Th2 y viceversa. La diferenciación de estos subtipos también se encuentra estimulada por las citocinas del entorno así, IL4 favorece activación de Th2, IL2 e INF $\gamma$ favorecen diferenciación de Th1. (Figura 14)

Dentro de las citocinas producidas por el subtipo Th2, la IL10 y el TGF $\beta$ son los principales mediadores de la inhibición. IL10 se une a su receptor en el macrófago e inhibe su activación bloqueando la síntesis de IL12. Como no se activa la célula presentadora tampoco se activa el TH1. El TGF $\beta$ se une al Th1 y lo inhibe de forma directa. El IFN $\gamma$ es la principal citocina sintetizada por Th1, se une al TH2 y lo inhibe.

Como la respuesta inmune supone un gran gasto celular las citocinas también son las encargadas de mantener el número de células, haciendo que se estimule la proliferación de células maduras capaces de encargarse del antígeno. Son las responsables de la hematopoyesis, llamadas también factores de crecimiento. Cuanto más inmadura es una célula más son las citocinas capaces de estimularla.

Las más conocidas son GM-SCF (factor estimulador de colonias granulocito-macrófago), IL3, EPO, IL7 y G-CSF (factor estimulador de colonias de granulocitos). 


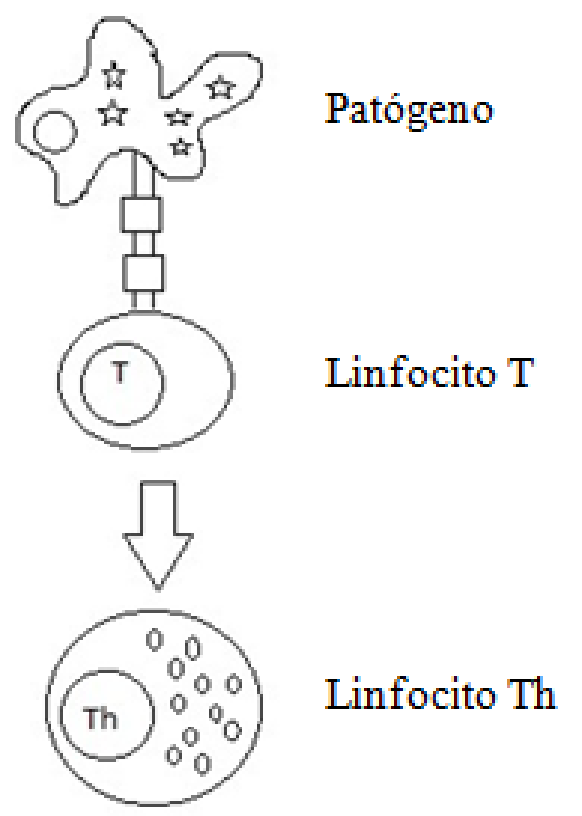

INTERFERON, IL 2
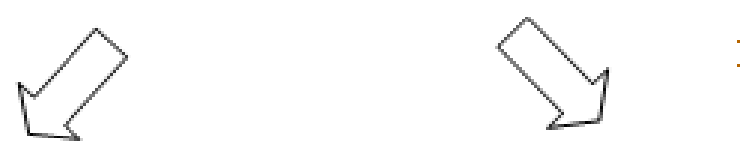

IL 4, IL 5
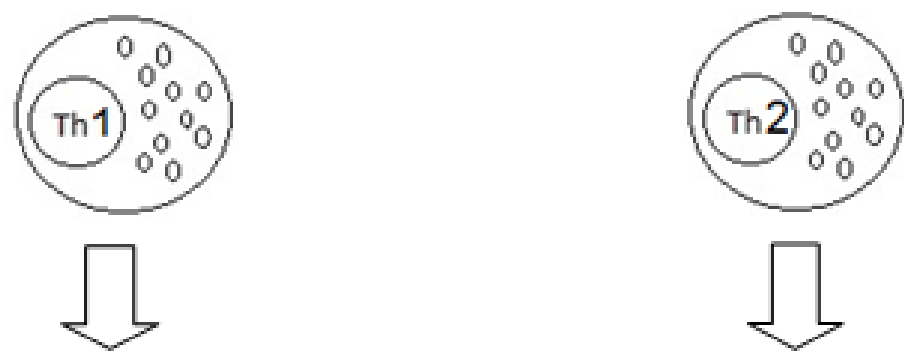

IL 2 ,INFo , TNFB

IL4, IL5, IL6, IL10

Activan macrófagos

Activan Linf B

Figura 14.Diferenciación linfocitos T. 
1.6.c-.Descripción de las principales citocinas

Tienen distintas funciones: las hay que actúan de mediadoras de la inmunidad innata, otras regulan la activación de linfocitos, su crecimiento y diferenciación. Algunas regulan la activación linfocitaria o leucocitaria.

-Factor de necrosis tumoral (TNF)

Se secreta como una prohormona producida en monocitos, macrófagos, linfocitos, neutrófilos, endotelio, fibroblastos y queratinocitos. Existen dos polipéptidos, TNF- $\alpha$ y TNF- $\beta$. Al igual que existen dos polipéptidos, existen dos receptores, TNFR-I y TNFR-II. También existen en el suero proteínas solubles de unión al TNF, que son en esencia receptores de TNF no unidos a la membrana celular. Estos receptores solubles compiten con los otros receptores por el TNF y limitan la actividad de la citocina. Activa a las células $\mathrm{T}$, células $\mathrm{B}$, células $\mathrm{NK}$, neutrófilos, osteoblastos $\mathrm{y}$ endotelio. Contribuye a debilitar la estrecha unión existente entre las células endoteliales, favoreciendo la aparición de edema (58). Induce fiebre, sueño, anorexia, catabolismo, liberación de la hormona adrenocorticotrófica y síntesis hepática de proteínas de fase aguda. Conduce a un estado de depresión miocárdica, hipercoagulabilidad ( en la sepsis se libera TNF $\alpha$ de todos los macrófagos del organismo con las consecuencias que tienen a nivel local pero de forma generalizada : coagulación intravascular diseminada (CID), hipotensión, shock y muerte). Estimula la producción de IL-1, IL-6 e IL-8. El TNF tiene una acción quimiotáctica para los leucocitos polimorfonucleares y estimulan la liberación de radicales libres (89). 
-Interleucina-1 (IL-1)

Es el prototipo de citocina proinflamatoria, con la capacidad de inducir una gran cantidad de genes no expresados habitualmente en el individuo sano (95). Se produce en monocitos, macrófagos, linfocitos, neutrófilos, endotelio, fibroblastos y queratinocitos. Existen dos formas de IL-1: IL-1 $\alpha$ e IL-1 $\beta$. IL-1 tiene más poder inflamatorio que TNF. En común con el TNF, el principal estímulo para la liberación de IL-1, es el lipopolisacárido o endotoxina antigénica. Ambas citocinas juegan un papel importante en la estimulación de las células T y B y de los macrófagos (89). La IL-1 participa en la respuesta del huésped ante la agresión local (favorece la cicatrización de las heridas) (96) o sistémica (fiebre, supresión del apetito y respuestas neuroendocrinas), en la neuroinflamación y muerte celular en condiciones neurodegenerativas, como en el caso de accidente cerebrovascular, traumatismo craneal o isquemia (93, 97), así como en los mecanismos de reacciones ante el estrés. IL-1 y TNF liberan prostaglandinas, IL-6 e IL-8 de los monocitos y estimulan a las células endoteliales para producir prostaglandinas, IL-6, factor tisular, que participan en la coagulación intravascular diseminada. IL-1 media su actividad a través de receptores de la membrana celular (IL-1R tipo 1 e IL-1R tipo 2) (89).

-Interleucina-6 (IL-6)

La IL-6 es una neurotropina multifuncional que junto con TNF e IL1, es uno de los mediadores de la respuesta de fase aguda (98). Se libera desde los monocitos, macrófagos, células $\mathrm{T}$, endotelio, fibroblastos y queratinocitos. Además, interviene en la defensa del huésped, en la respuesta inmune, en la hematopoyesis (89) y en la respuesta celular al trauma neural (98). Su producción está regulada 
por diferentes señales, como la estimulación antigénica y mitogénica, el lipopolisacárido, IL-1, IL-2, TNF, interferón, factor de crecimiento derivado de las plaquetas y virus. La IL-6 ejerce su acción al unirse a un receptor de alta afinidad (IL-6R) expresado en la superficie de las células (99). La IL-6 es un marcador y un mediador en la sepsis. Las elevaciones mantenidas de IL-6 parecen ser más importantes que los niveles iniciales o pico en términos de resultados (100).

-Interleucina-2 (IL-2)

La IL-2 es el factor de crecimiento autocrino y paracrino más importante para los linfocitos $\mathrm{T}$ y la cantidad de IL-2 determina la magnitud de la respuesta inmune dependiente de los linfocitos $\mathrm{T}$ (101). IL-2 también estimula la producción de otras citocinas derivadas de las células T (IFN- $\gamma$ y TNF- $\alpha$ ). IL-2 e IFN- $\gamma$ favorecen el desarrollo de linfocitos $\mathrm{T}$ citotóxicos y son responsables de la inmunidad mediada por células. IL-2 también aumenta la función de los neutrófilos y macrófagos, estimula la función citolítica de las células NK y es un factor de crecimiento para las células B. La actividad biológica de la IL-2 es mediada por su unión a un receptor celular multimolecular, denominado IL-2R $\alpha$, IL-2R $\beta$ e IL-2R $\gamma$ (89).

-Interleucina-3 (IL-3)

Actúa como un factor estimulante de colonias (CSF) (89). Regula el crecimiento y diferenciación de los progenitores hematopoyéticos. Activa los neutrófilos y macrófagos ya maduros (102).

-Interleucina-4 (IL-4)

Está relacionada, junto IL-5 e IL-13 en la diferenciación de los linfocitos Th2 (103). IL-4 estimula la expresión de ciertas moléculas 
de adhesión (VCAM-1). IL-4 inhibe la activación de los macrófagos y de los efectos del INF- $\gamma$ sobre los macrófagos, previene la producción de citocinas proinflamatorias. Favorece la proliferación de mastocitos y la liberación por parte de éstos de citocinas Th2 (104).

-Interleucina-5 (IL-5)

Es un potente agente quimiotáctico para los eosinófilos y actúa como un estimulador de las células B (89).

\section{-Interleucina-7 (IL-7)}

Es un factor de crecimiento precoz para las líneas celulares de linfocitos T y B (89). Regula la homeostasis de los linfocitos T (105). Modula su activación a través de las células dendríticas (101). Es una citocina anti-apoptótica y restaura la producción de INF- $\gamma$ (106).

\section{-Interleucina-8 (IL-8)}

Liberada por los monocitos, macrófagos, linfocitos, endotelio, fibroblastos y queratinocitos, la IL-8 pertenece al grupo de las quimiocinas o citocinas quimiotácticas (107). Es un potente agente quimiotáctico, especialmente para los neutrófilos (108), que están implicados por ejemplo en la lesión por isquemia-reperfusión. Se secreta en respuesta a diferentes estímulos, como LPS, bacterias y otras citocinas (TNF, IL-1) (109). Se produce desde los primeros momentos de la inflamación y persiste durante bastante tiempo, semanas (110). Esto es muy importante porque puede continuar reclutando células proinflamatorias. Es relativamente resistente a la temperatura elevada y a ambientes ácidos, estas características bioquímicas la hacen idónea para permanecer en el lugar de la 
inflamación. Se detecta de forma importante alrededor de zonas necróticas, lo que sugiere que la hipoxia puede contribuir a su sobreexpresión (111).

\section{-Interleucina-9 (IL-9)}

Actúa sobre el crecimiento de las células T (89). Promueve el crecimiento de los mastocitos, regula la hematopoyesis. Tiene un importante papel en la inflamación que se produce durante la alergia, estimula la producción del IL-13, que tiene un efecto directo sobre el epitelio de la vía aérea induciendo la formación de moco (112). A parte del sistema respiratorio media en la inflamación de otros tejidos. Regula la inmunidad en varios procesos infecciosos, sobre todo con parásitos extracelulares. Confiere inmunidad a nivel intestinal (113).

- Interleucina-10 (IL-10)

Es producida por las células $\mathrm{T}$, monocitos/macrófagos, células dendríticas y células epiteliales, generalmente después de un estímulo. El mayor estímulo es la inflamación. La IL-1 y el TNF pueden estimular la producción de IL-10 directamente, sugiriendo la existencia de un feed-back negativo, en el que los procesos inflamatorios son autolimitados por la producción endógena de IL-10 (114); de hecho, las concentraciones de IL-10 a menudo indican la magnitud de la respuesta inflamatoria. La mayoría de sus efectos inmunosupresores provienen de la inhibición de la actividad de las células presentadoras de antígenos. IL-10 suprime la actividad de los macrófagos, inhibe su capacidad para secretar citocinas inflamatorias y para actuar como células accesorias en la estimulación de las células T y NK (115). La IL-10 regula a la baja la respuesta mediada 
por células, suprimiendo la producción de PGE2 y de las citocinas proinflamatorias IL-2 e INF- $\gamma$ (116-117). También aumenta la liberación del receptor soluble del TNF e inhibe la expresión en la superficie celular de la molécula ICAM-1. Inhibe las respuestas tanto Th1 como Th2, aunque parece ser más efectiva contra las Th1 (118).

-Interleucina-11 (IL-11)

Estimula la proliferación de células primitivas pluripotenciales. Tiene efectos sinérgicos con la IL-3 e IL-10 sobre los megacariocitos y los linfocitos pre-B (89). Fomenta la eritropoyesis y modula la diferenciación de las células mieloides. También es secretada a nivel de las células epiteliales que recubren los bronquios. Induce respuesta febril (119).

-Interleucina-12 (IL-12)

Funciona como puente entre la inmunidad innata y la adaptativa (120). Es especialmente importante porque su expresión durante la infección regula la inmunidad innata y determina el tipo y duración de la inmunidad adaptativa (121). Estimula el sistema innato y es un importante regulador de la respuesta inmune celular Th1, tiene múltiples efectos sobre las células T y las células NK, siendo además un potente inductor de la producción de INF- $\gamma$ (89). Es secretada principalmente por células inflamatorias activadas como monocitos, macrófagos y neutrófilos. Es esencial para hacer frente a diferentes tipos de infecciones.

-Interleucina-13 (IL-13)

Tiene propiedades fisiológicas que se superponen a la IL-4. La IL-13 puede inhibir la producción y expresión de las citocinas 
proinflamatorias y al igual que la IL-4 e IL-10, es una potente citocina antiinflamatoria que suprime la inmunidad mediada por las células. Estimula a los neutrófilos para producir el antagonista del receptor IL-1, IL-1ra, con lo que se inhibe la IL-1 (89). Modula la inmunidad celular, la resistencia a organismos intracelulares. En el pulmón es el mediador central del asma y regula la inflamación eosinófíla, la secreción de moco y la hiperreactividad bronquial (122).

-Interleucina-14 (IL-14)

Controla el crecimiento y la proliferación de células B activadas (89). Inhibe la secreción de anticuerpos. Es secretada principalmente por Linfocitos $\mathrm{T}$ y algunas poblaciones de Linfocitos $\mathrm{B}$ malignos (123)

-Interleucina 15 (IL-15)

Comparte propiedades con la IL-2 (89). Induce la proliferación de linfocitos T. Es el principal factor estimulante de las células NK, las hace pasar de su estado precursor a la madurez (106). Además de activar y hacer que proliferen los NK, regula la interacción de éstos con los macrófagos (124).

-Interleucina-16 (IL-16)

Induce una respuesta migratoria de linfocitos, monocitos y eosinófilos (89).Estimula la producción de IL-2 e inhibe al receptor de los linfocitos T. Su secreción se vincula a procesos inflamatorios como asma, lupus o dermatitis atópica (125). 
-Interleucina-17 (IL-17)

Estimula las células $\mathrm{T}$ (89). Elimina patógenos y promueve la inflamación tisular $(122,126)$

-Factor activador de las plaquetas (PAF)

Se sintetiza tras la activación de la fosfolipasa $\mathrm{A}_{2}$ y es liberada desde las plaquetas, neutrófilos, monocitos, macrófagos y desde el endotelio vascular por el TNF, IL-1 y lipopolisacárido. Está relacionado con el shock que aparece en la anafilaxia y en la endotoxemia (89). Se ha identificado como el inductor del factor $\kappa B$, que como ya se ha comentado, es el principal regulador en la transcripción de genes implicados en la inflamación (127).

-Interferón-gamma (INF- $\gamma$ )

Es producido los linfocitos T CD4, CD8 y por las células NK. Tiene efectos inmunorreguladores (89). Originariamente se denominó factor activador de macrófago. El INF- $\gamma$ junto con los macrófagos inducen los principales mecanismos antimicrobianos y antitumorales, así como la expresión de moléculas presentadoras y procesadoras de antígenos (128). Organiza la atracción de leucocitos y dirige la maduración, crecimiento y diferenciación de muchos tipos celulares, como los linfocitos B (129). El aumento de producción de esta citocina está asociado con mayor resistencia a infección por bacterias y virus (130).

-Interferón-alfa (INF- $\alpha$ ) e interferón-beta (INF- $\beta$ )

Ejercen una potente actividad antiviral (89). 
-Factor transformador del crecimiento alfa y beta (TGF- $\alpha$ y TGF- $\beta$ ) El TGF- $\alpha$ es estructuralmente similar al factor de crecimiento epidérmico. TGF- $\alpha$ favorece la proliferación celular de varios tejidos, como el hueso y la cicatrización de las heridas.

El TGF- $\beta$ se encuentra en elevadas concentraciones en las plaquetas y en el hueso. Inhibe la proliferación de las células T y la activación de los macrófagos (89).

La IL-1, IL-6 y TNF- $\alpha$ tienen efectos locales y sistémicos, para limitar la lesión y la extensión de la infección. Los efectos locales incluyen la migración de los neutrófilos, linfocitos y monocitos a la zona inflamada, como resultado del aumento de la permeabilidad del endotelio, moléculas de adhesión y citocinas quimiotácticas, como IL-8. Las citocinas podrían inducir de una forma directa la expresión de la ICAM-1 y VCAM-1 en las células endoteliales vasculares (131). Los cambios sistémicos incluyen neutrofilia, fiebre, liberación de hormonas adrenocorticotropas, descenso de hierro y cinc $\mathrm{y}$ síntesis de las proteínas de la fase aguda por el hígado (89).

\section{6.d-. Clasificación}

\section{6.d.1-.Proinflamatorias}

Las moléculas proinflamatorias son: TNF- $\alpha$, IL-1- $\beta$, IL-2, IL6 , IL-8, IL-15, elastasa procedente de los neutrófilos, IFN- $\gamma$, proteínquinasa, tromboxano, factor activador de las plaquetas, moléculas de adhesión solubles, neuropéptidos vasoactivos, fosfolipasa $A_{2}$, tirosín- 
quinasa, inhibidor del activador del plasminógeno I, radicales libres, prostaciclina y prostaglandina (132).

\section{6.d.2-. Antiinflamatorias}

Las moléculas antiinflamatorias son: IL-Ira, IL-4, IL-10, IL13, receptor de IL-1 tipo II, factor $\beta$ de crecimiento transformante, epinefrina, receptores solubles del TNF- $\alpha$, antagonista del receptor de leucotrieno $\mathrm{B}_{4}, \mathrm{CD} 14$ recombinante soluble y la proteína de unión al lipopolisacárido.

\section{6.e-. Quimiocinas}

- Son un tipo de citocinas quimiotácticas que atraen leucocitos que tienen funciones proinflamatorias independientes de la respuesta inmune adaptativa. Entre estas se hallan la IL8 y factor activador de plaquetas.

- TNF $\alpha$ es el principal iniciador de la respuesta inflamatoria, actúa en los vasos de la zona infectada provocando vasodilatación y aumento de permeabilidad permitiendo que se acumulen inmunoglobulinas, complemento. Asimismo induce la expresión de moléculas de adhesión en el endotelio favoreciendo la unión y posterior migración de los leucocitos circulantes a la zona infectada.

- IL1, IL6 e IL2 elevan la temperatura corporal, inducen el inicio de la respuesta aguda (hígado crea proteínas que opsonizan las bacterias) y activan $\operatorname{linf} \mathrm{T}$, NK y B. La temperatura elevada es beneficiosa porque disminuye el crecimiento de patógenos y alerta al organismo. 
- IL2 induce y aumenta la actividad citolítica de los NK.

- IL2, IL4, IL7, IL9 e IL15 actúan como factores de crecimiento de linfocitos T.

- El interferón $\alpha$ y $\beta$ son sintetizados tras infecciones virales por los leucocitos y losfibroblastos.

- El interferón $\gamma$ es sintetizado por los linfocitos NK y es un potente activador de macrófagos. 
2.JUSTIFICACIÓN 

La sepsis es una respuesta inflamatoria a nivel sistémico descontrolada que se da tras una infección. El estadío más grave es el shock séptico, que conlleva disfunción multiorgánica. A pesar de múltiples investigaciones, continúa asociándose a altas tasas de mortalidad (52), llegando a alcanzar en algunas series el $70 \%(29,133)$ por eso constituye un reto tanto para investigadores como para clínicos. Continúa sin clarificarse lo que acontece a nivel molecular, se han realizado hasta la fecha más de 25 estudios probando diferentes terapias y todos han obtenido resultados insatisfactorios $(26,134-137)$.

La sepsis no debe ser vista como un proceso caótico, incontrolado y dañino sino como un intrincado y complejo, que implica a multitud de elementos del sistema inmune y cuya finalidad es la de controlar la inflamación que prosigue a la agresión del patógeno (138).

El modo en que responden las citocinas en la sepsis suele explicarse con un modelo bifásico. En la fase más precoz se crea un estado proinflamatorio mediante la producción de citocinas inflamatorias (IL-6, IL-1, TNF, INF), a continuación se secretan antiinflamatorias como IL-10, cuyo objetivo podría ser el compensar la respuesta inicial (139). El estado proinflamatorio podría contribuir a aumentar el daño tisular y la mortalidad, mientras que en la fase antiinflamatoria podría verse aumentado el riesgo de infección bacteriana secundaria. Para tratar de mejorar el conocimiento del balance entre citocinas proinflamatorias y antiinflamatorias es necesario entender los mecanismos de regulación del sistema inmune durante el transcurso de esta entidad.

Otros estudios se han centrado en la expresión de moléculas proinflamatorias como el de Boomer et al (53) y encuentran que los pacientes que presentan infecciones más virulentas son los que asocian mayor expresión de citocinas proinflamatorias, lo que respalda lo 
perjudicial que resulta el estado de hiperinflamación $(62,65)$. Mera $\mathrm{S}$ et al han puesto de manifiesto el valor que tiene las concentraciones de IL-8 (citocina proinflamatoria) para predecir la mortalidad en sepsis (140). La aparición de nuevas teorías no hace sino acrecentar el número de patrones de inmunológicos, haciendo que nos acerquemos cada vez más a la verdadera respuesta inmune del huésped.

La sepsis involucra tanto a la inmunidad innata como a la adaptativa (141). Ésta comienza a estar implicada porque la respuesta innata se autoperpetúa. Existe creciente evidencia de la relación que existe entre la producción endógena de inmunoglobulinas y el pronóstico del shock séptico. Recientemente Venet $\mathrm{F}$ et al han publicado que los pacientes con shock séptico presentan bajos niveles plasmáticos de $\operatorname{IgG}$ e $\operatorname{IgM}$ durante los cuatro primeros días, sin asociación con morbilidad, severidad o mortalidad (142). Taccone et al demostraron en un estudio piloto la existencia de baja concentración de $\gamma$ globulinas (especialmente $\operatorname{IgG}$ ) de forma persistente, en pacientes con shock séptico adquirido en la comunidad, asociándose a mayores requerimientos de vasopresores, distres respiratorio y mayor mortalidad (143).

A pesar de la relación entre los niveles de inmunoglobulinas en los primeros momentos de la sepsis y el pronóstico de la enfermedad, los resultados acerca del potencial beneficio que tendrían las inmunoglobulinas intravenosas en la sepsis son controvertidos. El metaanálisis realizado por Laupland et al demostró una disminución global de la mortalidad con el uso de inmunoglobulinas intravenosas concomitantemente al resto de terapias en el shock séptico y sepsis severa en adultos (144). Sin embargo, el estudio SBIT (145) encontró que los pacientes con sepsis severa tratados con inmunoglobulinas intravenosas no mostraban una disminución en las cifras de mortalidad (145). Los preparados de inmunoglobulinas 
policlonales enriquecidos con $\operatorname{IgA}$ e $\operatorname{IgG}(\operatorname{IgGAM})$ parecen dar mejores resultados, disminuyendo la mortalidad si se comparan con los preparados que únicamente tienen $\operatorname{IgG}$ (146). La regla general en este tipo de estudios es la ausencia de información referente a los niveles de isotipos de inmunoglobulinas previos al tratamiento. Además existe una completa falta de datos acerca del papel que tiene la IgG en el shock séptico.

Un objetivo importante en el futuro tratamiento de la sepsis sería determinar con precisión el estado inmune de los pacientes durante la enfermedad. Aquellos con mayor compromiso inmunológico serían beneficiarios de tratamientos específicos (147). 

3.OBJETIVOS 

1. Analizar los niveles séricos de citocinas y quimiocinas en pacientes con shock séptico o SIRS.

2. Análisis de quimiocinas y citocinas como factor de mortalidad en pacientes con shock séptico postquirúrgico.

3. Asociar los niveles plasmáticos de subclases de IgG, IgA e IgM en el momento del diagnóstico, con la severidad de la patología y el resultado final. 

4.PUBLICACIONES 



\subsection{LAS RESPUESTAS PRO Y ANTIINFLAMATORIAS SE DAN DE FORMA SIMULTÁNEA DESDE LOS PRIMEROS MOMENTOS DE LA SEPSIS}

Publicado en: European Cytokine Network

Eur Cytokine Netw. 2011 Jun;22(2):82-7.

\section{ABSTRACT}

La relación entre la respuesta de las citocinas y el shock séptico está actualmente poco entendida. Algunos estudios apuntan a un modelo bifásico para explicar la patogenia de las formas más severas de sepsis, con una fase inicial proinflamatoria, seguida de una reacción antiinflamatoria. Sin embargo, no se ha encontrado evidencia de la coexistencia de ambas respuestas. En este estudio se han analizado los niveles plasmáticos de 17 citocinas y quimiocinas en 20 pacientes con shock séptico, 11 pacientes con SIRS en las primeras 24 horas tras el diagnóstico y 10 controles sanos. Los pacientes con shock séptico mostraron niveles elevados de IL-6, IL-8, MCP-1, MIP-1 $\beta$, INF- $\gamma$, GM-CSF e IL-10, comparado con los controles sanos. Los pacientes con SIRS mostraron niveles mayores de IL-6, IL-8, MCP-1, MIP-1 $\beta$, G-CSF e IL-10 que los de los controles. Los pacientes con shock séptico mostraron niveles más elevados de IL-8, GM-CSF, MIP-1 $\beta$ que los pacientes con SIRS. El test de Spearman demostró una asociación positiva entre los mediadores proinflamatorios IL-6, IL-8, MCP-1, MIP-1 $\beta$, IFN- $\gamma$, GM-CSF y la citocina inmunomoduladora IL-10 en los pacientes con shock séptico. Consecuentemente los estudios respaldan la secreción de mediadores pro y antiinflamatorios en el shock séptico como una respuesta inmune simultánea iniciada desde el comienzo de la entidad, revelando que ambos tipos de citocinas juegan un papel desde los inicios de esta patología tan grave. 


\section{INTRODUCCIÓN}

La sepsis es una respuesta inflamatoria sistémica incontrolada que es consecuencia de la infección, cuya forma más severa es el shock séptico. Éste causa disfunción multiorgánica e hipotensión. Incluso hoy en día el shock séptico está asociado con una alta tasa de mortalidad y representa todo un reto para clínicos e investigadores (148) . La implicación de la respuesta de citocinas en la patogénesis de la sepsis y se suele explicar como un modelo bifásico, con una fase inicial caracterizada por la producción de citocinas proinflamatorias (IL-6,IL-1,TNF, INF), seguido de una fase en la que se sintetizan citocinas antiinflamatorias como IL-10 (139). La fase proinflamatoria contribuiría al daño tisular y a incrementar la mortalidad mientras que la segunda fase, antiinflamatoria (llamado síndrome de respuesta antiinflamatoria compensatoria CARS) aumentaría el riesgo de una infección bacteriana secundaría (73) Sin embargo, existe evidencia que contradiga la teoría de las dos fases (149).

Es esencial un mejor entendimiento de la regulación y balance entre ambas respuestas de citocinas en respuesta a la sepsis, para mejorar el conocimiento en su patogénesis.

La aparición de diferentes teorías ofrece la oportunidad de obtener distintos patrones de mediadores que ayuden a averiguar cuál es la verdadera respuesta inmune del huésped.

Se realizó un análisis de los niveles séricos de citocinas y quimiocinas en pacientes con shock séptico o SIRS usando un kit 17-plex. Esto permitió la verificación de que existe una respuesta inmune simultánea y antagónica desde el comienzo del establecimiento del shock séptico. 


\section{MATERIAL Y MÉTODOS}

\section{Pacientes y controles}

Los pacientes y los controles fueron reclutados prospectivamente en la unidad de cuidados críticos del Hospital Clínico Universitario de Valladolid. Tras obtener el permiso del comité ético y científico del centro. Se usaron las recomendaciones de la conferencia de consenso del colegio americano de neumólogos y la sociedad de cuidados críticos americana para definir SIRS y shock séptico $(50,150)$. Para definir la severidad de la enfermedad se usaron dos escalas : APACHE II para las primeras 24 horas tras el diagnóstico (151) y SOFA (152) para el seguimiento del fallo de los distintos órganos.

Veinte pacientes con shock séptico y 11 con SIRS fueron reclutados para el estudio. Se extrajeron muestras de diez voluntarios sanos que trabajan en la Universidad de Valladolid y cuya edad estaba en el rango de la de los pacientes incluidos en el estudio.

\section{Muestras y perfil de citocinas}

Se obtuvo una muestra de sangre de cada paciente y cada control en tubos que contenían Ácido etilendiamino tetraacético (EDTA) en las primeras 24 horas tras el diagnóstico de shock séptico o SIRS. Las muestras de plasma fueron obtenidas tras centrifugación y almacenadas a $-80^{\circ} \mathrm{C}$ hasta que se realizaba el perfil de citocinas. Los niveles plasmáticos de citocinas y quimiocinas fueron evaluados usando el sistema Biorad@17, siguiendo las instrucciones del fabricante. Este sistema permite una medición cuantitativa de 17 quimiocinas, citocinas, factores de crecimiento y mediadores inmunes consumiendo una cantidad mínima de material biológico. Este sistema tiene una buena representación de los análisis de citoquinas inflamatorias y antiinflamatorias, citocinas Th1, Th2, Th17 y citocinas permitiendo testar diferentes niveles de citocinas reguladoras en el plasma de los pacientes 
Límites de detección (pg/mL): IL-1b (2,4);IL-6 (2,1); IL-8 (1,8); IL7 (2,4); IL-17 (2,1); G-CSF (1,5);MCP-1 (1,8); MIP-1b (1,4); IL-2 (1,3); IL-4 (0,2); IL-5(2,5); IL-10 (1,8); IL-12(p70) $(2,6)$; IL-13 (2,6); GM-CSF $(0,7) ; \mathrm{IFN}-\gamma(2,4) ; \mathrm{TNF}-\alpha(6,4)$.

\section{Estadística}

Se usó el test de Mann-Whitney debido a que el test de SaphiroWilk demostró la ditribución no normal de los datos y el test de Levene demostró la ausencia de homogeneidad en la variablilidad de los grupos comparados. Para estudiar la correlación entre los niveles de citocinas y los parámetros clínicos se usó el test de Spearman. Todos los test se realizaron de forma bidireccional y la $\mathrm{p}$ se consideraba significativa si era menor de 0.05. Los coeficientes de correlación de Spearman se representaron como mapas de calor usando el software J Color Grid (Universidad de California San Francisco y Universidad de California Berkeley) (153).

\section{RESULTADOS}

\section{Características clínicas y demográficas (tabla 2)}

Los pacientes en ambos grupos tenían edad avanzada. La comorbilidad más frecuente era patología cardiovascular. El antecedente más común en el grupo del shock séptico era la cirugía abdominal. Los niveles de procalcitonina y PCR eran más altos en los pacientes con shock que en los que presentaban SIRS ( $\mathrm{p}<0.05)$, así como el número de leucocitos $(\mathrm{p}<0.05)$.

Comparación entre niveles de mediadores inmunológicos (figura 15)

Los niveles de IL-1, IL-7, IL-5 e IL-13 estaban por debajo del límite de detección para el método empleado de cada mediador en la gran 
mayoría de pacientes. Consecuentemente no se consideraron para el análisis.

Los pacientes con shock séptico mostraron niveles elevados de IL-6, IL-8, MCP-1, MIP-1 $\beta$, IFN- $\gamma$, GM-CSF e IL-10 comparado con los controles. Los pacientes con SIRS mostraron niveles elevados de IL-6, IL8, MCP-1, MIP-1 $\beta, G-C S F$ e IL-10 comparado con el grupo control. Siete de los pacientes con shock séptico mostraron niveles detectables de IL-17; otros siete mostraron niveles elevados de TNF $\alpha$.

Seis pacientes de este grupo mostraron niveles detectables de IL-2 e IL-4, mientras que tres pacientes mostraron niveles detectables de IL12p70. Únicamente un paciente con SIRS mostró niveles detectables de IL-17 (13,9 pg/mL), mientras que otro mostró niveles detectables de IL-2, IL-4, IL-12p70 y TNF $\alpha$ (datos no mostrados).

Ninguno de los controles presentaba niveles detectable de IL-17, IL2, IL-4, IL-12p70 o TNFa. Cuando los niveles de los mediadores inmunes se comparan entre los grupos de shock séptico y SIRS, el grupo de shock séptico muestra niveles más elevados de IL-8, GM-CSF y MIP-1 $\beta$ $(\mathrm{p}<0.05)$.

\section{Correlación de los niveles de mediadores inmunes (figura 16)}

Los estudios de correlación muestran una asociación positiva entre los niveles de IL-6, IL-8, MCP-1, MIP-1 $\beta$, IFN $\gamma$, GMCSF e IL-10 en los pacientes con shock séptico, con unos coeficientes de correlación de Spearman de (r) >0.4. Esta correlación positiva demuestra que estos mediadores se secretan de forma simultánea en respuesta a la agresión que supone el shock séptico. Las correlaciones positivas que se han encontrado en los pacientes con SIRS son: [IL-6, IL-8), [IL-6, G-CSF], [IL-8, IFN- $\gamma$ ], [G-CSF, MCP-1], [MCP-1, MIP-1 $\beta$ ], con r >0.5 (datos no mostrados). 
Tabla 2. Características clínicas y demográficas

\begin{tabular}{|c|c|c|}
\hline \multicolumn{3}{|c|}{ Shock séptico $(\mathrm{n}=20) \quad$ SIRS $(\mathrm{n}=11)$} \\
\hline \multicolumn{3}{|l|}{ Descripción } \\
\hline Género $(\mathrm{M} / \mathrm{F})$ & $12 / 8$ & $9 / 2$ \\
\hline Edad (años) & $68,00(14,6)$ & $76,6(8,6)$ \\
\hline Hipertensión arterial(n) & 7 & 9 \\
\hline Cardiopatía (n) & 7 & 6 \\
\hline Diabetes mellitus (n) & 1 & 1 \\
\hline Obesidad (n) & 0 & 1 \\
\hline Patología respiratoria (n) & 3 & 1 \\
\hline Cáncer (n) & 3 & 4 \\
\hline Patología renal $(\mathrm{n})$ & 3 & 0 \\
\hline Cirugía (abdominal/cardiaca/vascular) & $15 / 5 / 0$ & $5 / 5 / 1$ \\
\hline Días en unidad de críticos & $12,00(13,5)$ & $1,00(0,5)$ \\
\hline Día toma muestra tras ingreso en unidad de críticos & $6,00(7,0)$ & $1,00(0,7)$ \\
\hline \multicolumn{3}{|c|}{ Estado clínico al diagnóstico } \\
\hline Puntuación APACHE & $22,24(6,7)$ & $9,00(2,4)$ \\
\hline Puntuación SOFA & $7,70(3,7)$ & $3,36(2,6)$ \\
\hline Ventilación mecánica & $18 / 20$ & $9 / 11$ \\
\hline Frecuencia cardiaca & $112,0(20,4)$ & $86,00(16,2)$ \\
\hline Frecuencia respiratoria & $14,53(4,5)$ & $13,90(3,6)$ \\
\hline Temperatura & $37,46(1,4)$ & $36,7(1,1)$ \\
\hline Tensión arterial media & $67,54(11,3)$ & $82,2(10,1)$ \\
\hline Noradrenalina & $20 / 20$ & $2 / 11$ \\
\hline \multicolumn{3}{|c|}{ Estado analítico al diagnóstico } \\
\hline Hematocrito (\%) & $32,71(6,6)$ & $32,21(5,0)$ \\
\hline Leucocitos (número/mL) & $17487,47(10867,2)$ & $11582(4962,6)$ \\
\hline Neutrófilos (número/mL) & $15431,2(11120,8)$ & $8475,1(2768,9)$ \\
\hline Procalcitonina & $26,69(38,7)$ & $1,45(3,4)$ \\
\hline Proteina $\mathrm{C}$ reactiva & $184,2(106,5)$ & $45,9(68,8)$ \\
\hline Creatinina (mg/dL) & $1,63(1,1)$ & $1,09(0,4)$ \\
\hline Pacientes con cultivos positivos & $18 / 2$ & $0 / 11$ \\
\hline Fallecidos/Supervivientes & $11 / 9$ & $1 / 10$ \\
\hline
\end{tabular}




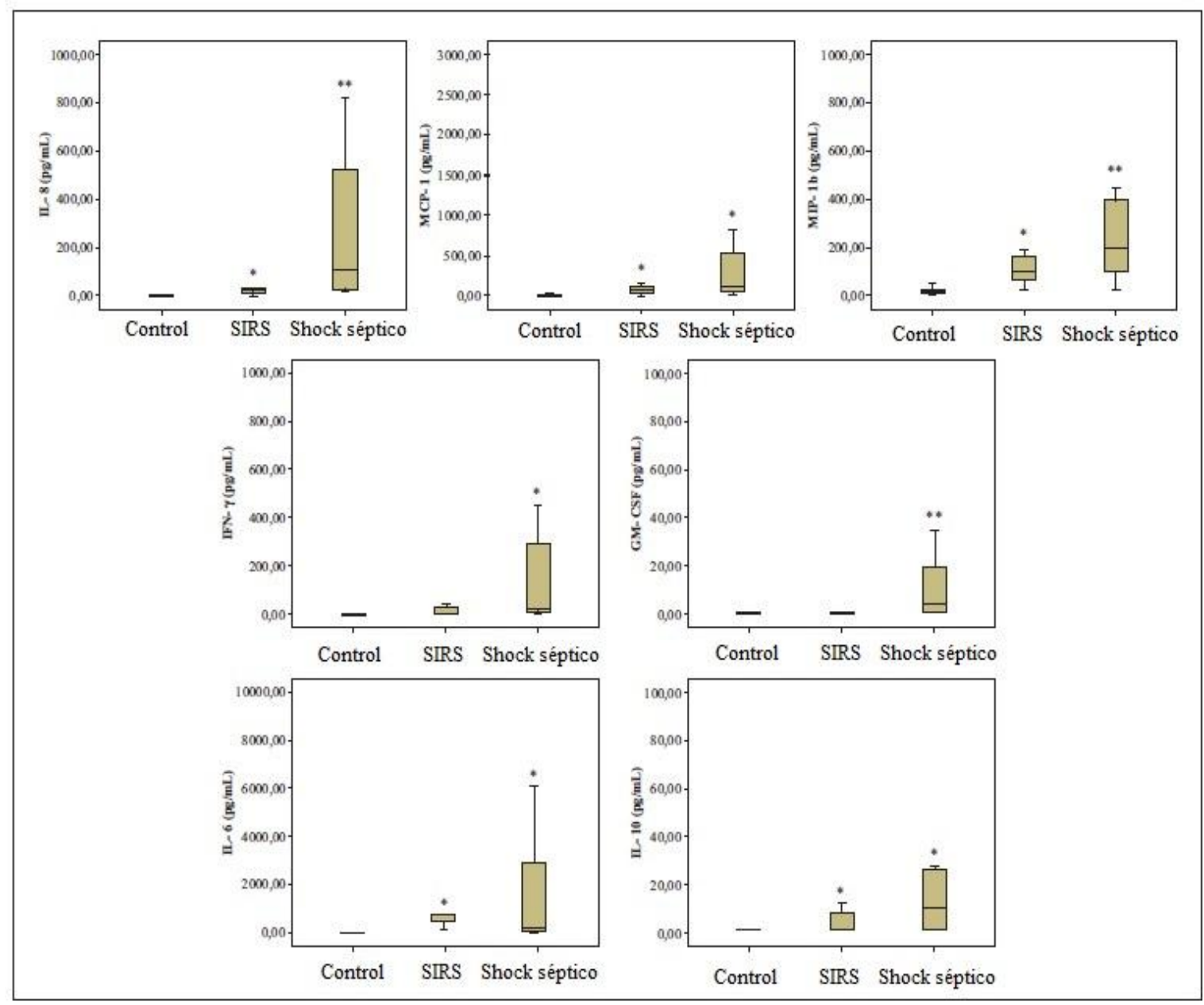

Figura 15.Niveles de mediadores inmunes en controles sanos, SIRS y shock séptico.

* Significativamente diferentes del grupo control. ** Significativamente diferentes del grupo control y del grupo SIRS $(\mathrm{p}<0.05)$

\section{DISCUSIÓN}

La presencia de niveles plasmáticos elevados de IL-6, IL-8,MCP-1, MIP-1 $\beta$, IFN- $\gamma$ y GM-CSF encontrados en nuestro estudio está en consonancia con un artículo publicado previamente (154), que mostraba la existencia de una respuesta sistémica proinflamatoria muy severa de citocinas y quimiocinas en los casos más severos de sepsis y shock séptico. La mayoría de éstas han sido estudiadas como marcadores biológicos en sepsis (155). Estos mediadores son moléculas quimiotácticas que atraen monocitos, neutrófilos, linfocitos $\mathrm{T}$ y macrófagos a los tejidos dañados, 
jugando un papel importante no sólo en la lucha contra la infección sino también en la patogénesis de procesos agudos y crónicos con gran componente inflamatorio (156). Al mismo tiempo, nuestros resultados aportan una nueva evidencia de la existencia de una respuesta tanto pro como antiinflamatoria, mostrado en los niveles elevados de IL-10 en plasma. IL-10 es una molécula con propiedades inmunorreguladoras. La secreción de IL-10 en el shock séptico podría representar un intento de modular la respuesta proinflamatoria que se da en esta situación.

Por otro lado, los niveles elevados de IL-10 podrían inducir a un estado de inmunodeficiencia funcional, comprometiendo la respuesta del huésped a los patógenos y al manejo de la infección (157).

Los trabajos previos como los de Bozza et al (158) y Mera et al (140) revelaban la relación entre casos de sepsis severa y aumento de IL-6,IL-8, MCP-1, IFN $\gamma$ e IL-10. Estos estudios también mostraban niveles elevados de IL-4, IL-12p70 y TNF $\gamma$ en aquellos pacientes con peor desenlace. A pesar de que no hemos encontrado niveles elevados de estas tres citocinas en todos nuestros pacientes, los hemos encontrado en algunos. El pequeño tamaño de la cohorte analizada quizás impida obtener resultados más fiables en lo referente a estas citocinas.

Por otro lado nuestros resultados para GM-CSF y MIP-1 $\beta$ contradicen en cierta manera los de Mera et al (140) ya que ellos encontraron niveles más bajos de estas moléculas en los pacientes que presentaban shock séptico que en los que no lo presentaban.

La distinta localización de la infección inicial (respiratorio y urinario en el trabajo de Mena et al y abdominal en el nuestro) podría explicar algunas diferencias en el perfil de citocinas encontrado. De acuerdo con el resultado de este estudio, los niveles elevados de la citocina Th17, IL-17 en el 35\% de los pacientes con shock séptico, podrían indicar un potencial 
papel de este mediador en la autoinmunidad y la defensa antibacteriana (156) en algunos casos de sepsis severa.

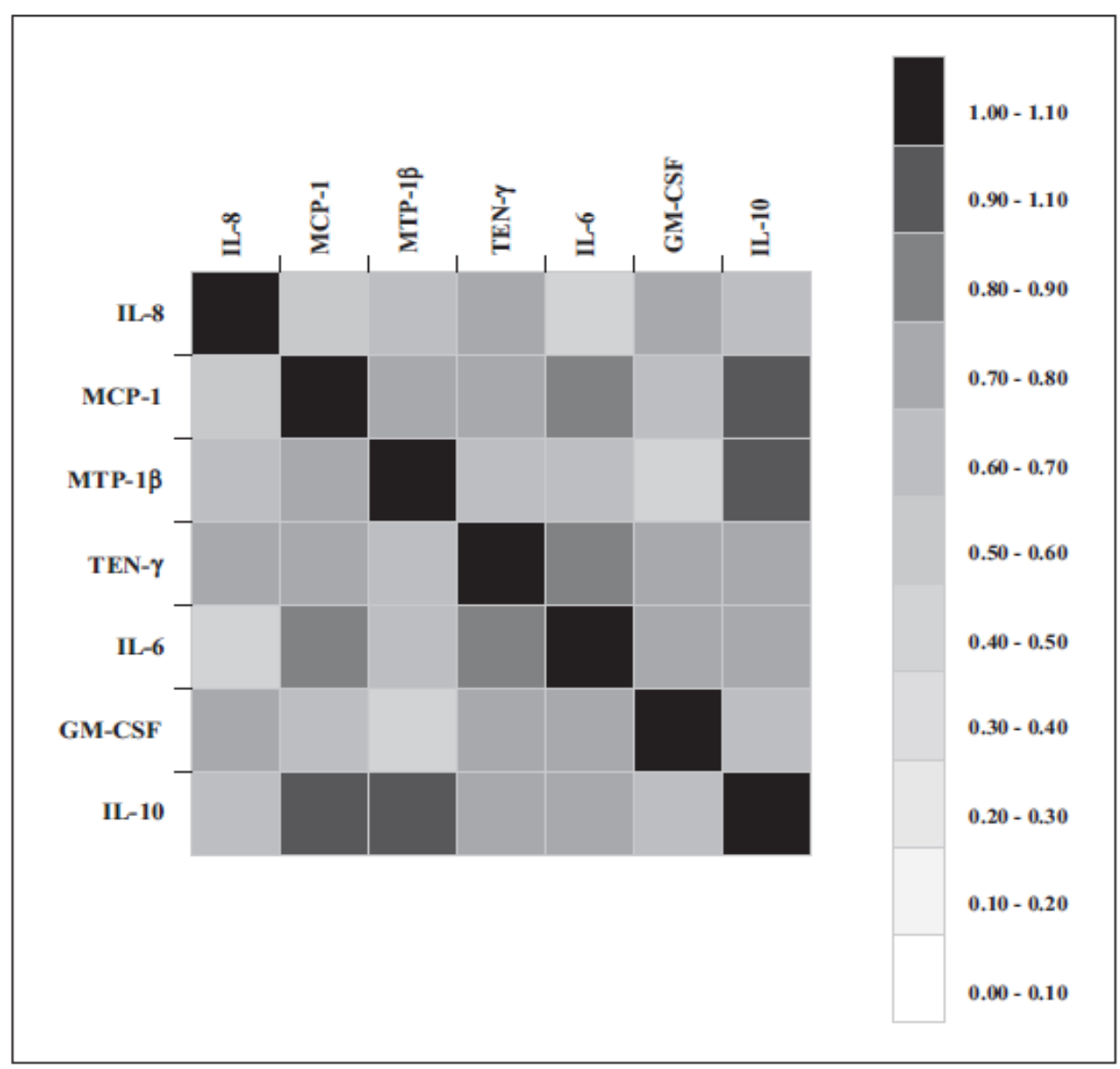

Figura 16.Mapa de calor representando el coeficiente de Spearman (r) correspondiente a las relaciones estadísticamente significativas $\mathrm{p}<0.05$. Valores de " $\mathrm{r}$ " representados por escala de grises. Figura realizada usando Jcolorgrid software.

Más importante, las asociaciones de niveles de mediadores inmunes que se observa en este estudio confirma que ambas respuestas tanto pro como antiinflamatoria ocurren al mismo tiempo. En este sentido, Cavaillon et al. han encontrado una correlación positiva entre IL-8, MCP-1, MIP-b, RANTES e IL-1ra, IL-10 en sepsis (159). De acuerdo con los resultados de Cavaillon et al., este estudio demuestra que las respuestas pro y antiinflamatoria se dan desde el momento en que se instaura el cuadro séptico. 
La potencial influencia de esta respuesta temprana y combinada en posteriores eventos patológicos, como el descubrimiento de una fase tardía de inmunoparálisis (117), incluso sobre la mortalidad (160-161), continúa sin averiguarse, ya que en el diseño de este estudio no se incluyó el seguimiento de los pacientes.

Tenemos resultados similares a los comunicados por RodríguezGaspar et al. (162), los pacientes con SIRS muestran valores elevados de mediadores proinflamatorios (IL-6, IL-8, MCP-1, MIP-1 $\beta$, G-CSF) y antiinflamatorios (IL-10), comparados con los de los controles, aunque el incremento de IL-10 es menos llamativo en estos pacientes. La ausencia de correlación entre mediadores proinflamatorios e IL-10 en pacientes con SIRS podría ser consecuencia del limitado número de individuos incluidos en este grupo o a que en el SIRS se produce un estado menos inflamatorio comparándolo con el que se da en el shock séptico, con una secreción compensatoria de IL-10 limitada.

La ausencia de infección en el SIRS podría también explicar las diferencias en los perfiles de citocinas comparándolo con el del shock (163).

En conclusión, los estudios de correlación de niveles plasmáticos de citocinas, apoyan la teoría de la secreción simultánea de mediadores pro y antiinflamatorios desde el primer momento de la instauración del shock séptico y formaría parte del programa de la respuesta inmune.

El papel exacto (beneficioso o no) de esta respuesta simultánea en la evolución de los pacientes requiere futuras investigaciones. 


\subsection{IL-8 Y PREDICCIÓN DE MORTALIDAD EN SHOCK SÉPTICO}

Aceptado en Acta Pathologica,Microbiologica et Immuno,

Scandinavica

APMIS. 2013 May;121(5):463-5. Epub 2012 Oct 22. PMID: 23083496

\section{Al editor:}

Hemos leído con interés el artículo titulado "Perfil de múltiples citocinas en pacientes con sepsis" de Mera et al (140). En este artículo los autores miden de forma simultánea 17 citocinas en 30 pacientes sépticos durante los 7 primeros días de ingreso en la unidad de críticos. Los autores encontraron en una regresión logística multivariante que los niveles iniciales de IL-8 eran losmejores predictores de mal pronóstico.

Mientras que en la cohorte de Mera et al (140), el número de pacientes que presentaba shock séptico era de 9 sobre 30, nosotros hemos intentado evaluar el papel pronóstico de las mismas citocinas en una cohorte de pacientes que presentara más casos de shock séptico. De esta forma, hemos reclutado 38 pacientes con shock séptico postquirúrgico. Los pacientes han sido reclutados de forma prospectiva en la unidad de cuidados críticos de nuestro hospital desde Enero a Diciembre de 2011. Para la definición de shock séptico se han utilizado las guías de consenso del colegio americano de Neumólogos y la sociedad americana de cuidados críticos (150). El estudio ha sido aprobado por comité ético de nuestro hospital. Se han obtenido los consentimientos de cada paciente previamente al estudio. Se han extraído $5 \mathrm{ml}$ de EDTA en las primeras 24 horas tras el diagnóstico de shock séptico. 12 pacientes habían sido intervenidos de cirugía cardiaca y 26 de cirugía abdominal.15 pacientes fallecieron durante su estancia en la Unidad de Cuidados Críticos. Se encontró infección 
fúngica o bacteriana en las muestras de sangre o en cultivos locales de 27 pacientes. 6 casos presentaron infección únicamente de bacterias gram positivas; 10 casos solamente por bacterias gram negativas ; un caso presentó infección únicamente por hongos; 6 pacientes tuvieron infección combinada de gram positivos y negativos; 2 gram negativos y hongos; 3 pacientes se infectaron por gram positivos, negativos $\mathrm{y}$ hongos.16 voluntarios que trabajan en el hospital, de edades similares fueron reclutados como controles con finalidad comparativa.

El Kit de múltiples citocinas que se usó fue 17 plex de BioRad (Hercules, CA,USA) e incluye: IL-1b, IL-2,IL-4, IL-5, IL-6, IL-7, IL-8, IL10, IL-12, IL13, IL-17, interferón gamma(IFN- $\gamma$ ), factor estimulador de colonias granulocíticas(G-CSF), factor estimulador de colonias de macrógafos (GMCSF), proteína monocítica quimiotáctica (MIP-1 $\beta$ ) y factor de necrosis tumoral (TNF- $\alpha$ ).

El test de Mann Whitney evidenció que los pacientes con shock séptico tenían mayores niveles plasmáticos de IL-6, IL-8, IL-10, IL-13, MCP-1 y MIP-1 $\beta$ que los controles, independientemente del desenlace (datos no mostrados). Los pacientes que murieron tenía niveles del IL-8 y MIP-1 en el momento del diagnóstico, significativamente mayores que los de los supervivientes [mediana, rango intercuartílico $(\mathrm{pg} / \mathrm{ml})$ en supervivientes y fallecidos]: IL-8 [(80.8,172.4);(158.6,217.9)] (figura 17) ; MCP-1[(148.4,441.7);(346.8,1347.7)] $\quad(\mathrm{p}<0.05)$. Los pacientes que murieron eran de mayor edad y presentaron en la Unidad de críticos mayores puntuaciones en el APACHE II [principal, desviación estándar]: edad (años) en supervivientes [68.0,14.3]; edad (años) en fallecidos [75.2,11.7]; APACHE II en supervivientes[13.2,5.5]; APACHE II en fallecidos[18.4,3.6]. El análisis de la regresión multivariante COX ajustada por edad y APACHE II mostraba que IL-8 era la única citocina asociada 
con el aumento de mortalidad a los 28 días tras el diagnóstico de shock séptico (RR,[ Intervalo de confianza 95\% ],p): 2.91[1.04-8.13], 0.041).

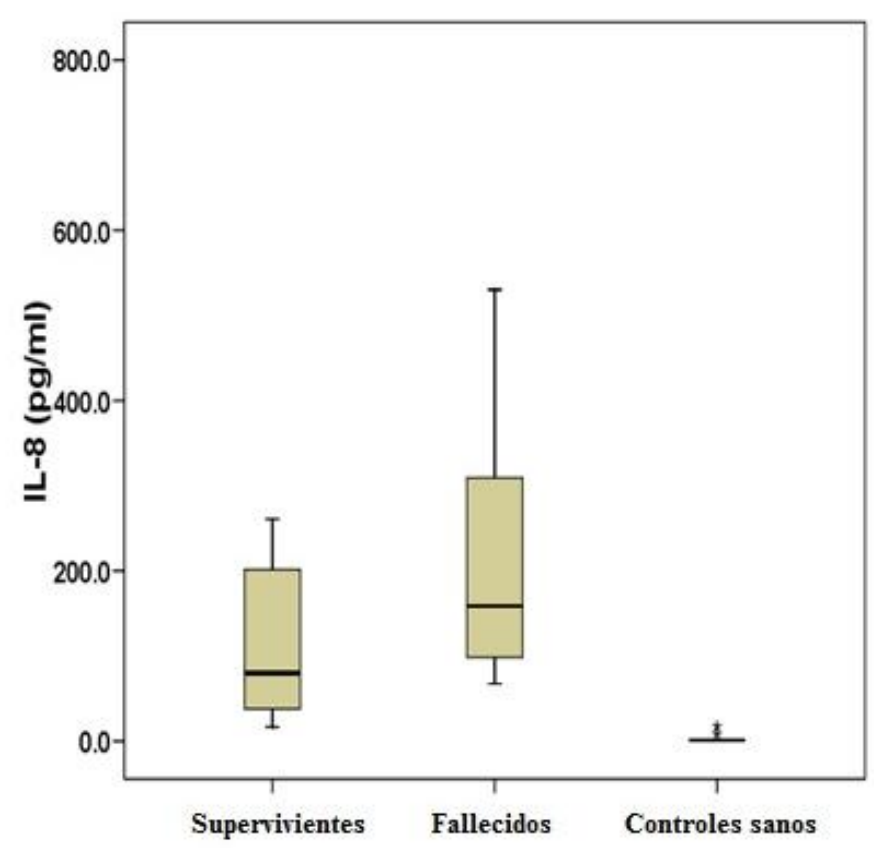

Figura 17. Niveles de IL-8 en el momento de diagnóstico de shock séptico dependiendo del desenlace.

Sin embargo en el mismo análisis, MCP-1 también aumentaba el riesgo de mortalidad pero con una $\mathrm{p}<0.1$ (datos no mostrados). Se utilizaron concentraciones logarítmicas de citocinas en el análisis de regresión para satisfacer la presunción de relación lineal.

Las curvas de supervivencia de Kaplan Meier evidenciaron que los pacientes que mostraban niveles de IL-8 por debajo del percentil 75 $(257 \mathrm{pg} / \mathrm{ml})$ del valor de la cohorte sobrevivían más días(tiempo medio se supervivencia en días [Intervalo de Confianza del 95\%] : supervivientes (25.3[23.0-27.7]); fallecidos (17.8[9.8-25.7]) (Figura 18A). Finalmente la curva característica operativa para el receptor (ROC) evidenció que IL-8 mostraba una buena asociación con la mortalidad, con un área bajo la curva de $0.72(\mathrm{p}=0.022)$ (Figura 18B). 
A)

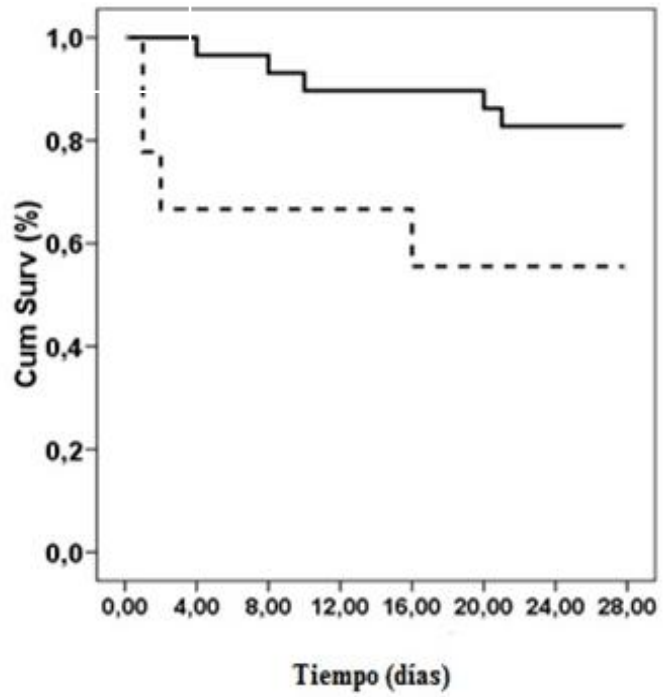

B)

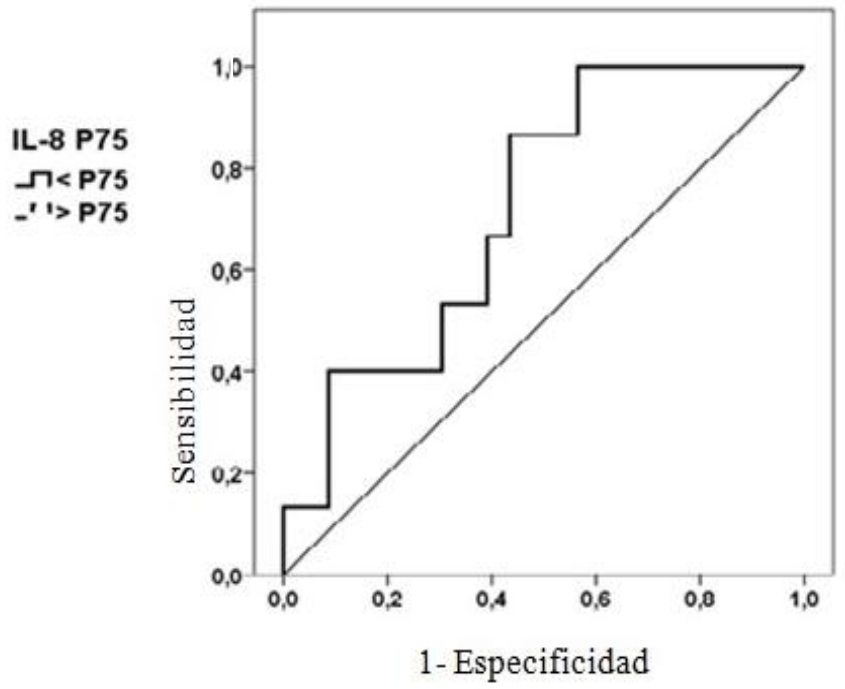

Figura 18. (A) Curvas de supervivencia dependiendo de los niveles de IL-8 en el momento del diagnóstico de shock séptico. (B) Curvas ROC de predicción de mortalidad según los niveles de IL-8 en el momento del diagnóstico.

Los pacientes con identificación microbiológica positiva no mostraron diferencias significativas ni en la proporción de pacientes con peor pronóstico (test chi cuadrado), ni en los niveles de IL-8 (test MannWhitney) comparados con aquellos que presentaban cultivos negativos (datos no mostrados).

Nuestros resultados están en consonancia con los encontrados por Fujushima $\mathrm{S}$ et al, que publicaron que los niveles detectables de IL-8 iniciales predicen una alta mortalidad en sepsis (164). Bozza et al (165) y Marty C et al (166), también asociaron IL-8 con mal pronóstico en sepsis. En una cohorte de pacientes que incluían estudios de estrategias de ventilación para daño agudo pulmonar: ALI (Acute Lung Injury), Calfee CS et al encontraron que los niveles plasmáticos de IL8 $\geq 220 \mathrm{pg} / \mathrm{ml}$ estaban asociados de forma importante con la mortalidad a los 28 días, aunque la curva ROC encontró poca correlación entre IL-8 y mortalidad (área bajo la curva de 0.59) (167). Las diferencias en la composición de la cohorte de 
pacientes (médicos/quirúrgicos) podría explicar las diferencias observadas en el papel de este mediador como predictor de mortalidad.

IL-8 es una citocina proinflamatoria. Está producida por muchos tipos de células tras la estimulación de Il-1, TNF o productos microbianos como las endotoxinas (166). Esta citocina promueve la angiogénesis, así como la migración y activación de neutrófilos (168). IL-8 podría reclutar neutrófilos hacia órganos vitales, lo que haría que se liberaran mediadores implicados en la patogenia de la sepsis (164).

En conclusión, nuestros resultados confirman el valor predicitivo de IL-8 incluso en los casos más severos de sepsis, apoyando su importante implicación en la fisiopatología de esta entidad. 


\subsection{BENEFICIOS DE SUBCLASES E ISOTIPOS DE INMUNOGLOBULINAS ENDÓGENAS EN EL SHOCK SÉPTICO.}

Publicado en Journal of Critical Care

J Crit Care. 2012 Dec;27(6):616-22.

\section{ABSTRACT}

Objetivos: Hay una evidencia creciente sobre la relación que existe entre las Igs producidas de forma endógena y el desenlace clínico del shock séptico.

Material y métodos: Se han medido los niveles plasmáticos de subclases de IgG, IgA ,IgM e IgE en 42 pacientes con shock séptico y en 36 pacientes con SIRS en el momento del diagnóstico. Se ha evaluado la asociación entre los niveles de Igs con la severidad y desenlace de la enfermedad.

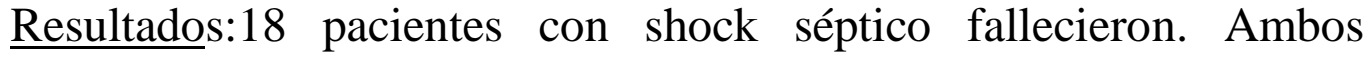
grupos SIRS y SS mostraron niveles de IgG total, IgG2 e Ig M por debajo de la normalidad. Los pacientes con SS que fallecieron mostraron los niveles más bajos de IgG total e IgG1 .Los niveles de IgG total, IgG1, IgG2, IgG3, IgG4 e IgA se correlacionaron de forma inversa con la escala de severidad APACHE II en shock séptico. El análisis de la regresión univariante COX mostró que los niveles de $\operatorname{IgG} 1$, IgG2, IgG3 $\operatorname{IgM}, \operatorname{Ig} \mathrm{A}$ e IgG total se asociaban de forma inversa a la probabilidad de muerte a los 28 días. El análisis multivariante mostró que $\operatorname{IgG1}, \operatorname{IgG}$ total e $\operatorname{IgA}$ se comportaban como factores protectores independientes contra la mortalidad [Riesgo relativo, p] : 0.23, 0.026;0.16,0.028;0.11, 0.042;0.05, 0.010 respectivamente, mientras que $\operatorname{IgG} 3$ mostraba así mismo tendencia protectora. 
Conclusiones: nuestro estudio evidencia que además de la $\operatorname{IgG} 1$, otras subclases e isotipos de inmunoglobulinas endógenas parecen tener un papel beneficioso en el shock séptico.

\section{INTRODUCCIÓN}

Hay una evidencia creciente de la relación entre las Igs producidas endógenamente y el pronóstico en sepsis severa y shock séptico. Recientemente Venet et al han publicado que niveles bajos de IgG e IgM en pacientes con shock séptico en los 4 primeros días del curso de esta enfermedad no tenían asociación con mortalidad, morbilidad o severidad.

Contrariamente nosotros hemos publicado que los pacientes con shock séptico que acaban falleciendo presentan bajos niveles de IgG (37). Taccone et al han demostrado en un estudio piloto la existencia de bajas concentraciones de gammaglobulinas, especialmente de IgG de forma persistente en pacientes con shock séptico adquirido en la comunidad, asociando mayor requerimiento de vasopresores, síndrome de distrés respiratorio agudo y mortalidad (143).

A pesar de la evidencia disponible sobre la relación entre niveles de inmunoglobulinas en los primeros momentos del shock séptico y el desenlace de la enfermedad, los resultados sobre el potencial papel de terapias sustitutivas con inmunoglobulinas intravenosas en la sepsis, son actualmente controvertidos. En el metaanálisis realizado por Laupland et al demostraron una disminución de la mortalidad usando inmunoglobulinas intravenosas como tratamiento adyuvante en la sepsis severa y shock séptico en adultos (144). Por el contrario el estudio SBIT encontró que en una cohorte de pacientes con sepsis, cuya severidad estaba definida por escalas clínicas, las inmunoglobulinas intravenosas no disminuían la mortalidad (145). La preparación de inmunoglobulinas policlonal enriquecidas con IgA e IgM (IgGAM) parece dar mejores resultados en 
cuanto a disminución de la mortalidad comparado con preparaciones que sólo contienen $\operatorname{IgG}$ (146). La regla general en estos estudios es la ausencia de información de los niveles de isotipos de inmunoglobulinas antes del tratamiento . Además existe gran desconocimiento acerca del papel individual de cada una de estas subclases de IgG en SS. En este artículo evaluamos en una cohorte de 42 pacientes con SS la asociación entre niveles plasmáticos de subclases de $\operatorname{IgG}$, $\operatorname{Ig} \mathrm{A}$ e $\operatorname{IgM}$ en el momento del diagnóstico, con la severidad de la patología y el resultado final.

\section{MATERIAL Y MÉTODOS}

\section{Pacientes}

Los pacientes con SIRS y SS fueron reclutados de forma prospectiva en la Unidad de Reanimación del hospital Clínico Universitario de Valladolid desde Enero a Diciembre de 2011.Se siguieron las recomendaciones de la conferencia de consenso del colegio Americano de Neumólogos y la sociedad de cuidados críticos de América para definir SIRS y SS (150). Tras obtener el permiso del comité ético y científico del centro . Se ha obtenido el consentimiento de cada paciente previamente al estudio.

\section{Toma de muestras y cuantificación de inmunoglobulinas}

Se han extraído $5 \mathrm{ml}$ de EDTA en las primeras 24 horas tras el diagnóstico de shock séptico o SIRS. Los tubos se centrifugaron y se obtuvo el plasma, que fue almacenado a $-80^{\circ} \mathrm{C}$ hasta la cuantificación. Se midieron niveles en plasma de $\operatorname{IgG} 1$, IgG2, IgG3, IgG4, IgA, IgM e IgE usando un kit de tipado de inmunoglobulinas múltiple de Biorad TM, en una plataforma Luminex. 


\section{Microbiología}

Se realizaron cultivos de las muestras biológicas tomadas de los pacientes presuntamente sépticos para evaluar la presencia de infección bacteriana o fúngica (169). Los microorganismos potencialmente contaminantes no se consideraron para el análisis.

\section{Análisis estadístico}

Para comparar las características clínicas y demográficas de los pacientes se ha usado chi cuadrado para variables cualitativas y para las continuas el test de Mann-Whitney U. con una regresión tipo COX determinamos el RR y el intervalo de confianza del 95\% y se evaluó el impacto de los niveles de inmunoglobulinas sobre la mortalidad a lo largo del tiempo. Además de los niveles de inmunoglobulinas se introdujeron las siguientes variables independientes como covariables: edad, sexo, cirugía cardiaca / abdominal ,escala APACHE II , número de hemoderivados recibidos y número de órganos dañados . El número de órganos dañados se calculó incluyendo la escala SOFA (Sequential Organ Failure Assesment), pulmones, sistema de coagulación, hígado, sistema cardiovascular, sistema nervioso central y riñones (170). Se considera fallo en un órgano cuando se puntúa en la escala SOFA 3 o 4 para dicho órgano. Se usaron concentraciones logarítmicas de inmunoglobulinas y valores logarítmicos de la escala APACHE II en el análisis de regresión para satisfacer la presunción de linearidad. Determinamos la incidencia de muerte usando las curvas de Kaplan-Meier. Se compararon los grupos usando el test log-rank (Mantel-Haenzel). Se estudiaron la exactitud y los valores predictivos de las inmunoglobulinas analizadas para supervivencia, calculando el área bajo la curva ROC. La correlación entre los niveles de inmunoglobulinas y las puntuaciones del APACHE II, se midió usando el test de Spearman-Karber. Todos los tests estadísticos se aplicaban de forma bilateral y la $\mathrm{p}$ se consideraba significativa por debajo de 0.05 .El análisis 
de los datos se ha realizado con el SPSS para Windows versión 15.0 software (SPSS, Chicago, IL, USA).

\section{RESULTADOS}

\section{Características clínicas}

Todos los pacientes habían sido intervenidos de cirugía cardiaca (recambio valvular o revascularización coronaria) o de cirugía abdominal (tabla 3). Dieciocho pacientes con shock séptico fallecieron. La mayoría de los pacientes eran varones de edad avanzada, aunque los que presentaron shock séptico que finalmente fallecieron, eran ligeramente más mayores. Los antecedentes más comunes eran de tipo cardiovascular e hipertensión. La cirugía de carácter urgente fue más frecuente en el grupo de shock séptico. Cuarenta y dos pacientes con SS mostraron fallo respiratorio y cardiovascular (100\%), dieciséis fallo renal (38\%) y dos mostraron alteraciones de la coagulación (4\%). Los pacientes con shock séptico que fallecieron presentaban peor situación respiratoria y estuvieron más tiempo sometidos a ventilación mecánica. Los niveles de lactato y procalcitonina fueron más elevados en los pacientes con shock séptico que fallecieron. . Los hallazgos microbiológicos se muestran en el anexo 1.

Niveles de inmunoglobulinas y asociación con severidad al diagnóstico

Los niveles de IgE eran inferiores a los límites de detección del kit y por ello no se incluyeron en el análisis. El análisis de la correlación mostraba que los niveles de IgG total, IgG1, IgG2, IgG3, IgG4 e IgA estaban inversamente asociados a la escala APACHE II en el momento del diagnóstico de SS (coeficiente r, P): -0.495, 0.001; -0.489, 0.001; -0.366, $0.017 ;-0.404,0.008 ;-0.297,0.050 ;-0.300,0.050$ respectivamente. Los 
niveles de subclases de $\operatorname{IgG}$, IgM e $\operatorname{IgA}$ se correlacionaban positivamente (datos no mostrados).

\section{Niveles de inmunoglobulinas y asociación con mortalidad}

El test de Mann-Whitney U reveló que los pacientes con SS que morían, tenían niveles significativamente más bajos de IgG1 e IgG total que los pacientes con SIRS o SS que sobrevivían (tabla 4). El análisis de la regresión Univariante Cox en el grupo de SS mostraba que los niveles de IgG1, IgG2, IgG3, IgM, IgA e IgG total estaban inversamente asociados con la probabilidad de muerte a los 28 días tras el diagnóstico (tabla 5).El análisis multivariante mostró que $\operatorname{IgG} 1$, $\operatorname{IgG}$ total e $\operatorname{IgA}$ se comportaban como factores protectores independientes frente a la mortalidad $(\mathrm{p}<0.05)$, mientras que IgG3 e IgM mostraban la misma tendencia ( $p<0.1$ ) (tabla 5).

Las curvas de Kaplan Meier evidenciaban que aquellos pacientes con SS que presentaban niveles de IgG1 eIgG total por debajo del percentil 30 (P30) morían antes que los que presentaban valores por encima de dicho percentil (Fig 19). Los tiempos de supervivencia eran los siguientes (media, intervalo de confianza del 95\%) : pacientes por debajo del P30,19.2 días (13.5 - 24.8); pacientes por encima del P30, 24.5 días (21.5 - 27.5), para ambas IgG1 e IgG total. El percentil 30 era $356 \mathrm{mg} / \mathrm{dl}$ para IgG1 y 484 $\mathrm{mg} / \mathrm{dl}$ para IgG total (Fig 19). El análisis de la curva característica operativa para el receptor mostraba que IgG1 e IgG total eran las mejores inmunoglobulinas para predecir la supervivencia, con un área bajo la curva de $0.73(p=0.01)$ para IgG1 y de $0.71(p=0.02)$ para IgG total. I (Fig 20). 
Tabla 3. Características clínicas de los pacientes con SIRS y shock séptico.

\begin{tabular}{|c|c|c|c|}
\hline & SIRS(n=36) & SS, supervivientes $(\mathrm{n}=24)$ & SS, fallecidos $(\mathrm{n}=18)$ \\
\hline Edad (años) $(\mathrm{m} \pm \mathrm{DE})$ & $66,7(13,0)$ & $68,3(14,4)$ & $74,8(11,3)$ \\
\hline $\operatorname{Sexo}(\mathrm{m} / \mathrm{f})$ & $24 / 12$ & $17 / 7$ & $13 / 5$ \\
\hline APACHE al Dx $(m \pm D E)$ & $10,2(3,2)$ & $13,0(5,6)$ & $18,4(3,5)$ \\
\hline Cirugía cardiaca/abd. & $22 / 14$ & $11 / 14$ & $5 / 12$ \\
\hline Diabetes, $\mathrm{n}(\%)$ & $9(25,0)$ & $8(33,3)$ & $3(16,6)$ \\
\hline Pat. Cardiovasc. $\mathrm{n}(\%)$ & $22(61,1)$ & $11(45,8)$ & $7(38,8)$ \\
\hline EPOC, $\mathrm{n}(\%)$ & $6(16,7)$ & $5(20,8)$ & $5(20,8)$ \\
\hline Hipertensión, n(\%) & $19(58,8)$ & $16(66,6)$ & $9(50,0)$ \\
\hline IRC, $\mathrm{n}(\%)$ & $3(8,8)$ & $4(16,0)$ & $2(11,8)$ \\
\hline Neoplasia, n (\%) & $8(22,2)$ & $6(24,0)$ & $5(29,4)$ \\
\hline Obesidad, IMC>30,n(\%) & $8(22,2)$ & $1(4,0)$ & $2(11,8)$ \\
\hline Hábito tabáquico, n(\%) & $6(16,7)$ & $4(16,0)$ & $5(29,4)$ \\
\hline Alcoholismo, n(\%) & $3(8,3)$ & $3(12,0)$ & $1(5,9)$ \\
\hline Pat.hepática, n(\%) & $1(2,8)$ & $0(0,0)$ & $0(0,0)$ \\
\hline Inmunosupresión, n(\%) & $2(5,6)$ & $3(12,0)$ & $0(0,0)$ \\
\hline Cirugía urgente, $\mathrm{n}(\%)$ & $2(5,6)$ & $12(50,0)$ & $13(72,2)$ \\
\hline $\mathrm{PaO}_{2 /} \mathrm{FiO}_{2}(\mathrm{~m} \pm \mathrm{DE})$ & $242,2(68,4)$ & $244,9(50,4)$ & $174,5(50,4)$ \\
\hline $\mathrm{Cr}(\mathrm{mg} / \mathrm{dL})(\mathrm{m} \pm \mathrm{DE})$ & $0,9(0,3)$ & $1,6(1,0)$ & $2,2(1,2)$ \\
\hline $\mathrm{Bb}(\mathrm{mg} / \mathrm{dL})(\mathrm{m} \pm \mathrm{DE})$ & $0,7(0,5)$ & $1,3(1,1)$ & $1,1(0,8)$ \\
\hline Lactato $(\mathrm{mg} / \mathrm{dL})(\mathrm{m} \pm \mathrm{DE})$ & $23,0(12,8)$ & $26,7(25,6)$ & $38,3(36,0)$ \\
\hline $\mathrm{PCT}(\mu \mathrm{g} / \mathrm{L})(\mathrm{m} \pm \mathrm{DE})$ & $0,6(0,8)$ & $21,2(33,6)$ & $31,1(34,8)$ \\
\hline $\mathrm{ScvO}_{2}(\%)(\mathrm{m} \pm \mathrm{DE})$ & $73,6(8,2)$ & $72,6(8,1)$ & $70,2(8,9)$ \\
\hline $\mathrm{PCR}(\mathrm{mg} / \mathrm{dL})(\mathrm{m} \pm \mathrm{DE})$ & $57,0(65,3)$ & $283,9(119,8)$ & $235,5(94,3)$ \\
\hline $\mathrm{Na}^{+}(\mathrm{mEq} / \mathrm{L})(\mathrm{m} \pm \mathrm{DE})$ & $135,3(18,0)$ & $138,1(3,3)$ & $130,9(26,0)$ \\
\hline $\mathrm{K}^{+}(\mathrm{mEq} / \mathrm{L})(\mathrm{m} \pm \mathrm{DE})$ & $3,8(0,6)$ & $5,6(9,1)$ & $4,3(1,0)$ \\
\hline Hto $(\%)(\mathrm{m} \pm \mathrm{DE})$ & $31,7(3,7)$ & $29,5(4,9)$ & $29,3(3,9)$ \\
\hline Leucocitos $/ \mathrm{mm}^{3}(\mathrm{~m} \pm \mathrm{DE})$ & $10502,6(5935)$ & $16093,5(10851,6)$ & $16263,9(9866,1)$ \\
\hline Neutrófilos(\%) $(\mathrm{m} \pm \mathrm{DE})$ & $84,5(4,8)$ & $86,3(4,5)$ & $88,8(6,3)$ \\
\hline Días VM $(m \pm D E)$ & No & $7.6(11,4)$ & $45,0(17,5)$ \\
\hline Días UCI al Dx $(\mathrm{m} \pm \mathrm{DE})$ & $2,2(4,7)$ & $4,2(7,2)$ & $3,9(4,9)$ \\
\hline $\begin{array}{l}\text { Días Dx hasta éxitus } \\
(\mathrm{m} \pm \mathrm{DE})\end{array}$ & No & No & $21,9(21,7)$ \\
\hline Días en $\mathrm{UCI}(\mathrm{m} \pm \mathrm{DE})$ & $1,6(1,1)$ & $35,0(119,1)$ & $18,4(18,7)$ \\
\hline
\end{tabular}


Dx, diagnóstico; Pat. Cardiovasc: patología cardiovascular; EPOC, enfermedad pulmonar obstructiva crónica; IRC, insuficiencia renal crónica; IMC, índice masa corporal; Pat. Hepática, patología hepática; Cr, creatinina; Bb, bilirrubina; PCT, procalcitonina; $\mathrm{ScvO}_{2}$, saturación venosa mixta; $\mathrm{PCR}$, proteína $\mathrm{C}$ reactiva; $\mathrm{m} \pm \mathrm{DE}$, media \pm desviación estándar

Tabla 4. Niveles de inmunoglobulinas en los grupos de SIRS y Shock Séptico

\begin{tabular}{|llll|}
\hline & $\begin{array}{l}\text { SIRS } \\
(\mathrm{n}=36)\end{array}$ & $\begin{array}{l}\text { SS, supervivientes } \\
(\mathrm{n}=24)\end{array}$ & $\begin{array}{l}\text { SS, fallecidos } \\
(\mathrm{n}=18)\end{array}$ \\
\hline IgG total & $808,4(473,4)^{\mathrm{a}}$ & $830,1(705,5)^{\mathrm{a}}$ & $597,6(600,9)$ \\
\hline IgG1 & $644,6(431,5)^{\mathrm{a}}$ & $657,1(632,3)^{\mathrm{a}}$ & $368,6(357,9)$ \\
\hline IgG2 & $53,5(65,9)$ & $60,4(130,1)$ & $49,2(108,2)$ \\
\hline IgG3 & $69,0(72,9)$ & $81,1(118,1)$ & $52,1(101,1)$ \\
\hline IgG4 & $12,1(14,7)$ & $13,2(13,5)$ & $16,1(19,3)$ \\
\hline IgM & $32,9(33,8)$ & $33,0(72,4)$ & $30,2(43,0)$ \\
\hline IgA & $182,1(100,4)$ & $211,6(206,8)$ & $162,2(125,7)$ \\
\hline
\end{tabular}

Los resultados se muestran como mediana (rango intercuartílico). Los valores normales en adultos sanos son: IgG (870-2180 mg/dL), IgG1 (344-966 mg/dL), IgG2 (133-622 $\mathrm{mg} / \mathrm{dL}), \operatorname{IgG} 4$ (1-115 mg/dL), IgA (117-420 mg/dL), IgM (60-220 mg/dL).

${ }^{a}$ Diferencias estadísticamente significativas $\mathrm{p}<0.05$ en pacientes con SS que fallecieron

Tabla 5. Regresión de COX para la mortalidad a 28 días tras diagnóstico

\begin{tabular}{|lllll|}
\hline \multicolumn{3}{c}{ Análisis univariante } & \multicolumn{2}{c|}{ Análisis multivariante } \\
\hline & IC 95\% & $\mathrm{P}$ & IC 95\% & $\mathrm{P}$ \\
\hline IgG total & $0,27(0,10-0,74)$ &, 011 & $0,16(0,03-0,82)$ &, 028 \\
\hline IgG1 & $0,41(0,20-0,86)$ &, 018 & $0,23(0,06-0,84)$ &, 026 \\
\hline IgG2 & $0,35(0,12-0,99)$ &, 048 & $0,45(0,14-1,13)$ & No S. \\
\hline IgG3 & $0,31(0,10-0,95)$ &, 040 & $0,20(0,03-1,15)$ &, 071 \\
\hline IgG4 & $0,47(0,12-1,83)$ &, 276 & $0,50(0,11-2,30)$ & No S. \\
\hline IgM & $0,23(0,07-0,81)$ &, 022 & $0,11(0,01-0,93)$ &, 042 \\
\hline IgA & $0,20(0,06-0,70)$ &, 012 & $0,05(0,01-0,19)$ &, 010 \\
\hline
\end{tabular}


IC, intervalo de confianza; No S, no significativo.

a Análisis multivariante ajustado por edad, sexo, cirugía cardiaca/abdominal, APACHEII y número de hemoderivados recibidos

\section{DISCUSIÓN}

El perfil de los isotipos de inmunoglobulinas en shock séptico y SIRS evidencian en primer lugar que IgE no tiene un papel relevante. Es un resultado esperado ya que IgE está principalmente implicada en la defensa contra parásitos y tiene gran importancia en la fisiopatología de la alergia y el asma (171). Nuestros resultados evidencian que tanto los pacientes con SIRS como los pacientes con shock séptico presentaban valores de la mediana de IgG total al diagnóstico, compatible con hipogammaglobulinemia, atendiendo a los valores de normalidad de nuestro laboratorio (tabla 4). Sin embargo los pacientes con shock séptico que finalmente murieron presentaron los niveles más bajos de $\operatorname{IgG}$ total.

La IgG humana puede subdividirse en cuatro clases: IgG1, IgG2, IgG3 e IgG4 cada una de ellas cifrada en una región separada y constante a nivel génico y está ligada a una función biológica única. La cuantificación de subclases de $\operatorname{IgG}$ ha revelado que los pacientes con shock séptico que murieron mostraron niveles bajos de IgG total, sobre todo a costa de una disminución de $\operatorname{IgG} 1$, cuyos valores de la mediana estaban por debajo de la normalidad (tabla 4) (172).

IgG1 constituye la mayoría de la $\operatorname{IgG}$ total contribuyendo en un 66\%, seguido de IgG2 (24\%), IgG3 (7\%) (173-174). En consecuencia IgG1 constituye la fracción mayoritaria de IgG total y una disminución de IgG1 da como resultado hipogammaglobulinemia (175), como de hecho ocurre en nuestro estudio. Se induce generalmente la formación de IgG1 e IgG3 en respuesta a antígenos proteicos, mientras que los anticuerpos de 
IgG2 e IgG4 están asociados a antígenos polisacarídicos (171). IgG1 e IgG3 son activadores clásicos del complemento (174). La activación de la cascada del complemento es un importante eliminador de patógenos opsonizados (171). La deficiencia de IgG1 se asocia frecuentemente con mayor susceptibilidad a la infección bacteriana. Hasta la fecha sin embargo, no hay datos sobre el papel de las subclases de $\mathrm{IgG}$ en la sepsis.
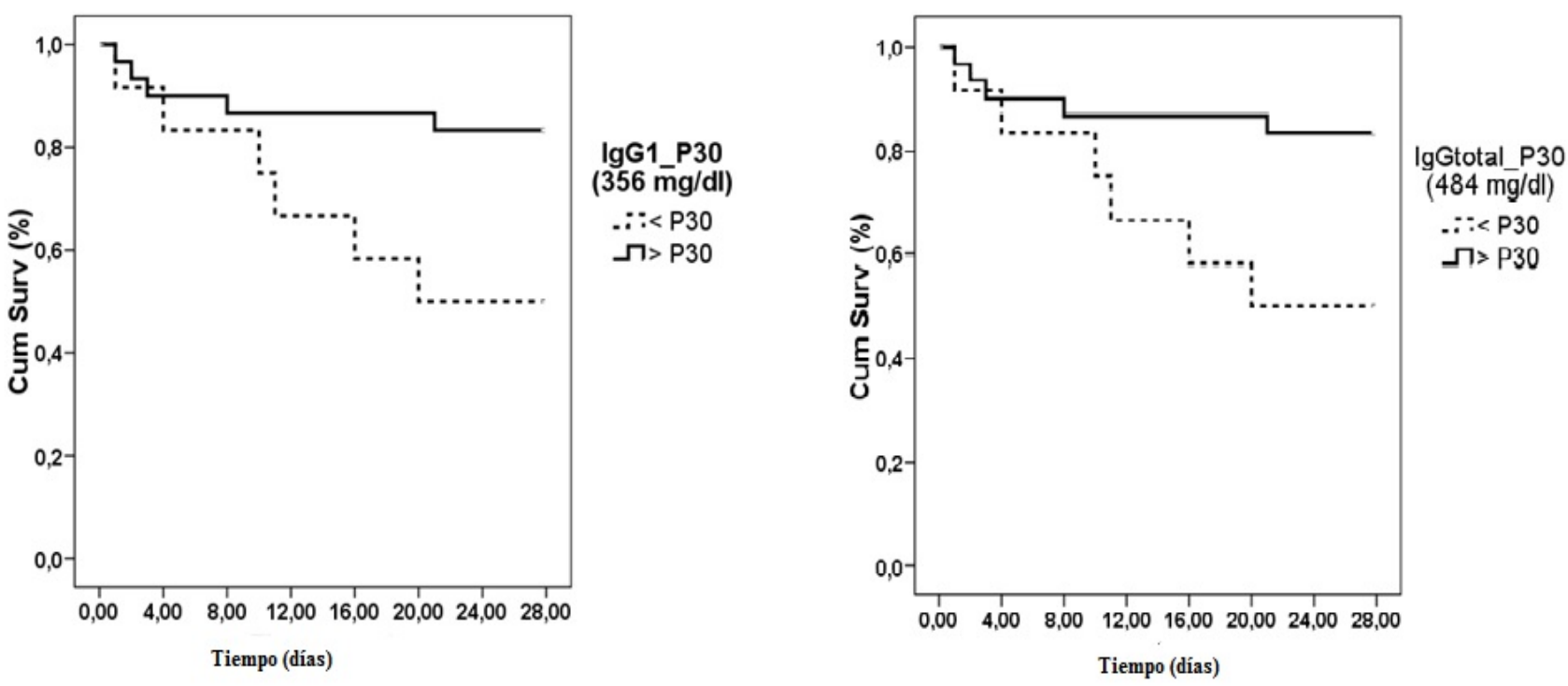

Figura19.Curvas de Kaplan Meier. Se calcularon los deciles desde percentil 10 a percentil 90 de niveles de inmunoglobulinas al diagnóstico y se usaron para comparar los tiempos de supervivencia en aquellos pacientes con altas o bajas concentraciones de inmunoglobulinas en plasma. El primer decil muestra diferencias significativas entre los grupos basadas en el test Mantel-Haenzel, fue usado como punto de corte el percentil 30.Los resultados de este análisis incluyen hasta el momento del fallecimiento. Tiempo medido hasta día 28. Cum Surv; supervivencia acumulada.

Comparando pacientes con SIRS y shock séptico no hemos encontrado diferencias en otros subtipos de $\operatorname{IgG}$ ni en los niveles de IgA o $\operatorname{IgM}$, aunque ambos grupos muestran niveles de $\operatorname{IgG} 2$ e IgM por debajo de los valores de referencia (tabla 4). Nuestros resultados muestran un escenario de inmunodeficiencia asociado al SIRS y shock séptico. Mientras que Venet et al (142), publican resultados similares a los nuestros para 
shock séptico, no encontramos información de niveles de inmunoglobulinas endógenas en SIRS.

El análisis avala el potencial efecto protector de las inmunoglobulinas producidas endógenamente en el shock séptico, así como se aprecia la relación inversa entre los niveles de inmunoglobulinas y la escala APACHE II que mide severidad. La regresión univariante COX refuerza el papel protector de las inmunoglobulinas en el shock séptico. El análisis multivariante muestra que la IgG total,IgG1 e IgA están asociadas de forma independiente con el aumento de probabilidad de supervivencia . IgG 3 muestra una tendencia protectora también. IgA es muy importante en cuanto a protección de mucosas frente a toxinas, virus y bacterias por medio de neutralización directa o la prevención de la unión a la superficie de la mucosa (171). IgM es una inmunoglobulina pentamérica secretada de forma precoz en el curso de la infección. IgM funciona opsonizando el antígeno para destruirlo u fijar el complemento (171). En consecuencia, niveles bajos de esta inmunoglobulina, podría disminuir el aclaramiento bacteriano. Coutinho HB et al (176), publicaron una disminución notable de $\operatorname{Ig} \mathrm{A}$ e IgM en células plasmáticas de tejidos intestinales de pacientes con sepsis abdominal.

La asociación entre niveles de inmunoglobulinas y la supervivencia no es dependiente de hemodilución, así lo respaldan los análisis multivariantes. Por otro lado, el defecto de una subclase de inmunoglobulinas podría ser primario, asociado a un defecto genético o secundario a otras patologías, generalmente con un componente inflamatorio (172-173), o como consecuencia de la existencia de un estado previo de inmunodeficiencia derivado de la condición crítica de los pacientes con shock séptico $(72,177)$. 

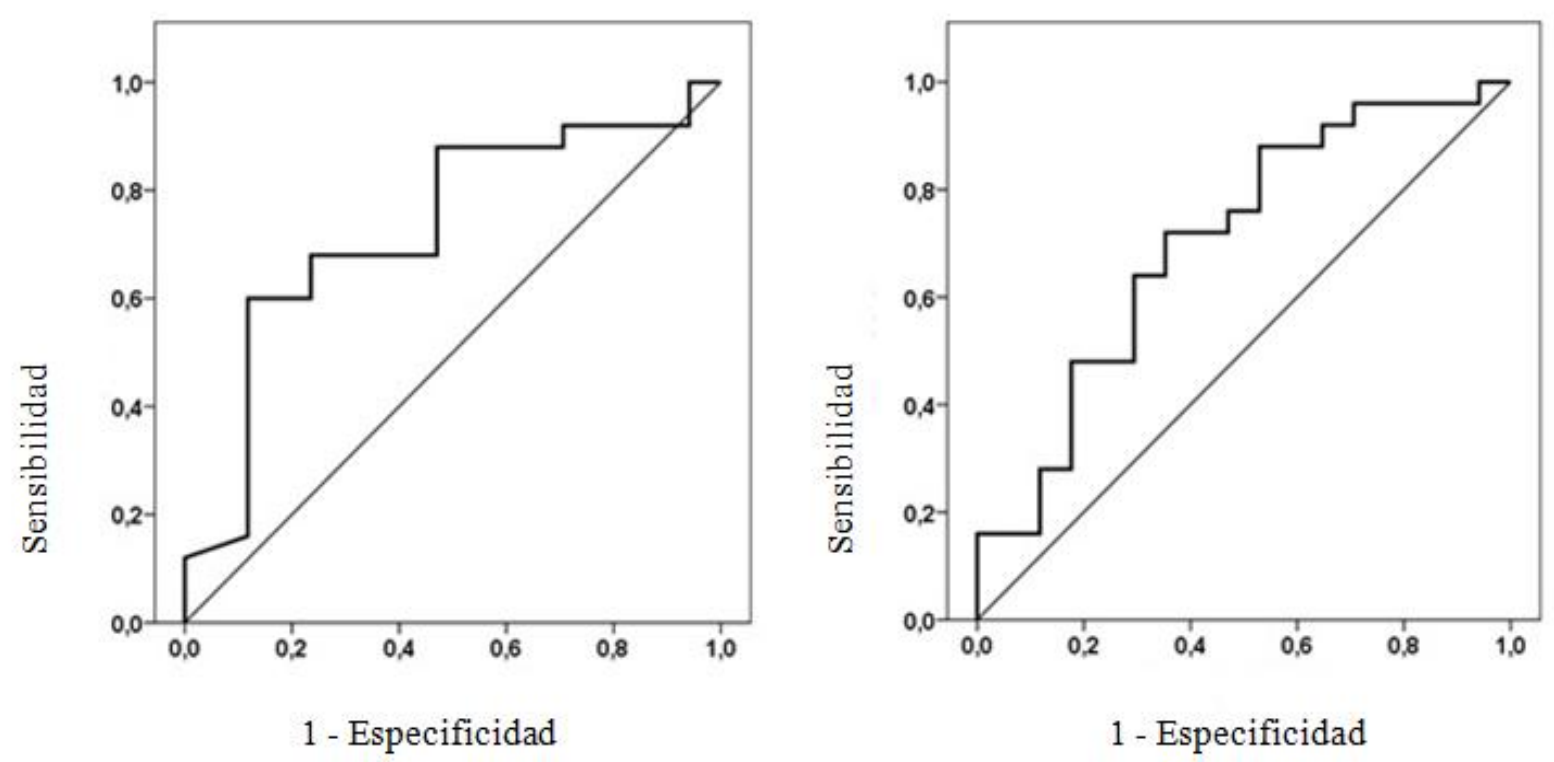

Figura 20.Curvas ROC de niveles de inmunoglobulinas al diagnóstico y prediciendo supervivencia.

Una limitación de nuestro estudio era la ausencia de datos de los niveles de inmunoglobulinas durante el transcurso de la enfermedad en los pacientes con SIRS o SS. El descubrimiento de respuestas específicas de anticuerpos es una prueba de la inmunidad adaptativa contra la infección y podría influir de forma importante en el pronóstico. Nuestro estudio demuestra claramente que los niveles de inmunoglobulinas endógenas en los primeros momentos del SS están asociados a la severidad y pronóstico, apoyando su importante papel en la patogenia de esta entidad. La evaluación precoz de los niveles de inmunoglobulinas endógenas en el SS podría representar la oportunidad para implementar actuaciones médicas precoces en estos pacientes con SS y mayor riesgo de fallecimiento. Un metaanálisis reciente indica que el efecto del tratamiento con inmunoglobulinas intravenosas en la mortalidad de los pacientes con SS está en el límite de la significación estadística con un alto grado de heterogeneidad en los resultados del tratamiento entre los diferentes 
estudios (178). A la luz de nuestros resultados en las áreas bajo las curvas operativas para el receptor y las curvas Kaplan-Meier, medir los niveles de inmunoglobulinas endógenas $\operatorname{IgG}$ total e $\operatorname{IgG} 1$ en el momento del diagnóstico podría representar una oportunidad para mejorar el rendimiento de los ensayos clínicos que evalúan las inmunoglobulinas intravenosas como tratamiento en el shock séptico, ayudando a seleccionar mejor aquellos pacientes que deben ser tratados. Además nuestro estudio evidencia que además de la IgG1, otras subclases y subtipos de inmunoglobulinas parecen jugar un papel beneficioso en el SS, que podría explicar los mayores beneficios de la terapia sustitutiva de inmunoglobulinas policlonales que aquellos tratamientos que únicamente contienen IgG. Se requieren más trabajos para evaluar el potencial papel protector de las inmunoglobulinas endógenas no sólo en SS sino también en sepsis severa. 
Anexo 1:

\begin{tabular}{|c|c|}
\hline HALLAZGOS MICROBIOLÓGICOS & $\begin{array}{c}\mathrm{N}^{\circ} \text { CASOS } \\
\text { POSITIVOS }\end{array}$ \\
\hline Bacteria Gram Positiva- Pulmón & 5 \\
\hline Bacteria Gram Positiva - Abdominal & 0 \\
\hline Bacteria Gram Positiva - Orina & 0 \\
\hline Bacteria Gram Positiva - Catéter & 1 \\
\hline Bacteria Gram Positiva - Sangre & 6 \\
\hline Bacteria Gram Positiva - Exudado herida & 5 \\
\hline Bacteria Gram Positiva - Líquido peritoneal & 2 \\
\hline Bacteria Gram Positiva- Axila- Faringe - Recto & 3 \\
\hline Bacteria Gram Positiva- Otra Localización & 3 \\
\hline Bacteria Gram Negativa- Pulmón & 7 \\
\hline Bacteria Gram Negativa - Abdominal & 0 \\
\hline Bacteria Gram Negativa - Orina & 3 \\
\hline Bacteria Gram Negativa - Catéter & 1 \\
\hline Bacteria Gram Negativa - Sangre & 5 \\
\hline Bacteria Gram Negativa - Exudado herida & 8 \\
\hline Bacteria Gram Negativa - Líquido peritoneal & 1 \\
\hline Bacteria Gram Negativa - Axila- Faringe - Recto & 12 \\
\hline Bacteria Gram Negativa - Otra Localización & 8 \\
\hline Hongos- Pulmón & 1 \\
\hline Hongos- Abdominal & 0 \\
\hline Hongos- Orina & 3 \\
\hline Hongos- Catéter & 0 \\
\hline Hongos- Sangre & 0 \\
\hline Hongos- Exudado herida & 1 \\
\hline Hongos- Líquido peritoneal & 0 \\
\hline Hongos - Axila- Faringe - Recto & 0 \\
\hline Hongos - Otra Localización & 3 \\
\hline
\end{tabular}





\section{CONCLUSIONES}



1. Desde el comienzo del shock séptico se secretan simultáneamente, mediadores pro y antiinflamatorios.

2. De 17 citocinas analizadas, IL-8 es la única asociada con el aumento de mortalidad a los 28 días tras el diagnóstico de shock séptico.

3. Los niveles de IgG1, IgG2, IgG3, IgM, IgA e IgG total se asocian de forma independiente con la probabilidad de mortalidad a los 28 días.

4. La IgG total, IgG1 e IgA se comportan como factores protectores independientes contra la mortalidad. 

6.BIBLIOGRAFIA 

1. Geroulanos S. D. Historical perspective of the world "sepsis". Intensive Care Med. 2006;32(12):2077.

2. Broughton G. JJE, Attinger CE. A brief story of wound care. Plast Reconstr Surg. 2006;117(7):S6-11.

3. Bishoy M. Surgery on papyrus. Student BMJ. 2004;12(2):338-9.

4. Majno. The ancient riddle of sigma eta psi iota sigma (sepsis). J Infect Dis. 1991;163(5):937-45.

5. Forrest RD. Early history of wound treatment. J R Soc Med. 1982;75 (3):198-205.

6. Forrest RD. Development of wound therapy from the Dark Ages to the present. J R Soc Med. 1982;75(4):268-73.

7. Francis A. The genuine works of Hippocrates. 2 ed. New York: Gryphon Editions Ltd; 1985.

8. Abbas A. K. Inmunología celular y molecular. 7 ed. Madrid: Elsevier; 2012.

9. Pastrana J, Civeira MP, Prieto JM. La clínica y el laboratorio. 20 ed. Barcelona: Elsevier-Masson; 2006.

10. Cinel I. Dellinger RP. Advances in pathogenesis and management of sepsis. Curr Opin Infect Dis. 2007;20(4):345-52.

11. Gabay C. K. Acute-phase proteins and other systemic responses to inflammation. N Engl J Med. 1999;340(6):448-54.

12. Majno. The Healing hand: man and wound in the ancient world. 1 ed. Boston: Harvard University Press; 1975.

13. Blum Y. EJ. The history of the treatment of musculoskeletal infection. Oper Tech Orthop. 2002;12(4):226-31.

14. Thurston AJ. Of blood, inflammation and gunshot wounds: the history of the control of sepsis. Aust N Z J Surg 2000;70(12):855-61. 
15. Botero H. Recuento histórico y análisis epistemológico de la sepsis secundaria a lesiones y su control quirúrgico: desde el papiro de Edwin Smith hasta el "pus bonum et laudabile". Iatreia. 2009;22(3):292-300.

16. Paget S. Ambroise Pare and his times 1510 to 1590.3 ed. Montana: Kessinger Publishing; 2005.

17. Lenz A, Franklin GA, Cheadle. Systemic inflammation after trauma. Injury. 2007;38(12):1336-45.

18. Keel M. T. Pathophysiology of polytrauma. Injury. 2005;36(6):691709.

19. Bosmann M. WP. The inflammatory response in sepsis. TREIMM. 2012;986 (1):1-8.

20. Helling TS. Mc Nabey WK. The role of amputation in the management of battlefield casualities: A history of two millenia. J Trauma. 2000;49(5):933-9.

21. De Costa C. "The contagiousness of childbed fever": a short history of puerperal sepsis and its treatment. Med J Aust. 2002;177(12):66871.

22. Funk D.J, Parrillo JE, Kumar A. . Sepsis and septic shock: a history. Crit Care Clin. 2009;25:83-101.

23. Baron R.M, Baron MJ, Perrella M. Pathobiology of sepsis.Are we still asking the same questions? Am J Respir Cell Mol Biol. 2006;34(2):129-34.

24. Debré P. F. Louis Pasteur.3 ed. Baltimore: Jonh Hopkins University Press; 2000.

25. Magner L. A history of infectious diseases and the microbial world. 4 ed.New York: Praeger Publishers; 2009.

26. Rittirsch D, Flierl MA, Ward PA. Harmful molecular mechanisms in sepsis. Nat Rev Immunol. 2008;8(10):776-87.

27. Rosengart MR. Critical care medicine:landmarks and legends. Surg Clin North Am. 2006;86(6):1305-21. 
28. Briceño I. Sepsis: definiciones y aspectos fisiopatológicos. Medicrit. 2005;2(8):164-78.

29. Dombrovskiy VY, Martin AA, Sunderram J, Paz HL. Rapid increase in hospitalization and mortality rates for severe sepsis in the United States: a trend analysis from 1993 to 2003. Crit Care Med. 2007;35(5):1244-50.

30. Venet F, Foray A.P, Villars-Mechin A, Malcus C, Poitevin-Later F, Lepape A, Monneret G. IL-7 restores lymphocyte functions in septic patients. J immunol. 2012;189:5073-81.

31. Levy MM, Fink MP, Marshall JC, Abraham E, Angus D, Cook D, Cohen J, Opal SM, Vincent JL, Ramsay G: 2001 SCCM/ESICM/ACCP/ATS/SIS International Sepsis Definitions Conference. Crit Care Med. 2003;31(4):1250-6.

32. Dellinger RP, Carlet JM, Masur H, Gerlach H, Calandra T, Cohen J, Gea-Banacloche J, Keh D, Marshall JC, Parker MM, Ramsay G, Zimmerman JL, Vincent JL, Levy MM. Surviving Sepsis Campaign guidelines for management of severe sepsis and septic shock. Crit Care Med 2004;32(3):858-73.

33. Coopersmith CM, Wunsch H.,Fink MP, Linde-Zwirble WT, Olsen KM, Sommers MS, Anand KJ, Tchorz KM, Angus DC, Deutschman CS.A comparison of critical care research funding and the financial burden of critical illness in the United States. Crit Care Med. 2012;40(4):1072-79.

34. Cohen J Guyatt G, Bernard GR, Calandra T, Cook D, Elbourne D, Marshall J, Nunn A, Opal S. New strategies for clinical trials in patients with sepsis and septic shock. Crit Care Med. 2001;29(4):880-6.

35. Riedemann NC, Guo RF, Ward PA. The enigma of sepsis.2003;112(4):460-7.

36. Marshall JC, Vincent JL, Fink MP, Cook DJ, Rubenfeld G, Foster D, Fisher CJ Jr, Faist E, Reinhart K. Measures, markers, and mediators:toward a staging system for clinical sepsis. A report of the Fifth Toronto Sepsis Roundtable, Toronto,Canadá. Crit Care Med. 2003;31(5):1560-7. 
37. Andaluz -Ojeda D, Iglesias V, Bobillo F, Almansa R, Rico L, Gandía F, Loma AM, Nieto C, Diego R, Ramos E, Nocito M, Resino S, Eiros JM, Tamayo E, de Lejarazu RO, Bermejo-Martín JF. Early natutal Killer cellcounts in blood predict mortality in severe sepsis. Critical Care. 2011;15(5):R243.

38. Levy MM, Fink MP, Marshall JC, Abraham E, Angus D, Cook D, Cohen J, Opal SM, Vincent JL, Ramsay G: 2001 SCCM/ESICM/ACCP/ATS/SIS International Sepsis Definitions Conference. Intensive Care Med. 2003;29(4):530-8.

39. Seong SY, Matzinger P. Hydrophobicity: an ancient damageassociated molecular pattern that initiates innate immune responses. Nat Rev Immunol. 2004;4(6):469-78.

40. Akira S, Uematsu S, Takeuchi O. Pathogen recognition and immunity. Cell. 2006;124(4):783-801.

41. Vivier E, Raulet DH, Moretta A Caligiuri MA, Zitvogel L, Lanier LL, Yokoyama WM, Ugolini S. Innate or adaptive immunity? The example of natural killer cells. Science. 2011;331(6013):44-9.

42. Boyle EM, Pohlman TH, Johnson MC, Verrier ED. Endotelial cell injury in cardiovascular surgery: the systemic inflammatory response. Ann Thorac Surg 1997;63(1):277-84.

43. Verrier ED, Morgan EN. Endothelial response to cardiopulmonary bypass surgery. Ann Thorac Surg 1998;66(5 Suppl):17-9.

44. Karimova A, Pinski DJ. The endotelial response to oxigen deprivation: biology and clinical implications. Intensive Care Med 2001; 27: 19-31. Intensive Care Med. 2001;27(1):19-31.

45. Sherwood E. Current Concept of the Inflammatory response. The American Society of Anesthesiologists. 2002;30:169-84.

46. Conference ACoCPSoCCMC. Definitions for sepsis and organ failure and guidelines for the use of innovative therapies in sepsis. Crit Care Med. 1992;20(6):864-74. 
47. Warren OJ, Smith AJ, Alexiou C, Rogers PL, Jawad N, Vincent C,Darzi AW, Athanasiou T. The inflammatory response to cardiopulmonary bypass: part 1-mechanisms of pathogenesis. JCardiothorac Vasc Anesth. 2009;23(2):223-31.

48. Johnson SB, Lissauer M, Bochicchio GV, Moore R, Cross AS, Scalea TM. Gene Expression Profiles Differentiate Between Sterile SIRS and Early Sepsis. Annals of Surgery. 2007;245(4):611-21.

49. Matsuda M, Hattori Y. Systemic Inflammatory Response Syndrome (SIRS): Molecular Pathophysiology and Gene Therapy J Pharmacol Sci. 2006 (3);101:189-98.

50. Bone R, Balk RA, Cerra F, Dellinger R, Fein A, Knaus W, Schein R, Sibbald W. Definitions for sepsis and organ failure and guidelines for the use of innovative therapies in sepsis. The ACCP/SCCM Consensus Conference Committee. American College of Chest Physicians/Society of Critical Care Medicine. Chest. 1992;101(6):1644-55.

51. Kornblit B, Munthe-Fog L, Madsen H, Strom J, Vindolov L, Garred P. Association of HMGB1 polymorphisms with outcome in patients with systemic inflammatory response syndrome. Crit Care. 2008;12(3):R83.

52. Celes MR, Prado CM, Rossi M. Sepsis: Going to the heart of the matter. Pathobiology. 2013;80(2):70-86.

53. Boomer JS, To K, Chang KC, Takasu O, Osborne DF, Walton AH, Bricker TL, Jarman SD 2nd, Kreisel D, Krupnick AS, Srivastava A, Swanson PE, Green JM, Hotchkiss RS. Immunosuppresion in patients who die of sepsis and multiple organ failure. JAMA. 2011;306(23):2594-605.

54. Matsuda A, Jacob A, Wu R, Aziz M, Yang WL, Matsutani T, Suzuki H, Furukawa K, Uchida E, Wang P. Novel Therapeutic Targets for Sepsis: Regulation of exaggerated Inflammatory responses. J Nippon Med Sch. 2012;79(1):4-18.

55. Chan JK, Roth J, Oppenheim JJ, Tracey KJ, Vogl T, Feldmann M, Horwood N, Nanchahal J.Alarmins:awaiting a clinical response. J Clin Invest. 2012; 122 (8):2711-9. 
56. Bone RC. Toward a theory regarding the pathogenesis of the systemic inflammatory response syndrome: What we do and do not know about cytokine regulation. Crit Care Med. 1996;24(1):163-72.

57. Jedynak M, Siemiątkowski A, Rygasiewicz K. Molecular basics of sepsis development. Anaesthesiol Intensive Ther. 2012;44(4):24852 .

58. Marshall JC. Sepsis: current status,future prospects. Curr Opin Crit Care. 2004;10(4):250-64.

59. Remick DG. Cytokine therapeutics for the treatment of sepsis: why has nothing worked? Curr Pharm Des. 2003;9(1):75-82.

60. Aird WC. The role of endotelium in severe sepsis and multiple organ dysfunction syndrome. Blood. 2003;101(10):3765-77.

61. Boos CJ, Goon PK, Lip GY. The endothelium, inflammation and coagulation in sepsis. Clin Pharmacol Ther. 2006;79(1):20-2.

62. Abraham E, Singer M. Mechanisms of sepsis-induced organ dysfunction. Crit Care med. 2007;35(10):2408-16.

63. Shapiro NI, Schuetz P, Yano K, Sorasaki M, Parikh SM, Jones AE, Trzeciak S, Ngo L, Aird WC. The association of endothelial cell signaling, severity of illness and organ dysfunction in sepsis. Crit Care. 2010;14(5):R182.

64. Bergmann M, Sautner T. Immunomodulatory effects of vasoactive catecholamines. Wien Klin Wochenschr. 2002;114(17-18):752-61.

65. Hotchkiss RS, Karl IE. The pathophysiology and treatment of sepsis. N Engl J Med. 2003;348(2):138-50.

66. Martin TR, Nakamura M, Matute-Bello G. The role of apoptosis in acute lung injury. Crit Care Med. 2003;31:(4 Suppl)S184-88.

67. Annane D, Bellisant E, Cavaillon J.C. Septic shock. Lancet. 2005;365 (9453):63-78. 
68. Koh IH, Liberatore AM, Menchaca-Diaz JL, Ruiz-Silva M, VilelaOliveira L, Watanabe AY, Salomao R, Fagundes-Neto U, Silva RM.. Bacterial translocation,microcirculation injury and sepsis. Endocr Metab Immune Disord Drug Targets. 2006;6(2):143-50.

69. Cavaillon JM, Adrie C, Fitting C, Adib-Conquy M. Reprogramming of circulatory cells in sepsis and SIRS. J Endotoxin Res. 2005;11(5):311-20.

70. Schefold JC, Hasper D, Reinke P, Monneret G, Volk HD. Consider delayed immunosupression into the concept of sepsis. Crit Care Med. 2008;36(11):3118.

71. Remick DG. Pathophysiology of sepsis. Am J Pathol. 2007;170(5):1435-44.

72. Monneret G,Venet F, Pachot A, Lepape A. Monitoring immune dysfunctions in the septic patient:a new skin for the old ceremony. Mol Med. 2008;14(1-2):64-78.

73. Adib-Conquy M, Cavaillon JM. Compensatory anti-inflammatory response syndrome. . Thromb Haemost. 2009;101(1):36-47.

74. Boomer JS, Shuherk-Shaffer J, Hotchkiss RS, Green JM. A prospective analysis of lymphocyte phenotype and function over the course of acute sepsis. Crit Care. 2012;16(3):R112.

75. Sirgo G, Claramonte R, Chánovas M, Esteban F, Forcadell I, Luna J, Masdeu G, Ramón Vázquez J, Artigas A. Células dendríticas en la sepsis: una aproximación a la inmunosupresión postinfecciosa. Med Intensiva. 2010;34(8):559-66.

76. Andaluz-Ojeda D, Bobillo F, Iglesias V, Almansa R, Rico L, Gandía F, Resino S, Tamayo E, de Lejarazu RO, Bermejo-Martin JF. A combined score of pro- and anti-inflammatory interleukins improves mortality prediction in severe sepsis. Cytokine. 2012;57(3):332-6.

77. Ward PA. Immunosupresion in sepsis. JAMA. 2011;306(23):261819.

78. Bickler SW, De Maio. A Dysfunction of the innate immune system during sepsis:a call for research. Crit Care Med. 2013;41(1):364-5. 
79. Takahashi HK, Cambiaghi TD, Luchessi AD, Hirabara SM, Vinolo A, Newsholme P, Curi R. Activation of survival and apoptotic signaling pathways in lymphocytes exposed to palmitic acid. J Cell Physiol. 2012;227(1):339-50.

80. Ward PA. Bosmann M. A historical perspective on sepsis. AJP. 2012;181(1):2-7.

81. Hotchkiss RS, Coopersmith CM, McDunn JE, Ferguson TA. The sepsis seesaw: tilting toward immunosupresion. Nat Med. 2009;15(5):496-7.

82. Kim OY, Monsel A, Bertrand M, Coriat P, Cavaillon JM, AdibConquy M. Differential down-regulation of HLA-DR on monocyte subpopulatios during systemic inflammation. Crit Care. 2010;14(2):R61.

83. Tracey KJ. The inflammatory reflex. Nature. 2002;420(6917):85359.

84. Tracey KJ. Physiology and immunology of the cholinergic antiinflammatory pathway. J Clin Invest. 2007;117(2):289-96.

85. Nathan C. Points of control in infammation. Nature. 2002;420(6917):846-52.

86. Bonaz B. The cholinergic anti-inflammatory pathway and the gastrointestinal tract. Gastroenterology. 2007;133(4):1370-73.

87. Wang $\mathrm{H}, \mathrm{Yu} \mathrm{M}$, Ochani M, Amella CA, Tanovic M, Susarla S, Li JH, Wang H, Yang H, Ulloa L, Al-Abed Y, Czura CJ, Tracey KJ. Nicotinic acetylcholine receptor alfa7 subunit is a essential regulator of inflammation. Nature. 2004;421(5):384-88.

88. Cohen J, Guyat G, Bernard GR, Calandra T, Cook D, Elbourne D,Marshall J, Nunn A, Opal S. New strategies for clinical trials in patients with sepsis and septic shock. Crit Care Med. 2001;29(4):880-6.

89. Sheeran $\mathrm{P}$, Hall G. Cytokines in anaesthesia. Br J Anaesth 1997;78(2):201-19. 
90. Wan S, LeClerk J, Vincent JL. Cytokine responses to cardiopulmonary bypass: lessons learned from cardiac transplantation. Ann Thorac Surg 1997;63(1):269-76.

91. Shini S, Hurf GR, Shini A, Kaisert P. Understanding stress-induced immunosuppression : Exploration of cytokine and chemokine gene profiles in chicken peripheral leukocytes. Poultry Science. 2010;89(4):841-51.

92. Walsh G, Shephard, Woods, Bishop, Fleshner, Green, Pedersen, Hoffman-Goetz, Rogers ,Northoff, Abbasi, Simon. Immune function and exercise. EIR. 2011;17(7):1-63.

93. Allan SM, Rothwell NJ. Cytokines and acute neurodegeneration. Nat Rev Neurosci. 2001;2(10):734-44.

94. Wieten L, Broere F, van der Zee R, Koerkamp EK, Wagenaar J,van Eden W. Cell stress induced HSP are targets of regulatory T cells: A role for HSP inducing compounds as anti-inflammatory immunomodulators? FEBS Letters. 2007;58(19)1:3716-22.

95. Dinarello CA. Interleukin-1b. Crit Care Med 2005;33(12 Suppl):S460-2.

96. Graves DT, Nooh N, Gillen T, Davey M, Patel S, Cottrell D, Amar S. IL-1 plays a critical role in oral, but no dermal, wound healing. J immunol 2001;167(9):5316-20.

97. Rothwell NJ, Luheshi GN. Interleukin 1 in the brain: biology, pathology and therapeutic target. Trends Neurosci 2000;23(12):61825 .

98. Galiano M, Liu ZQ, Kalla R, Bohatschek M, Koppius A, Gschwendtner A, Xu S, Werner A, Kloss CU, Jones LL, Bluethmann $\mathrm{H}$, Raivich G. Interleukin 6 and cellular response to facial nerve injury: effects on lymphocyte recruitment, early microglial activation and axonal outgrowth in IL-6-deficient mice. Eur $\mathrm{J}$ Neurosci 2001;14(2):327-41.

99. Montero-Julian FA. The soluble IL-6 receptors: serum levels and biological function. Cell Mol Biol (Noisy-le-grand) 2001;47(4):58397. 
100. Song M KellJ. Interleukin-6. Crit Care Med 2005; 33(12 Suppl): S463-5.

101. White M, Mahon V, Grealy R., Doherty D.G., Stordeur P., Kelleher D. P. Mc manus R., Ryan T. Post-operative infection and sepsis in humans is associated with deficient gene expression of gamma chain cytokines and their apoptosis mediators. Crit Care. 2011;15(3):R158.

102. Gruyter Wd. Hematopoietic cytokines as tumor markers. Clin Chem Lab Med. 2004;42(12):1347-54.

103. Olver S, Apte S, Baz A, Kienzle N. The duplicitous effects of IL-4 on tumour immunity:how can the same cytokine improve or impair control of tumour growth? Tissue Antigens. 2007;69(4):293-98.

104. Lorentz A Bischoff SC. Regulation of human intestinal mast cells by stem cell factor and IL-4. Immunol Rev. 2001;179(1):57-60.

105. Sawa Y, Arima Y, Ogura H, Kitabayashi C, Jiang JJ, Fukushima T, Kamimura D, Hirano T, Murakami M. Hepatic IL-7 Expression Regulates Tcell responses. Immunity. 2009;30(3):447-57.

106. Ward PA. New approaches to the study of sepsis. EMBO Mol Med. 2012;4(12):1234-43.

107. Baggiolini M. Chemokines in pathology and medicine. J Intern Med 2001;250(2):91-104.

108. Xie. Interleukin-8 and human cancer biology. Rev Cytokine Grow Factor 2001;112(3):375-91.

109. Remick DG. Interleukin-8. Crit Care Med 2005;33(12 Suppl):S4667.

110. DeForge LE, Fantone JC, Kenney JS. Oxygen radical scavengers selectively inhibit interleukin 8 production in human whole blood. $\mathrm{J}$ Clin Invest. 1992;90(5):2123-29.

111. Xie K. IL-8 and human cancer biology. Cytokine Growth Factor. 2001;12(4):375-91. 
112. Goswami R, Kaplan MH. A brief history of IL-9. J Immunol. 2011;186(6):3283-88.

113. Leech MD, Grencis RK. Induction of enhanced immunity to intestinal nematodes using IL-9-producing dendritic cells. J Immunol. 2006;176(4):2505-11.

114. Scumpia PO, Moldawer LL. Biology of interleukin-10 and its regulatory roles in sepsis syndromes. Crit Care Med. 2005;33(12 Suppl):S468-71.

115. Akdis CA, Blaser K. Mechanisms of interleukin-10 mediated immune suppression. Immunology 2001;103(2):131-6.

116. Sandoval S, Alrawi S, Samee M, Satheesan R, Raju R, Cunningham $\mathrm{JN}$ et al. . A cytokine analysis of the effect of cell saver on blood in coronary bypass surgery. Heart Surg Forum 2001;4(2):113-7.

117. Allen ML, Hoschtitzky J, Peters MJ, Elliot M, Goldman A, James I, Klein NJ. Interleukin-10 and its role in clinical immunoparalysis following pediatric cardiac surgery. Crit Care Med 2006;34(10):2658-65.

118. Asadullah K, Sterry W,Volk HD. IL-10 Therapy-Review of a new approach. Pharmacol Rev. 2003;55(2):241-69.

119. Du X, Williams DA. IL-11 Review of molecular, cell biology and clinical use. Blood. 1997;89(11):3897-908.

120. Trinchieri G. IL-12 and the regulation of innate resistance and adaptive immunity. Nat Rev Immunol. 2003;3(2):133-46.

121. Watford W, Moriguchi M, Morinobu A, O’Shea J. The biology of IL-12: coordinating innate and adaptative immune responses. Ciytokine Growth Factor Rev. 2003;14(5):361-8.

122. Wynn TA. IL-13 Effector Functions. Ann Rev Immunol. 2003;21(21):425-56. 
123. Shen L, Zhang C, Wang T, Brooks S, Ford RJ, Lin-Lee YC, Kasianowicz A, Kumar V, Martin L, Liang P, Cowell J, Ambrus JL Jr. Development of autoimmunity in IL-14alpha transgenic mice. J Immunol. 2006;177(8):5676-86.

124. Fehninger T.,Caligiuri MA. IL-15: biology and relevance to human disease Blood. 2001;97(1):14-32.

125. Lee J, Noh G, Lee S, Youn Y, Rhim J. Atopic dermatitis and cytokines: recent patents in immunoregulatory and therapeutic implications of citokines in atopic dermatitis. Recent Pat Inflamm Allergy Drug Discov. 2012;6(3):224-47.

126. Korn T, Betelli E, Oukka M, Kuchroo VK. IL-17 and Th 17 Cells. Ann Rev Immunol. 2009;27(3):485-517

127. Ying-Fang S, Jing-Fang H, Li Huan-Zhang and Qi Hao Wen. Effect of platelet-activating factor on cell proliferation and NF-kB activation in airway smooth muscle cells in rats. Indian $\mathbf{J}$ Med Res. 2007;126(2):139-45.

128. Souza-Fonseca-Guimares F, Parlato M, Philippart F.,Misset B.,Cavaillon J.M., Adib-Conquy. Toll-like receptors expression and interferon gamma production by NK cells in human sepsis. Crit Care. 2012;16(5):R206.

129. Schoeder K, Hertzog PJ, Ravasi T., Hume D. Interferon gamma:an overview of signals, mechanisms and functions. J Leukoc Biol. 2004;75(2):163-9.

130. Sen GC. Viruses and interferons. Microbiol. 2001;55(4):255-81.

131. Chen H, Liu C, Sun S, Mei Y, Tong E. Cytokine-induced cell surface expression of adhesion molecules in vascular endothelial cells in vitro. J Tongji Med Univ 2001;21(1):68-71.

132. Bone RC, Grodzin CJ, Balk RA. Sepsis: a new hypothesis for pathogenesis of the disease process. Chest. 1997;112(1):235-43. 
133. Angus DC, Linde-Zwirble WC, Lidicker J, Clermont G, Garcillo J, Pinsky M.R. Epidemiology of severe sepsis in the United States:analysis of incidence, outcome and associated costs of care. Crit Care Med. 2001;29(7):1303-10.

134. Warren HS. Strategies for the treatment of sepsis. N Engl J Med. 1997;336(13):952-53.

135. Munford RS, Pujin J. Normal responses to injury prevent systemic inflammation and can be immunosupresive. Am J Respir Crit Care Med. 2001;163(2):316-21.

136. Oberholzer A, Oberholzer C, Moldawer L. Sepsis syndromes: understanding the role of innate and acquired immunity. Shock. 2001;16(2):83-96.

137. Wheeler AP, Bernard GR. Treating patients with severe sepsis. N Engl J Med. 1999;340(3):207-14.

138. Singer M, De Santis V, Vitale D, Jeffcoate W. Multiorgan failure is an adaptative, endocrine-mediated, metabolic response to overwelming systemic inflammation. Lancet. 2004;364(9433):545-8.

139. Muenzer JT, Davis CG, Chanq K, Schmidt RE, Dunne WM, Coopersmith CM, Hotchkiss RS. Characterization and modulation of the immunosuppresive phase of sepsis. Infect immun. 2010;78(4):1582-92.

140. Mera S, Tatulescu D, Cismaru C, Bondor C, Slavcovivi A, Zanc V,Carstina D, Oltean M. Multiplex cytokine profiling in patients with sepsis. APMIS. 2011;119(2):155-63.

141. Kasten KR, Prakash PS, Unsinger J, Goetzman HS, England LG, Cave CM, Seitz AP, Mazuski CN, Zhou TT, Morre M, Hotchkiss RS, Hildeman DA, Caldwell CC .IL-7 treatment accelerates Neutrophil Recruitment through gammadelta T-cell IL-17 Production in a Murine Model of Sepsis. Infect Inmun. 2010;78(11):4714-22. 
142. Venet F, Gebeile R, Bancel J, Guinant C, Poitevin-Later F, Malcus C, Lepape A,Monneret G. Assessment of plasmatic immunoglobulin $\mathrm{G}, \mathrm{A}$ and $\mathrm{M}$ levels in septic shock patients. Int Immunopharmacol. 2011;11(12):2086-90.

143. Taccone FS, Stordeur P, De Backer D, Creteur J, Vincent JL. Gamma-globulin levels in patients with community-acquired septic shock. Shock. 2009;32(4):379-85.

144. Laupland KB, Kirkpatrick AW, Delaney A. Policlonal intravenous immunoglobulin for the treatment of severe sepsis and septic shock in critically ill adults: a systematic review and meta-analysis. Crit Care Med. 2007;35(12):2686-92.

145. Werdan K, Pilz G, Bujdoso O,Fraunberger P,Neeser G, Schmieder RE,Viell B,Marget W,Seewald M,Walger P,Stuttmann R, Speichermann N,Peckelsen C,Kurowski V,Osterhues HH, Verner L, Neumann R,Muller-Werdan U. Score-based immunoglobulin G therapy of patients with sepsis: the SBITS study. Crit Care Med. 2007;35(12):2693-701.

146. Kreymann KG, de Heer G, Nierhaus A, Kluge S. Use of polyclonal immunoglobulins as adjunctive therapy for sepsis or septic shock. Crit Care Med. 2007;35(12):2677-85.

147. Meisel C. Schefold JC, Pschowski R, Baumann T, Hetzger K, Gregor J, Weber-Carstens S, Hasper D, Keh D, Zuckermann H, Reinke P, Volk HD . Granulocite-macrophage colony-stimulating factor to reverse sepsis-associated immunosupression: a double blind,randomized placebo mulcenter trial. Am J Respir Crit Care Med 2009;180(7):640-8.

148. Schramm GE, Kashyap R, Mullon JJ, Gajic O, Afessa B. Septic shock: A Multidisciplinary response team and weekly feedback to clinicians improve the process of care and mortality. Crit Care Med 2011;39(2):252.

149. Cavaillon JM, Adib-Conquy M, Cloëz-Tayarani I, Fitting C. Immunodepression in sepsis and SIRS assessed by ex vivo cytokine production is not a generalized phenomenon: a review. J Endotoxin Res. 2001;7(2):85. 
150. Bone RC, Balk RA, Cerra FB, Dellinger RP, Fein AM, Knaus WA, Schein RM, Sibbald WJ; Definitions for sepsis and organ failure and guidelines for the use of innovative therapies in sepsis The ACCP/SCCM Consensus Conference Committee. American College of Chest Physicians/Society of Critical Care Medicine. Chest. 2009;136(5Suppl):e28.

151. Knaus WA, Draper EA, Wagner DP, Zimmerman JE. APACHE II: a severity of disease classification system. Crit Care Med. 1985;13(10):818.

152. Vincent JL, Moreno R, Takala J, Willatts S, De Mendonça A, Bruining H, Reinhart CK, Suter PM, Thijs LG The SOFA (Sepsisrelated Organ Failure Assessment) score to describe organ dysfunction/failure On behalf of the Working Group on SepsisRelated. Problems of the European Society of Intensive Care Medicine. Intensive Care Med. 1996;22(7):707.

153. Joachimiak MP, Weisman JL, May B. JColorGrid: software for the visualization of biological measurements. BMC Bioinformatics. 2006;7(3):225.

154. Okazaki Y, Matsukawa A. Pathophysiology of sepsis and recent patents on the diagnosis, treatment and prophylaxis for sepsis. Recent Pat Inflamm Allergy Drug Discov 2009;3(1):26.

155. Pierrakos C, Vincent JL. Sepsis biomarkers: a review. Crit Care. 2010; 14 (1): R 15.

156. Jager A, KuchrooVK. Effector and regulatory T-cell subsets in autoimmunity and tissue inflammation. Scand $\mathrm{J}$ Immunol. 2010;72(3):173.

157. Abe R, Hirasawa H, Oda S, Sadahiro T, Nakamura M, Watanabe E, Nakada TA, Hatano M, Tokuhisa T . Up-regulation of interleukin-10 mRNA expression in peripheral leukocytes predicts poor outcome and diminished human leukocyte antigen-DR expression on monocytes in septic patients. J Surg Res 2008;147(1):1-8. 
158. Bozza FA, Salluh JI, Japiassu AM, Soares M, Assis EF, Gomes RN, Bozza MT, Castro-Faria-Neto HC,Bozza PT. Cytokine profiles as markers of disease severity in sepsis: a multiplex analysis. Crit Care. 2007;11(2):R49.

159. Cavaillon JM, Adib-Conquy M, Fitting C, Adrie C, Payen D. Cytokine cascade in sepsis. Scand J Infect Dis. 2003;35(9):535.

160. Nguyen HB, Loomba M, Yang JJ, Jacobsen G,Shah K, Otero RM, Suarez A, Parekh H, Jaehne A, Rivers EP. Early lactate clearance is associated with biomarkers of inflammation, coagulation, apoptosis,organ dysfunction and mortality in severe sepsis and septic shock. J Inflamm 2010;7(6): 1-11.

161. de Pablo R, Monserrat J, Reyes E, Diaz-Martin D, Rodriguez Zapata M, Carballo F, de la Hera A, Prieto A, Alvarez-Mon M. Mortality in Patients With Septic Shock Correlates With Anti-Inflammatory But not Proinflammatory Immunomodulatory Molecules. J Intensive Care Med. 2011;26(2):125-32.

162. Rodríguez-Gaspar M, Santolaria F, Jarque-López A, GonzálezReimers E, Milena A, de la Vega MJ, Rodríguez-Rodríguez E, Gómez-Sirvent JL. Prognostic value of cytokines in SIRS general medical patients. Cytokine. 2001;15(4):232.

163. Lesur O, Roussy JF, Chagnon F, Gallo-Payet N, Dumaine R, Sarret P, Chraibi A, Chouinard L, Hogue B . Proven infection-related sepsis induces a differential stress response early after ICU admission. Crit Care. 2010;14(4):R131.

164. Fujishima S, Sasaki J, Shinozawa Y, Takuma K, Kimura H, Suzuki M, Kanazawa M, Hori S, Aikawa N. Serum MIP-1 alpha and IL-8 in septic patients. Intensive Care Med. 1996;22(11):1169-75.

165. Bozza FA, Salluh JI, Japiassu AM, Soares M, Assis EF, Gomes RN, Bozza MT, Castro-Faria-Neto HC, Bozza PT Japiassu AM. Cytokine profiles as markers of disease severity in sepsis: a multiplex analysis. Crit Care Med. 2007;11(2):1-8. 
166. Marty C, Misset B, Tamion F, Fitting C, Carlet J, Cavaillon JM. Circulating Interleukin-8 concentrations in patients with multiple organ failure of septic and non septic origin. Crit Care Med. 1994;22(4):673-9.

167. Calfee CS, Thompson BT, Parsons PE, Ware LB, Matthay MA, Wong HR. Plasma interleukin-8 is not an effective risk stratification tool for adults with vassopresor-dependent septic shock. Crit Care Med 2010;38(6):1436-41.

168. Esche C, Stellato C, Beck LA. Chemokines: key players in innate and adaptive immunity. J Invest Dermatol. 2005;125(4):615-28.

169. Lennette EH, Shadomy HJ. Manual of clinical microbiology. 4 ed.Washington: American Society for Microbiology; 1985.

170. Ferreira FL, Bota DP, Bross A, Melo C, Vincent JL. Serial evaluation of the SOFA score to predict outcome in critically ill patients. JAMA. 2001;286(14):1754-8.

171. Schroeder HW Jr, Cavacini L. Structure and function of immunoglobulins. J Allergy Clin Immunol 2010.125(2Suppl):S4152.

172. Rose ME, Lang DM. Evaluating and managing hypogammaglobulinemia. Cleve Clin J Med. 2006;73(2):1337,140,143-4.

173. Pan Q, Hammarström L. Molecular basis of IgG subclass deficiency. Immunol Rev. 2000;178(3):99-110.

174. Blaese RM, Winkelstein J. Patient \& Family handbook for Primary Immunodeficiency Diseases. 4 ed. Maryland: Immune Deficiency Foundation; 2007.

175. Driessen G, van der Burg M. Educational paper: primary antibody deficiencies. Eur J Pediatr 2011;170(6):693-702. 
176. Coutinho HB, Robalinho T, Coutinho VB,Amorim AM,Furtado AF,Ferraz A, Ferraz E, Walker F, King G, Sewell HF, Wakelin D. Intra-abdominal sepsis: an immunocytochemical study of the small intestine mucosa. J Clin Pathol. 1997;50(4):194-8.

177. Monneret G, Venet F, Kullberg BJ,Netea MG. ICU-acquired immunosuppresion and the risk for secondary fungal infections. Med Mycol 2011;49 (Suppl 1): S17-23.

178. Soares MO, Welton NJ, Harrison DA, Peura P, Shankar-Hari M, Harvey SE, Madan JJ, Ades AE, Palmer SJ, Rowan KM. An evaluation of the feasibility,cost and value of information of a multicentre randomised controlled trial of intravenous immunoglobulin for sepsis (severe sepsis and septic shock): incorporating a systematic review,meta-analysis and value of information analysis. Health Technol Asses 2012;16 (7):1-186. 
7.ORIGINALES 


\title{
Pro- and anti-inflammatory responses are regulated simultaneously from the first moments of septic shock
}

\author{
Eduardo Tamayo ${ }^{1,2, *}$, Ana Fernández ${ }^{1,2, *}$, Raquel Almansa ${ }^{2,3,}$, Elena Carrasco ${ }^{1,2}$, María Heredia ${ }^{1,2}$, \\ Carmen Lajo ${ }^{1,2}$, Lisbeth Goncalves ${ }^{2,3}$, Jose I. Gómez-Herreras ${ }^{1,2}$, Raúl Ortiz de Lejarazu ${ }^{2}$, \\ Jesus F. Bermejo-Martin ${ }^{23,4}$ \\ ${ }^{1}$ Anesthesiology and Reanimation Service, Hospital Clínico Universitario de Valladolid, \\ 2 Investigación Médica en Infección e Inmunidad (IMI). Hospital Clínico Universitario de Valladolid-IECSCYL, Valladolid \\ ${ }^{3}$ Servicio de Microbiología e Inmunología, Hospital Clínico Universitario de Valladolid \\ ${ }^{4}$ Grupo Cooperativo de Investigación Biomédica en Inmunología (CIBI), Madrid, Spain
}

Correspondence: J.F. Bermejo-Martin. Unidad de Investigación Médica en Infección e Inmunidad (IMI). Hospital Clínico Universitario de ValladolidIECSCYL, Avda Ramón y Cajal 3, 47005 Valladolid, Spain

$<$ jfbermejo@saludcastillayleon.es>

Accepted for publication May 2, 2011

To cite this article: Tamayo E, Fernández A, Almansa R, Carrasco E, Heredia M, Lajo C, Goncalves L, Gómez-Herreras JI, Ortiz de Lejarazu R, Bermejo-Martin JF. Proand anti-inflammatory responses are regulated simultaneously from the first moments of septic shock. Eur. Cytokine Netw. 2011; 22(2): 82-7 doi:10.1684/ecn.2011.0281

\begin{abstract}
The relationships between cytokine responses in septic shock are currently poorly understood. Some studies have pointed to a biphasic model, with an initial proinflammatory phase, followed by a reactive, antiinflammatory response to explain the pathogenesis of the most severe form of sepsis. However, evidence for the coexistence of both responses has been found. In this study, the plasma levels of 17 cytokines and chemokines, in 20 patients with septic shock, 11 patients with systemic inflammatory response syndrome (SIRS), during the first 24 hours following diagnosis, and 10 healthy controls, were analyzed and compared. Patients with septic shock showed increased levels of IL-6, IL-8, MCP-1, MIP-1ß, IFN- $\gamma$, GM-CSF and IL-10 compared to healthy controls. Patients with SIRS showed higher levels of IL-6, IL-8, MCP-1, MIP-1ß, G-CSF and IL-10 than controls. Patients with septic

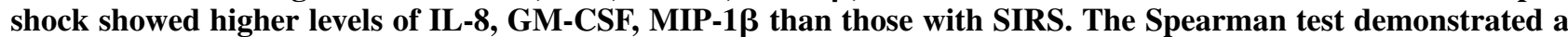

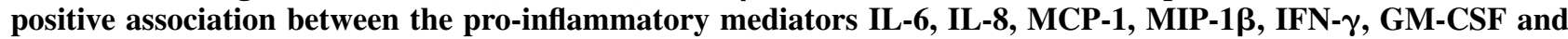
the immunomodulatory cytokine IL-10 in septic shock. Consequently, correlation studies supported the notion that secretion of pro- and anti-inflammatory mediators in septic shock occurs as a simultaneous immune response program initiated early in the course of the disease, revealing that both types of cytokine play a role from the very beginning of this life-threatening condition.
\end{abstract}

Key words: pro-inflammatory, anti-inflammatory, septic, shock, simultaneous

Sepsis is an uncontrolled, systemic, inflammatory response which is a consequence of infection that, in its most severe form (septic shock), causes organ dysfunction and hypotension. Even today, septic shock remains associated with high mortality rates, presenting a challenge for both physicians and researchers [1]. Involvement of cytokine responses in the pathogenesis of sepsis tends to be explained using a bi-phasic model, with an initial state characterized by systemic production of inflammatory cytokines (IL-6, TNF- $\alpha$, IFN- $\gamma$, IL-1), followed by the secretion of anti-inflammatory mediators such as IL-10 [2]. The early, pro-inflammatory state would contribute to tissue damage and mortality, while the secondary, anti-inflammatory phase (termed compensatory anti-inflammatory response syndrome, CARS), would induce an increased risk of secondary bacterial infection

\footnotetext{
* These authors contributed equally to this work.
}

[3]. However, evidence contradicting the existence of two phases in the immune response in sepsis as a generalized phenomenon, also exists [4].

A better understanding of the regulation and overall balance between pro- and anti-inflammatory cytokine responses in sepsis is essential in order to explain the pathogenesis of this disease.

The emergence of several different approaches offers an opportunity to profile simultaneously a wide range of immune mediators, thus helping to obtain a clearer picture of the ongoing host immune response [5]. An analysis of systemic chemokine and cytokine levels in serum from patients with septic shock or systemic inflammatory response syndrome (SIRS) was performed using a 17-plex quantification kit. This allowed identification of the existence of simultaneous, antagonistic, immune response signatures, early in the onset of septic shock. 


\section{DONORS AND METHODS}

\section{Patients and controls}

Patients and controls were prospectively recruited from the Intensive Care Unit (ICU) of the Hospital Clínico Universitario de Valladolid in Spain. Approval for the study protocol for both the scientific and the ethical aspects was obtained from the Scientific Committee for Clinical Research of our Hospital. Recommendations of the the American College of Chest Physicians/Society of Critical Care Medicine Consensus Conference were followed in order to define SIRS and septic shock [6]. Severity of illness was assessed by two different scores: the acute physiology and chronic health evaluation (APACHE) II score for the first 24 hours following diagnosis [7], and the sequential organ failure assessment (SOFA) score [8]. Twenty patients with septic shock and eleven patients fulfilling the criteria for SIRS were recruited for the study. Ten healthy volunteers were recruited from the staff of the University of Valladolid, and had an age range similar to patients included in the study.

\section{Samples and cytokine profiling}

A single blood sample was obtained from each patient or control in tubes containing ethylenediaminetetraacetic acid (EDTA) within the first 24 hours following diagnosis of septic shock or SIRS. Plasma samples were obtained after proper centrifugation and these were stored at $-80^{\circ} \mathrm{C}$ until cytokine profiling. Plasma chemokine and cytokine levels were evaluated using the multiplex Biorad $^{\circledR} 17$ plex assay, following manufacturer's instructions. This system allows for quantitative measurement of 17 different chemokines, cytokines, growth-factors and immune mediators, while consuming only a small amount of biological material. Furthermore, this system has good representation of analytes for inflammatory cytokines, antiinflammatory cytokines, Th1 cytokines, Th2 cytokines, Th17 cytokines and chemokines, allowing for testing of different levels of regulatory cytokines in patients' plasma. Limits of detection were as follows (pg/mL): IL-1b $(2,4)$; IL-6 (2,1); IL-8 (1,8); IL-7 (2,4); IL-17 (2.1); G-CSF (1,5); MCP-1 (1,8); MIP-1b (1,4); IL-2 (1,3); IL-4 (0,2); IL-5 (2,5); IL-10 (1,8); IL-12(p70) (2,6); IL-13 (2,6); GM-CSF $(0,7) ; \mathrm{IFN}-\gamma(2,4) ; \mathrm{TNF}-\alpha(6,4)$.

\section{Statistical analysis}

The Mann-Whitney U test was employed for cytokine comparison purposes, since the Saphiro-Wilk test demonstrated the absence of normal distribution of the data, and the Levene test demonstrated the absence of homogeneity of variance in the compared groups. Correlation studies between cytokine levels and clinical parameters were performed by using the Spearman test. All statistical tests were two-sided, and $\mathrm{p}<0.05$ was considered significant. Spearman correlation coefficients were also represented as heat maps using the JColorGrid software (University of California San Francisco and University of California Berkeley) [9].

\section{RESULTS}

\section{Clinical and demographic characteristics (table 1)}

Patients were elderly individuals in both groups. The most common co-morbidity was cardiovascular disease. The most common immediate antecedent in the septic shock group was abdominal surgery. Procalcitonin and C-reactive protein levels were higher in the shocked patients compared to those with SIRS $(\mathrm{p}<0.05)$, as were the leucocytes counts $(\mathrm{p}<0.05)$.

\section{Comparisons of immune mediator levels (figure 1)}

IL-1 $\beta$, IL-7, IL-5, and IL-13 levels were below the limit of detection of the method employed for each mediator in the vast majority of the patients studied. As a consequence, they were not considered in the analysis. Patients with septic shock demonstrated increased levels of IL-6, IL-8, MCP-1, MIP-1 $\beta$, IFN- $\gamma$, GM-CSF and IL-10 compared to healthy controls. Patients with SIRS showed significantly higher levels of IL-6, IL-8, MCP-1, MIP-1 $\beta$, G-CSF and IL-10 compared to the control group. Seven patients with septic shock showed detectable levels of IL-17; the other seven showed increased levels of TNF$\alpha$. Six patients from this group showed detectable levels of IL-2 and IL-4, while three patients showed detectable levels of IL-12p70. Only one patient with SIRS showed detectable levels of IL-17 (13.9 pg/mL), while another showed detectable levels of IL-2, IL-4, IL-12p70 and TNF$\alpha$ (data not shown). None of the controls had detectable levels of IL-17, IL-2, IL-4, IL-12p70 or TNF- $\alpha$. When the levels of immune mediators were compared between the septic shock group and the SIRS group, the shocked group showed higher levels of IL-8, GM-CSF and MIP-1 $\beta$ $(\mathrm{p}<0.05)$.

\section{Correlation of immune mediator levels (figure 2)}

Correlation studies demonstrate a positive association between levels of IL-6, IL-8, MCP-1, MIP-1 $\beta$, IFN- $\gamma$, GMCSF and IL-10 in those patients with septic shock, with Spearman correlation coefficients $(r)>0.4$. This positive correlation demonstrates that these mediators are secreted simultaneously in response to the insult leading to septic shock. In patients with SIRS, the following positive correlations were found: [IL-6, IL-8), [IL-6, G-CSF], [IL-

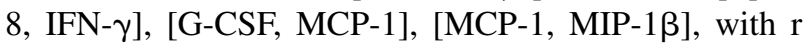
coefficients $>0.5$ (data not shown).

\section{DISCUSSION}

The presence of increased plasma levels of IL-6, IL-8, MCP-1, MIP-1 $\beta$, IFN- $\gamma$ and GM-CSF found in our patients are in agreement with a previous study [10], which reports the existence of a strong, systemic, proinflammatory cytokine and chemokine response in the most severe form of sepsis, septic shock. Most have already been studied as biomarkers in sepsis [11]. These mediators are chemotactic molecules that attract monocytes, neutrophils, T cells and macrophages to the injured tissues, 
Table 1

Clinical and demographic data.

\begin{tabular}{|c|c|c|}
\hline & Septic shock $(n=20)$ & SIRS $(n=11)$ \\
\hline \multicolumn{3}{|c|}{ Description } \\
\hline Gender (M/F) & $12 / 8$ & $9 / 2$ \\
\hline Age (years) & $68.00(14.6)$ & $76.6(8.6)$ \\
\hline Arterial hypertension (n) & 7 & 9 \\
\hline Cardiopathy (n) & 7 & 6 \\
\hline Diabetes mellitus (n) & 1 & 1 \\
\hline Obesity (n) & 0 & 1 \\
\hline Respiratory disease (n) & 3 & 1 \\
\hline Cancer (n) & 3 & 4 \\
\hline Renal disease (n) & 3 & 0 \\
\hline Surgery (abdominal/cardiac/vascular) & $15 / 5 / 0$ & $5 / 5 / 1$ \\
\hline Days at the $\mathrm{CCU}$ & $12.00(13.5)$ & $1.00(0.5)$ \\
\hline Sampling day following admission to the CCU & $6.00(7.0)$ & $1.00(0.7)$ \\
\hline \multicolumn{3}{|c|}{ Clinical status at diagnosis } \\
\hline APACHE score & $22.24(6.7)$ & $9.00(2.4)$ \\
\hline SOFA score & $7.70(3.7)$ & $3.36(2.6)$ \\
\hline Mechanical ventilation & $18 / 20$ & $9 / 11$ \\
\hline Heart rate & $112.00(20.4)$ & $86.00(16.2)$ \\
\hline Respiratory rate & $14.53(4.5)$ & $13.90(3.6)$ \\
\hline Temperature & $37.46(1.4)$ & $36.7(1.1)$ \\
\hline Average blood pressure (BP) & $67.54(11.3)$ & $82.2(10.1)$ \\
\hline Noradrenaline & $20 / 20$ & $2 / 11$ \\
\hline \multicolumn{3}{|c|}{ Analytical status at diagnosis } \\
\hline Hematocrit $(\%)$ & $32.71(6.6)$ & $32.31(5.0)$ \\
\hline Leucocytes (number/mL) & $17487.47(10867.2)$ & $11582(4962.6)$ \\
\hline Neutrophils (number/mL) & $15431.2(11120.8)$ & $8475.1(2768.9)$ \\
\hline Procalcitonin & $26.69(38.7)$ & $1.45(3.4)$ \\
\hline C Reactive Protein & $184.2(106.5)$ & $45.9(68.8)$ \\
\hline Creatinine $(\mathrm{mg} / \mathrm{dL})$ & $1.63(1.1)$ & $1.09(0.4)$ \\
\hline Patients with positive/negative microbiology cultures & $18 / 2$ & $0 / 11$ \\
\hline Fatal outcome/survivors & $11 / 9$ & $1 / 10$ \\
\hline
\end{tabular}

playing not only a main role in fighting infection, but also in the pathogenesis of acute and chronic diseases with a strong inflammatory component [12]. At the same time, our results provide new evidence of the coexistence of the pro- and anti-inflammatory responses, as revealed by the increased levels of IL-10 in plasma. IL-10 is a molecule with immune-regulatory properties. Secretion of IL-10 in septic shock could represent an attempt to modulate the pro-inflammatory response observed in this condition. On the other hand, high levels of IL-10 could induce a state of functional immunodeficiency, compromising the host response to pathogens and the management of infection [13].
Previous works using the multiplex approach (Bozza et al. [5] and Mera et al. [14]) have revealed the relationship between severe septic disease and increases in IL-6, IL-8, MCP-1, IFN- $\gamma$, IL-10. These studies also reported increased levels of IL-4, IL-12p70 or TNF- $\alpha$ in those patients with the worst outcomes. In spite of the fact that we failed to find increased levels of these three cytokines in all of our patients, they were found in some of them. The small size of the cohort analyzed perhaps precluded obtaining more robust results regarding these cytokines. On the other hand, our results for GM-CSF and MIP-1 $\beta$ contradict, to a certain extent, those of Mera et al. [14], since they found lower levels of these molecules in 


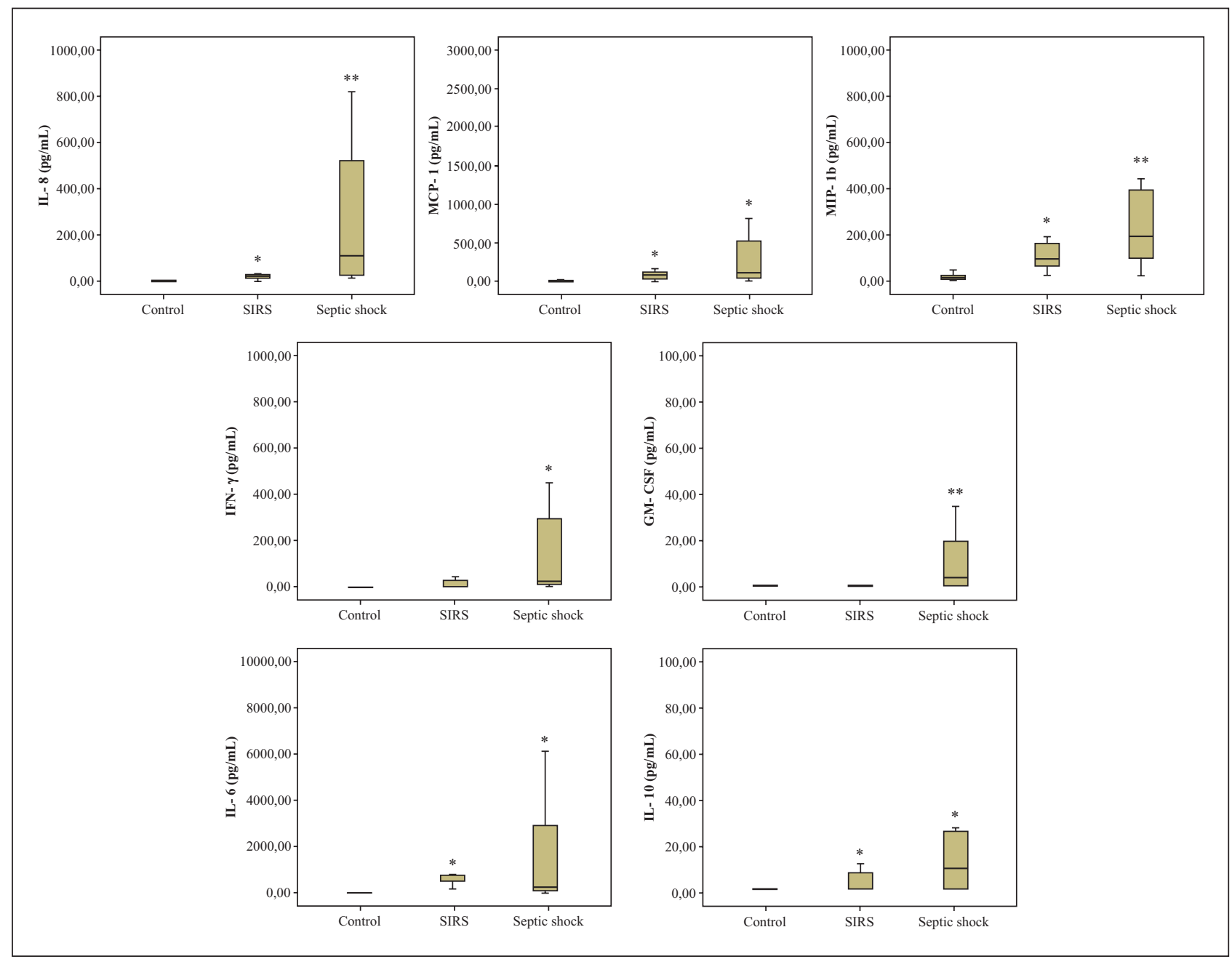

Immune mediator levels in healthy controls, SIRS and septic shock.

Figure 1

${ }^{*}$ Significantly different from the control. ${ }^{* *}$ Significantly different from the the control and also the SIRS group $(\mathrm{p}<0.05)$.

patients with septic shock than in patients without shock. The different location of the initial infection site (respiratory and urinary in the work of Mera et al. abdominal in our work), could explain some differences in the profile of the cytokines found. According to the result of this study, increased levels of the Th17 cytokine, IL-17 in 35\% of the patients with septic shock might indicate a potential role of this mediator in autoimmunity and antibacterial defense [12], in some cases of severe septic disease.

Most importantly, association observations of immune mediator levels in this study, confirm that both pro and antiinflammatory responses occur in a simultaneous manner. In this sense, Cavaillon et al. had already found positive correlations between IL-8, MCP-1, MIP-b, RANTES and IL-1ra, IL-10 in sepsis [15]. In agreement with the results of Cavaillon et al., this study demonstrates that the simultaneous pro-inflammatory and anti-inflammatory responses occur from the very first moments of onset of the disease. The potential influence of this early, combined response on further pathogenic events, such as the development of a late phase of immunoparalysis [16], and also on mortality $[17,18]$ remains to be elucidated, since the design of this study did not include a follow-up of the patients.
Similarly to the results reported by Rodríguez-Gaspar et al. [19], patients with SIRS also demonstrated significant increases in pro-inflammatory (IL-6, IL-8, MCP-1, MIP-1 $\beta$, G-CSF) and anti-inflammatory mediators (IL$10)$, compared to controls, although the increase in IL-10 levels was slight in these patients. The absence of positive correlations between pro-inflammatory mediators and IL-10 in patients with SIRS could be a consequence of the limited number of individuals included in this group, or alternatively, to a less severe proinflammatory state in SIRS compared to septic shock, with a limited compensatory secretion of IL-10. The absence of a suspected infection in SIRS could also explain the differences in the cytokine profiles compared with shock [20].

In conclusion, correlation studies for cytokine levels in plasma, support the notion that secretion of pro- and anti-inflammatory mediators in septic shock occurs as a simultaneous, immune response program initiated early in the course of the disease. The exact role of this simultaneous response (detrimental or beneficial), in the evolution of patients with sepsis is worth further investigation. 


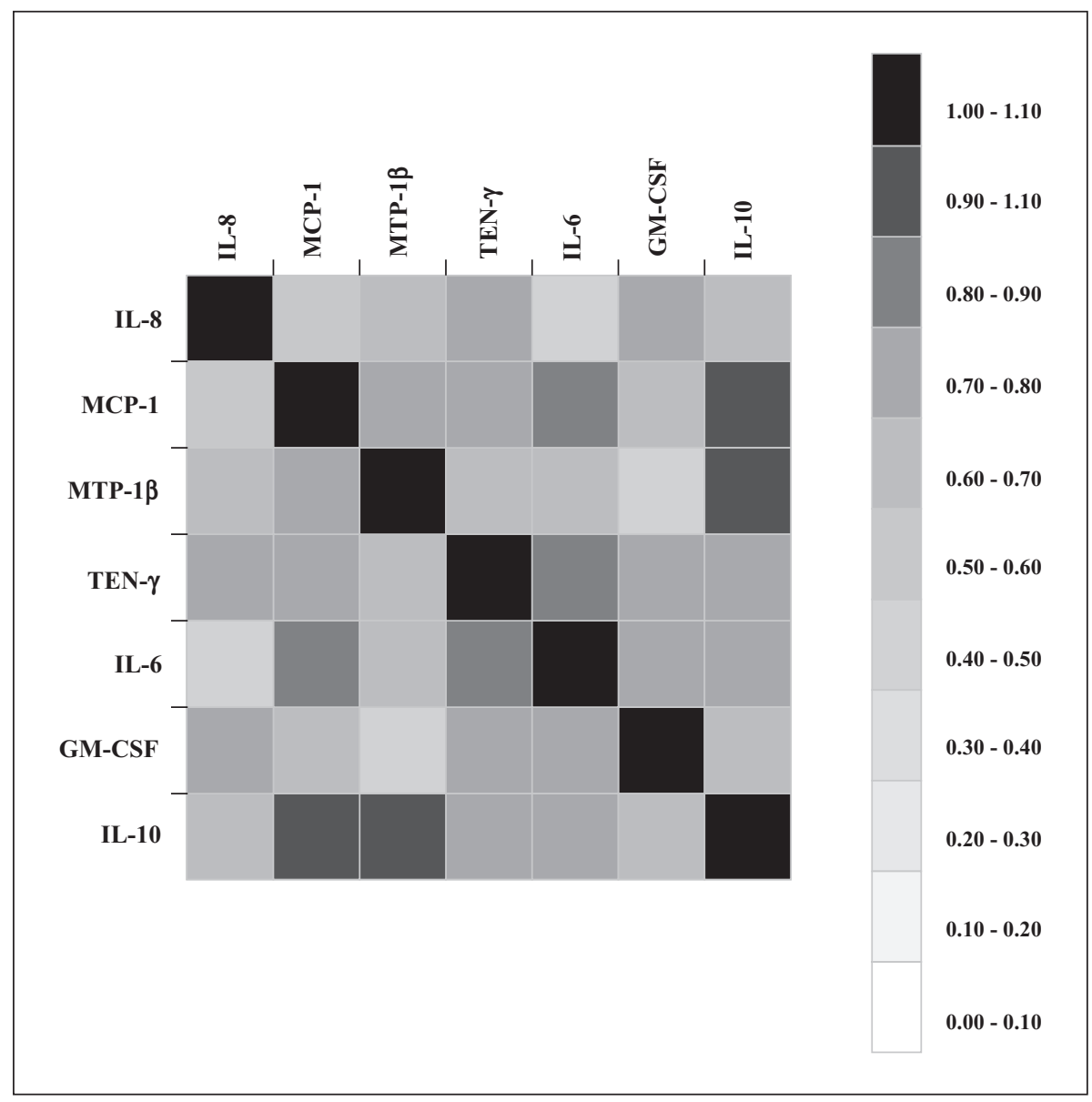

Figure 2

Heat map representing the Spearman coefficient (r) corresponding to the correlations found to be significant at the level $p<0.05$. Values of " $r$ " coefficients were represented using a grey scale. The figure was prepared using the Jcolorgrid software.

Acknowledgments. The authors wish to thank Lucia Rico and Veronica Iglesias for their technical support. Likewise, the authors are grateful to the nursing team of the Internal Medicine Unit of our Hospital, who kindly collected the samples. We also thank Alicia San Joséfor her assistance with the English language aspects.

Disclosure. This study was possible because of a grant obtained from the Spanish Ministry of Science and Innovation and the "Consejería de Sanidad Junta de Castilla y León" ("Programa para favorecer la incorporación de grupos de investigación en las Instituciones del Sistema Nacional de Salud, EMER07/050" y "Proyectos de Investigación Sanitaria, PI 10/01362).

None of the authors has any conflict of interest to disclose.

\section{REFERENCES}

1. Schramm GE, Kashyap R, Mullon JJ, Gajic O, Afessa B. Septic shock: A Multidisciplinary response team and weekly feedback to clinicians improve the process of care and mortality. Crit Care Med 2011;39: 252.

2. Muenzer JT, Davis CG, Chang K, et al. Characterization and modulation of the immunosuppressive phase of sepsis. Infect Immun 2010; 78: 1582 .

3. Adib-Conquy M, Cavaillon JM. Compensatory anti-inflammatory response syndrome. Thromb Haemost 2009; 101: 36-47.

4. Cavaillon JM, Adib-Conquy M, Cloëz-Tayarani I, Fitting C. Immunodepression in sepsis and SIRS assessed by ex vivo cytokine production is not a generalized phenomenon: a review. $J$ Endotoxin Res 2001; 7: 85.

5. Bozza FA, Salluh JI, Japiassu AM, et al. Cytokine profiles as markers of disease severity in sepsis: a multiplex analysis. Crit Care 2007; 11: R49.

6. Bone RC, Balk RA, Cerra FB, et al. Definitions for sepsis and organ failure and guidelines for the use of innovative therapies in sepsis The ACCP/SCCM Consensus Conference Committee. American College of Chest Physicians/Society of Critical Care Medicine. 1992. Chest 2009; 136: e28.

7. Knaus WA, Draper EA, Wagner DP, Zimmerman JE. APACHE II: a severity of disease classification system. Crit Care Med 1985; 13: 818 .

8. Vincent JL, Moreno R, Takala J, et al. The SOFA (Sepsis-related Organ Failure Assessment) score to describe organ dysfunction/failure On behalf of the Working Group on Sepsis-Related Problems of the European Society of Intensive Care Medicine. Intensive Care Med 1996; 22: 707.

9. Joachimiak MP, Weisman JL, May B. JColorGrid: software for the visualization of biological measurements. BMC Bioinformatics 2006; 7: 225 .

10. Okazaki Y, Matsukawa A. Pathophysiology of sepsis and recent patents on the diagnosis, treatment and prophylaxis for sepsis. Recent Pat Inflamm Allergy Drug Discov 2009; 3: 26.

11. Pierrakos C, Vincent JL. Sepsis biomarkers: a review. Crit Care 2010; 14: R15. 
12. Jager A, Kuchroo VK. Effector and regulatory T-cell subsets in autoimmunity and tissue inflammation. Scand J Immunol 2010; $72: 173$.

13. Abe R, Hirasawa $\mathrm{H}$, Oda $\mathrm{S}$, et al. Up-regulation of interleukin-10 mRNA expression in peripheral leukocytes predicts poor outcome and diminished human leukocyte antigen-DR expression on monocytes in septic patients. J Surg Res 2008; 147: 1.

14. Mera S, Tatulescu D, Cismaru C, et al. Multiplex cytokine profiling in patients with sepsis. APMIS 2011; 119: 155.

15. Cavaillon JM, Adib-Conquy M, Fitting C, Adrie C, Payen D. Cytokine cascade in sepsis. Scand J Infect Dis 2003; 35: 535.

16. Allen ML, Hoschtitzky JA, Peters MJ, et al. Interleukin-10 and its role in clinical immunoparalysis following pediatric cardiac surgery. Crit Care Med 2006; 34: 2658.
17. Nguyen HB, Loomba M, Yang JJ, et al. Early lactate clearance is associated with biomarkers of inflammation, coagulation, apoptosis, organ dysfunction and mortality in severe sepsis and septic shock. $J$ Inflamm (Lond) 2010; 28: 6.

18. de Pablo R, Monserrat J, Reyes E, et al. Mortality in Patients With Septic Shock Correlates With Anti-Inflammatory But not Proinflammatory Immunomodulatory Molecules. I Intensive Care Med 2011;26: 125-32.

19. Rodríguez-Gaspar M, Santolaria F, Jarque-López A, et al. Prognostic value of cytokines in SIRS general medical patients. Cytokine $2001 ; 15: 232$

20. Lesur O, Roussy JF, Chagnon F, et al. Proven infection-related sepsis induces a differential stress response early after ICU admission. Crit Care 2010; 14: R131. 


\section{Letter to the Editor}

\section{IL-8 and mortality prediction in post- surgical septic shock}

To the Editor:

We read with interest the article entitled 'Multiplex cytokine profiling in patients with sepsis', by Mera $\mathrm{S}$ and col (1). In this article, the authors simultaneously measured in 30 septic patients 17 cytokines during the first 7 days following admission. The authors found in the multivariate logistical regression analysis that the initial levels of interleukin (IL)-8 were the most predictive for fatal outcome.

Although the presence of septic shock in the Mera and col cohort was limited to 9 of 30 patients, we actually tried to evaluate the prognostic role of the same cytokines in a cohort of patients with a more severe form of the disease. This way, we recruited 38 patients with post-surgical septic shock. Patients were prospectively recruited from our Intensive Care Unit from January to December 2011. Recommendations of the American College of Chest Physicians/Society of Critical Care Medicine Consensus Conference were followed to define septic shock (2). Approval for the study protocol for both the scientific and the ethical aspects was obtained from the Scientific Committee for Clinical Research of our Hospital. Informed consent was obtained directly from the patients'legal representative before enrolment. A $5 \mathrm{~mL}$ Ethylenediaminetetraacetic acid (EDTA) tube was collected in the 24 first hours following diagnosis of Septic Shock. Twelve patients had suffered a cardiac surgery, whereas 26 had suffered an abdominal surgery.
Fifteen patients died during hospitalization at the ICU. A positive bacterial or fungal infection was found in 27 patients in blood and/or local culture. Six cases had an exclusive infection by a gram-positive bacteria; 10 cases had an exclusive infection by a gram-negative bacteria; an exclusive fungal infection was found in one patient; six patients had a combined infection by gram-positive + gram-negative bacteria; two patients had a combined infection by gram-negative bacteria + fungi; three patients had a combined infection by grampositive, gram-negative bacteria and fungi. Sixteen healthy volunteers working at our hospital of similar age were recruited as controls for comparison purposes. The multiplex cytokine kit was also a 17 plex kit purchased from BioRad (Hercules, CA, USA), including [IL-1b, IL-2, IL-4, IL-5, IL-6, IL-7, IL-8, IL-10, IL12 , IL-13, IL-17, interferon- $\gamma$, granulocyte colony-stimulating factor, granulocyte macrophage colony-stimulating factor, monocyte chemotactic protein (MCP-1), macrophage inflammatory protein (MIP)-1b and tumour necrosis factor (TNF)-a].

Mann-Whitney $U$-test evidenced that patients with septic shock had higher plasma levels of IL-6, IL-8, IL-10, IL-13, MCP-1 and MIP-1 $\beta$ than controls, independently of their final outcome (data not shown). Patients who died had significant higher levels of IL-8 and MCP-1 at the moment of diagnosis than those who survived [median, interquartile rank $(\mathrm{pg} /$ $\mathrm{mL})$ in survivors and fatal cases]: IL-8 [(80.8, 172.4); (158.6, 217.9)] (Fig. 1); MCP-1 [(148.4, 441.7); $(346.8,1347.7)](\mathrm{p}<0.05)$. Patients
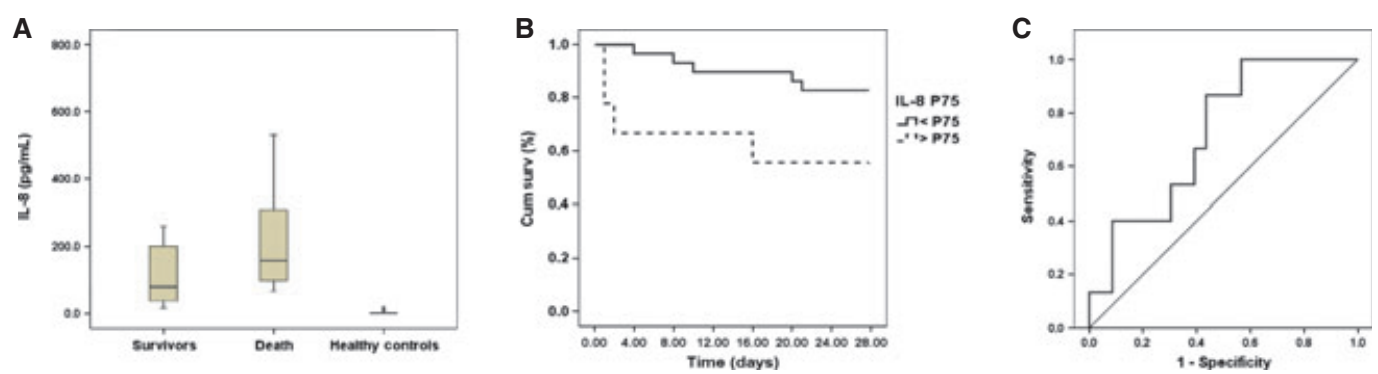

Fig. 1. (A) Interleukin (IL)-8 levels at diagnosis of septic shock depending on the final outcome (B) Survival curves depending on IL-8 levels at diagnosis of septic shock. (C) Receiver operating characteristic curves of IL-8 levels at diagnosis predicting mortality. 
who died were in turn older and presented at the ICU with higher Acute Physiology and Chronic Health Evaluation II (APACHE II) scores (mean, SD): age (years) in survivors (68.0, 14.3); age (years) in fatal cases (75.2, 11.7); APACHE II in survivors (13.2, 5.5); APACHE II in fatal cases (18.4, 3.6). Multivariate Cox regression analysis adjusted by (age) and (APACHE II score) showed that IL-8 was the only cytokine associated with increased risk of mortality at 28 days following diagnosis of septic shock [Hazard ratio, (CI 95\%), p]: [2.91 (1.04-8.13), 0.041)] Nonetheless, in the same analysis, MCP-1 behaved also as a risk factor for mortality, but at the level $\mathrm{p}<0.1$ (not statistically significant, data not shown). Logarithmic concentrations of the cytokines were employed in the regression analysis to satisfy the linearity assumption. Kaplan-Meier survival curves evidenced that the patients showing IL-8 levels below percentile 75 $(257 \mathrm{pg} / \mathrm{mL})$ of the values of the cohort evaluated survived longer survival mean time in days [CI 95\%]: (<percentile 75) [25.3 (23.0 27.7)]; (>percentile 75) $\left.\quad\left[\begin{array}{ll}17.8 & (9.8-25.7)\end{array}\right]\right\}$ (Fig. 1). Finally, receiver operating characteristic curve analysis evidenced that IL- 8 showed a good association with mortality, with an area under the curve of $0.72(\mathrm{p}=0.022)$ (Fig. 1).

Patients with positive microbiological identification showed no significant differences in the proportion of patients with fatal outcome as assessed by Chi-squared test or in IL-8 levels in plasma (Mann-Whitney test) compared to those with absence of positive microbiological identification (data not shown).

Our results are in agreement with those found by Fujishima et al. (3), who reported that an initially detectable level of circulating IL-8 predict a high mortality in sepsis. Bozza et al. (4) and Marty et al. (5) had also linked IL-8 to unfavourable outcome in sepsis. In a cohort of patients included in controlled trials of ventilator strategy for acute lung injury, Calfee et al. found that plasma levels of IL$8>$ or $=220 \mathrm{pg} / \mathrm{mL}$ were significantly associated with death at 28 days, although receiver operating characteristic analysis found a poor correlation between IL-8 and mortality (area under the curve of 0.59) (6). Differences in the composition of the patients'cohort (surgical/ medical origin) could explain the differences observed on the prognostic role of this mediator.

Interleukin- 8 is a pro-inflammatory $\mathrm{CXC}$ chemokine. IL-8 is produced by many cell types after stimulation by IL-1, TNF, or microbial products such as endotoxins (5). This chemokine promotes angiogenesis, as well as neutrophil migration and activation (7). IL8 may recruit neutrophils to vital organs, which in turn could release mediators involved in the pathogenesis of sepsis (3).

In conclusion, our results confirm the predictive role of IL-8 also in the most severe scenario of sepsis, septic shock, supporting their important implication in the pathophysiology of this disease.

The authors thank Lucia Rico and Veronica Iglesias for their technical assistance. This study was made possible by a grant from the 'Instituto de Salud Carlos III, Proyectos de Investigación Sanitaria' (PI 10/01362).

ANA FERNÁNDEZ, ${ }^{1}$ EDUARDO TAMAYO, ${ }^{1}$ MARÍA HEREDIA, ${ }^{1}$ LISBETH GONCALVES, ${ }^{2}$ RAQUEL ALMANSA, ${ }^{2,3}$ JOSE I. GÓMEZ-HERRERAS, ${ }^{1}$ RAÚL O. DE LEJARAZU ${ }^{2,3}$ and JESUS F. BERMEJO-MARTIN ${ }^{2,3}$

${ }^{1}$ Intensive Care Unit, Anesthesiology and Reanimation Service, Hospital Clínico Universitario-SACYL, Valladolid;

${ }^{2}$ Microbiology and Immunology Service, Hospital Clínico Universitario-SACYL, Valladolid; and ${ }^{3}$ Unidad de Investigación, Programa de Investigación Biomédica del Clínico (ibC), Hospital Clínico Universitario de Valladolid-IECSCYL, Valladolid, Spain E-mail:jfbermejo@saludcastillayleon.es

\section{REFERENCES}

1. Mera S, Tatulescu D, Cismaru C, Bondor C, Slavcovici A, Zanc V, et al. Multiplex cytokine profiling in patients with sepsis. APMIS 2011; 119:155-63.

2. Bone RC, Balk RA, Cerra FB, Dellinger RP, Fein AM, Knaus WA, et al. Definitions for sepsis and organ failure and guidelines for the use of innovative therapies in sepsis. The ACCP/SCCM Consensus Conference Committee. American College 
of Chest Physicians/Society of Critical Care Medicine. 1992. Chest 2009;136(Suppl 5):e28.

3. Fujishima S, Sasaki J, Shinozawa Y, Takuma K, Kimura H, Suzuki M, et al. Serum MIP-1 alpha and IL-8 in septic patients. Intensive Care Med 1996;22:1169-75.

4. Bozza FA, Salluh JI, Japiassu AM, Soares M, Assis EF, Gomes RN, et al. Cytokine profiles as markers of disease severity in sepsis: a multiplex analysis. Crit Care 2007;11:R49.

5. Marty C, Misset B, Tamion F, Fitting C, Carlet J, Cavaillon JM. Circulating interleukin-8 concentrations in patients with multiple organ failure of septic and nonseptic origin. Crit Care Med 1994;22:673-9.

6. Calfee CS, Thompson BT, Parsons PE, Ware LB, Matthay MA, Wong HR. Plasma interleukin-8 is not an effective risk stratification tool for adults with vasopressor-dependent septic shock. Crit Care Med 2010;38:1436-41.

7. Esche C, Stellato C, Beck LA. Chemokines: key players in innate and adaptive immunity. J Invest Dermatol. 2005;125:615-28. 


\title{
Beneficial role of endogenous immunoglobulin subclasses and isotypes in septic shock
}

\author{
Eduardo Tamayo MD, PhD ${ }^{a, b, 1}$, Ana Fernández MD ${ }^{a, b, 1}$, Raquel Almansa PhD ${ }^{b, c, 1}$, \\ Elena Carrasco MD ${ }^{a, b}$, Lisbeth Goncalves MD ${ }^{b}$, María Heredia MD ${ }^{a, b}$, \\ David Andaluz-0jeda MD ${ }^{\text {,d }}$, Gabriel March MSc ${ }^{b}$, Lucia Rico MLT ${ }^{\text {b, }}$, \\ Jose I. Gómez-Herreras MD PhD ${ }^{a, b}$, Raúl Ortiz de Lejarazu MD PhD b', \\ Jesus F. Bermejo-Martin MD PhD ${ }^{b, c, *}$
}

\author{
anesthesiology and Reanimation Service, Hospital Clínico Universitario-SACYL, 47005 Valladolid, Spain \\ ${ }^{\mathrm{b}}$ Investigación biomédica del Clínico (ibC), Hospital Clínico Universitario de Valladolid-SACYL, 47005 Valladolid, Spain \\ ${ }^{\mathrm{c}}$ Infection and Immunity Medical Investigation Unit (IMI), Microbiology and Immunology Service, \\ Hospital Clínico Universitario-IECSCYL, 47005 Valladolid, Spain \\ ${ }^{\mathrm{d}}$ Critical Care Medicine Service. Hospital Clínico Universitario-SACYL, 47005 Valladolid, Spain
}

\section{Keywords: \\ Endogenous; Immunoglobulin; Isotype; \\ Subclass; \\ Sepsis}

\begin{abstract}
Purpose: There is increasing evidence on the relationship between endogenously produced immunoglobulins and the clinical outcome in septic shock (SS).

Materials and methods: Levels of immunoglobulin $\mathrm{G}$ ( $\operatorname{IgG})$ subclasses, immunoglobulin A ( $\operatorname{IgA}$ ), immunoglobulin $\mathrm{M}(\mathrm{IgM})$, and immunoglobulin E were measured in plasma from 42 patients with SS and in 36 patients with systemic inflammatory response syndrome at diagnosis. Association of immunoglobulins levels with disease severity and outcome was evaluated.

Results: Eighteen patients with SS finally died. Both patients with systemic inflammatory response syndrome and SS showed subnormal levels of total $\mathrm{IgG}$, IgG2, and IgM. Patients with SS who died showed the lowest levels of total IgG and IgG1. Total IgG, IgG1, IgG2, IgG3, IgG4, and IgA correlated inversely with Acute Physiology and Chronic Health Evaluation II score in SS. Univariate Cox regression analysis showed that levels of $\operatorname{IgG} 1, \operatorname{IgG} 2, \operatorname{IgG} 3, \operatorname{IgM}, \operatorname{IgA}$, and total $\operatorname{IgG}$ were inversely associated to the probability of death at 28 days. Multivariate analysis showed that $\operatorname{IgG1}$, total $\operatorname{IgG}, \operatorname{IgM}$, and $\operatorname{IgA}$ behaved as independent protective factors against mortality (hazard ratio, $P$ ): $0.23,0.026 ; 0.16$, $0.028 ; 0.11,0.042 ; 0.05,0.010$, respectively, whereas IgG3 showed a protective trend also.

Conclusions: Our study evidenced that, in addition to IgG1, other major endogenous immunoglobulins isotypes and subclasses seem to play a beneficial role in SS.

(C) 2012 Elsevier Inc. All rights reserved
\end{abstract}

* Corresponding author. Investigación Biomédica del Clínico (ibC). Hospital Clínico Universitario de Valladolid-SACYL, Avda Ramón y Cajal 3, 47005 Valladolid, Spain. Ramón y Cajal 3, 47005 Valladolid, Spain. Tel.: +34 983420000x383; fax: +34 983420040.

E-mail address: jfbermejo@saludcastillayleon.es (J.F. Bermejo-Martin).

${ }^{1}$ Eduardo Tamayo, Ana Fernández, and Raquel Almansa contributed equally to this work. 


\section{Introduction}

There is increasing evidence on the relationship between endogenously produced immunoglobulins and prognosis in septic shock (SS). Recently, Venet et al [1] reported low plasma levels of immunoglobulin $\mathrm{G}$ (IgG) and immunoglobulin M (IgM) in patients with SS in the first 4 days of the disease course, with no association with mortality, morbidity, or severity. In turn, we have recently reported decreased levels of IgG in plasma from patients with SS with fatal outcome [2]. Taccone et al [3] demonstrated in a pilot study the existence of persistent low concentration of $\gamma$-globulins, especially $\mathrm{IgG}$, in patients with community-acquired SS, associated to greater vasopressor requirements, acute respiratory distress syndrome, and higher mortality.

In spite of the available evidence on the relationship between immunoglobulin levels in the early stages of SS and disease outcome, results on the potential beneficial role of replacement therapies with intravenous immunoglobulin (IVIG) in sepsis are actually controversial. The metaanalysis performed by Laupland et al [4] demonstrated an overall reduction in mortality with the use of IVIG for the adjunctive treatment of severe sepsis and SS in adults. On the contrary, the SBIT study found that IVIG did not reduce mortality in a cohort of septic patients whose severity was defined by clinical scores [5]. Polyclonal immunoglobulins preparation enriched with immunoglobulin A (IgA) and IgM seem to provide better results in reducing mortality compared with preparations containing only IgG [6]. Lack of information on endogenous immunoglobulin isotypes levels before treatment is the general rule in these studies. In addition, there is a great absence of information on the individual role of $\operatorname{IgG}$ subclasses in SS. Here, we evaluated in a cohort of 42 patients, the association between levels in plasma of $\mathrm{IgG}$ subclasses, IgA, and IgM with severity of SS at diagnosis and clinical outcome.

\section{Materials and methods}

\subsection{Patients}

Patients with SS or systemic inflammatory response syndrome (SIRS) were prospectively recruited from the Reanimation Unit of the Hospital Clínico Universitario de Valladolid in Spain from January to December 2011. Recommendations of the American College of Chest Physicians/Society of Critical Care Medicine Consensus Conference were followed to define SS and SIRS [7]. Approval for the study protocol for both the scientific and the ethical aspects was obtained from the Scientific Committee for Clinical Research of our hospital. Informed consent was obtained directly from each patient before enrollment.

\subsection{Sample collection and immunoglobuling quantification}

A 5-mL EDTA tube was collected in the 24 first hours following diagnosis of SIRS or SS. The tubes were appropriately centrifuged, and plasma was obtained and stored at $-80^{\circ} \mathrm{C}$ until immunoglobulin quantification. Levels of $\operatorname{IgG} 1, \operatorname{IgG} 2$, IgG3, IgG4, IgA, IgM, and immunoglobulin $\mathrm{E}(\mathrm{IgE})$ in plasma were measured by using a multiplex Immunoglobulin Isotyping kit purchased to Biorad TM (Hercules, CA, USA) on a Luminex platform.

\subsection{Microbiology}

Standard cultures in biological samples guided by the presumptive source of the septic insult were performed to assess the presence of bacterial and fungal infection [8]. Potentially contaminant microorganisms were not considered.

\subsection{Statistical analysis}

For the demographic and clinical characteristics of the patients, differences between groups were assessed using the $\chi^{2}$ test for categorical variables and the Mann-Whitney $U$ test for continuous variables when appropriate. We determined the hazard ratio (HR) and 95\% confidence interval by Cox regression analysis, which was used to assess the impact of immunoglobulin levels on mortality over time. In addition to immunoglobulin levels, the following independent variables were introduced in the regression analysis as covariables: age, sex, cardiac/ abdominal surgery, Acute Physiology and Chronic Health Evaluation (APACHE) II score, number of hemoderivative units received, and number of failing organs. The number of failing organs was calculated based on the variables included in the Sequential Organ Failure Assessment score (respiratory, coagulation, liver, cardiovascular, central nervous system, renal) [9]. A Sequential Organ Failure Assessment score of 3 or 4 in a given variable was considered as organ failure. Logarithmic concentrations of the immunoglobulins evaluated and logarithmic values of APACHE-II score were used in the regression analysis to satisfy the linearity assumption. We determined the occurrence of death by using Kaplan-Meier curves. Groups were compared by the log-rank test (MantelHaenzel). The accuracy and the predictive values of the immunoglobulins analyzed for survival were studied by calculating areas under the receiver operating characteristic curve. Correlation studies between immunoglobulin levels and APACHE II score were performed using the Spearman-Karber test. All statistical tests were 2 sided, and $P<.05$ was considered significant. Data analysis was performed using SPSS for Windows version 15.0 software (SPSS, Chicago, Ill). 


\section{Results}

\subsection{Clinical characteristics}

All patients had cardiac surgery (valvular replacement or coronary revascularization) or abdominal surgery (Table 1). Eighteen patients with SS finally died. Most patients were elderly males, although those with SS who died were slightly older. The most common clinical antecedent was cardiovascular disease and high blood pressure. Necessity of urgent surgery was more frequent in the SS group. Forty-two patients with SS showed respiratory and cardiovascular failure (100\%), 16 showed renal failure $(38 \%)$, and 2 showed severe coagulation alterations (4\%). Those patients with SS who died showed worse respiratory conditions and stayed under mechanical ventilation for longer. Lactate and procalcitonin levels were higher in those patients with SS who died. Microbiologic findings were as showed in the supplementary file 1 .

\subsection{Immunoglobulin levels and association with severity at diagnosis}

Immunoglobulin $\mathrm{E}$ was below the detection limit of the employed kit and, in consequence, was not included in the analysis. Correlation analysis showed that levels of total IgG, IgG1, IgG2, IgG3, IgG4, and IgA were inversely associated to APACHE II score at diagnosis of SS ( $r$ coefficient, $P$ ): $-0.495,0.001 ;-0.489,0.001 ;-0.366,0.017 ;-0.404$, $0.008 ;-0.297,0.050 ;-0.300,0.050$, respectively. Levels of IgG subclasses, IgM, and IgA correlated positively with each other (data not shown).

\subsection{Immunoglobulin levels and association with mortality}

Mann-Whitney $U$ test revealed that patients with SS who died showed significantly lower levels of IgG1 and total IgG compared with those patients with SIRS and those with SS who survived (Table 2). Univariate Cox regression analysis

Table 1 Clinical characteristics of the patients with SIRS and SS

\begin{tabular}{|c|c|c|c|}
\hline & SIRS $(n=36)$ & SS, survivors $(n=24)$ & $\mathrm{SS}$, fatal $(\mathrm{n}=18)$ \\
\hline Age (y) (mean \pm SD) & $66.7(13.0)$ & $68.3(14.4)$ & $74.8(11.3)$ \\
\hline Sex (male/female) & $24 / 12$ & $17 / 7$ & $13 / 5$ \\
\hline APACHE II at diagnosis (mean $\pm \mathrm{SD}$ ) & $10.2(3.2)$ & $13.0(5.6)$ & $18.4(3.5)$ \\
\hline Cardiac/abdominal surgery & $22 / 14$ & $11 / 14$ & $5 / 12$ \\
\hline Diabetes, n (\%) & $9(25.0)$ & $8(33.3)$ & $3(16.6)$ \\
\hline Cardiovascular disease, $\mathrm{n}(\%)$ & $22(61.1)$ & $11(45.8)$ & $7(38.8)$ \\
\hline COPD, n (\%) & $6(16.7)$ & $5(20.8)$ & $5(20.8)$ \\
\hline Hypertension, n (\%) & $19(52.8)$ & $16(66.6)$ & $9(50.0)$ \\
\hline Chronic kidney disease, $\mathrm{n}(\%)$ & $3(8.3)$ & $4(16.0)$ & $2(11.8)$ \\
\hline Neoplasia, n (\%) & $8(22.2)$ & $6(24.0)$ & $5(29.4)$ \\
\hline Obesity (BMI > 30), n (\%) & $8(22.2)$ & $1(4.0)$ & $2(11.8)$ \\
\hline Smoking habit, n (\%) & $6(16.7)$ & $4(16.0)$ & $5(29.4)$ \\
\hline Alcoholism, n (\%) & $3(8.3)$ & $3(12.0)$ & $1(5.9)$ \\
\hline Chronic liver disease, $\mathrm{n}(\%)$ & $1(2.8)$ & $0(0.0)$ & $0(0.0)$ \\
\hline Immunosuppression, $\mathrm{n}(\%)$ & $2(5.6)$ & $3(12.0)$ & $0(0.0)$ \\
\hline Urgent surgery, $\mathrm{n}(\%)$ & $2(5.6)$ & $12(50.0)$ & $13(72.2)$ \\
\hline $\mathrm{PaO}_{2} / \mathrm{FIO}_{2}($ mean $\pm \mathrm{SD})$ & $242.2(68.4)$ & $244.9(50.4)$ & $174.5(50.4)$ \\
\hline Creatinine $(\mathrm{mg} / \mathrm{dL})($ mean $\pm \mathrm{SD})$ & $0.9(0.3)$ & $1.6(1.0)$ & $2.2(1.2)$ \\
\hline Bilirubin $(\mathrm{mg} / \mathrm{dL})($ mean $\pm \mathrm{SD})$ & $0.7(0.5)$ & $1.3(1.1)$ & $1.1(0.8)$ \\
\hline Lactate $(\mathrm{mg} / \mathrm{dL})($ mean $\pm \mathrm{SD})$ & $23.0(12.8)$ & $26.7(25.6)$ & $38.3(36.0)$ \\
\hline Procalcitonin $(\mu \mathrm{g} / \mathrm{L})($ mean $\pm \mathrm{SD})$ & $0.6(0.8)$ & $21.2(33.6)$ & $31.1(34.8)$ \\
\hline $\mathrm{ScvO}_{2}(\%)($ mean $\pm \mathrm{SD})$ & $73.6(8.2)$ & $72.6(8.1)$ & $70.2(8.9)$ \\
\hline $\mathrm{CRP}(\mathrm{mg} / \mathrm{dL})($ mean $\pm \mathrm{SD})$ & $57.0(65.3)$ & $283.9(119.8)$ & $235.5(94.3)$ \\
\hline $\mathrm{Na}+(\mathrm{mEq} / \mathrm{L})($ mean $\pm \mathrm{SD})$ & $135.3(18.0)$ & $138.1(3.3)$ & $130.9(26.0)$ \\
\hline $\mathrm{K}+(\mathrm{mEq} / \mathrm{L})($ mean $\pm \mathrm{SD})$ & $3.8(0.6)$ & $5.6(9.1)$ & $4.3(1.0)$ \\
\hline Hematocrit $(\%)($ mean $\pm \mathrm{SD})$ & $31.7(3.7)$ & $29.5(4.9)$ & $29.3(3.9)$ \\
\hline Leukocytes $/ \mathrm{mm}^{3}($ mean $\pm \mathrm{SD})$ & $10502.6(5935.0)$ & $16093.5(10851.6)$ & $16263.9(9866.1)$ \\
\hline Neutrophils $(\%)($ mean \pm SD) & $84.5(4.8)$ & $86.3(4.5)$ & $88.8(6.3)$ \\
\hline Duration of mechanical ventilation $(\mathrm{d})($ mean $\pm \mathrm{SD})$ & NA & $7.6(11.4)$ & $15.0(17.5)$ \\
\hline Days from ICU admission to diagnosis (mean $\pm \mathrm{SD}$ ) & $2.2(4.7)$ & $4.2(7.2)$ & $3.9(4.9)$ \\
\hline Days from diagnosis to death (mean $\pm \mathrm{SD}$ ) & NA & NA & $21.9(21.7)$ \\
\hline Length of ICU stay $(d),($ mean \pm SD) & $1.6(1.1)$ & $35.0(119.1)$ & $18.4(18.7)$ \\
\hline
\end{tabular}

COPD indicates chronic obstructive pulmonary disease; BMI, body mass index; $\mathrm{ScvO}_{2}$, central venous oxygen saturation; CRP, C-reactive protein. 
Table 2 Immunoglobulin levels in the SIRS and SS groups (mg/dL)

\begin{tabular}{llcc}
\hline & $\begin{array}{l}\text { SIRS } \\
(\mathrm{n}=36)\end{array}$ & $\begin{array}{l}\text { SS (survivors) } \\
(\mathrm{n}=24)\end{array}$ & $\begin{array}{l}\text { SS (death) } \\
(\mathrm{n}=18)\end{array}$ \\
\hline IgG (total) & $808.4(473.4)^{\mathrm{a}}$ & $830.1(705.5)^{\mathrm{a}}$ & $597.6(600.9)$ \\
IgG1 & $644.6(431.5)^{\mathrm{a}}$ & $657.1(632.3)^{\mathrm{a}}$ & $368.6(357.9)$ \\
IgG2 & $53.5(65.9)$ & $60.4(130.1)$ & $49.2(108.2)$ \\
IgG3 & $69.0(72.9)$ & $81.1(118.1)$ & $52.1(101.1)$ \\
IgG4 & $12.1(14.7)$ & $13.2(13.5)$ & $16.1(19.3)$ \\
IgM & $32.9(33.8)$ & $33.0(72.4)$ & $30.2(43.0)$ \\
IgA & $182.1(100.4)$ & $211.6(206.8)$ & $162.2(125.7)$ \\
\hline
\end{tabular}

Results are provided as (median [interquartile rank]). Normal values in adult healthy individuals are as follows: $\operatorname{IgG}(870-2180 \mathrm{mg} / \mathrm{dL}), \operatorname{IgG} 1$ (344-966 mg/dL), IgG2 (133-622 mg/dL), IgG3 (12-138 mg/dL), IgG4 (1-115 mg/dL), IgA (117-420 mg/dL), IgM (60-220 mg/dL).

a Significant differences with patients with SS who died at the level $P<.05$.

in the SS group showed that levels of $\operatorname{IgG} 1, \operatorname{IgG} 2, \operatorname{IgG} 3$, $\operatorname{IgM}, \operatorname{IgA}$, and total $\operatorname{IgG}$ were inversely associated to the probability of death at 28 days following diagnosis (Table 3 ). Multivariate analysis showed that $\operatorname{IgG1}$, total $\operatorname{IgG}$, IgM, and IgA behaved as independent protective factors against mortality $(P<.05)$, whereas IgG3 showed the same trend $(P<.1)$ (Table 3). Kaplan-Meier curves evidenced that those patients with SS with $\operatorname{IgG1}$ and total $\operatorname{IgG}$ values below percentile 30 (P30) died earlier than those with values over P30 (Fig. 1). Survival times were as follows (mean, 95\% confidence interval): patients less than P30, 19.2 days (13.524.8); patients more than P30, 24.5 days (21.5-27.5), for both IgG1 and total IgG. Percentile 30 was $356 \mathrm{mg} / \mathrm{dL}$ for IgG1 and $484 \mathrm{mg} / \mathrm{dL}$ for total $\mathrm{IgG}$ (Fig. 1). Receiver operating characteristic curve analysis showed that $\operatorname{IgG1}$ and total $\operatorname{IgG}$ were the best immunoglobulins for predicting survival, with an area under the curve of $0.73(P=.01)$ for IgG1 and of 0.71 $(P=.02)$ for total IgG (Fig. 2).

Table 3 Cox regression analysis for mortality at 28 days following diagnosis

\begin{tabular}{|c|c|c|c|c|}
\hline & \multicolumn{2}{|c|}{ Univariate analysis } & \multicolumn{2}{|c|}{ Multivariate analysis ${ }^{\mathrm{a}}$} \\
\hline & $\begin{array}{l}\text { HR }(95 \% \\
\text { confidence } \\
\text { interval) }\end{array}$ & $P$ & $\begin{array}{l}\text { HR }(95 \% \\
\text { confidence } \\
\text { interval) }\end{array}$ & $P$ \\
\hline Total IgG & $0.27(0.10-0.74)$ & .011 & $0.16(0.03-0.82)$ & .028 \\
\hline IgG1 & $0.41(0.20-0.86)$ & .018 & $0.23(0.06-0.84)$ & .026 \\
\hline IgG2 & $0.35(0.12-0.99)$ & .048 & $0.45(0.14-1.43)$ & NS \\
\hline IgG3 & $0.31(0.10-0.95)$ & .040 & $0.20(0.03-1.15)$ & .071 \\
\hline IgG4 & $0.47(0.12-1.83)$ & .276 & $0.50(0.11-2.30)$ & NS \\
\hline $\operatorname{IgM}$ & $0.23(0.07-0.81)$ & .022 & $0.11(0.01-0.93)$ & .042 \\
\hline $\operatorname{Ig} \mathrm{A}$ & $0.20(0.06-0.70)$ & .012 & $0.05(0.01-0.49)$ & .010 \\
\hline
\end{tabular}

\section{Discussion}

Immunoglobulin isotypes profiling in SS and SIRS evidenced first of all that $\operatorname{IgE}$ does not seem to play any significant role in these conditions. It is somehow an expected result because IgE is mainly involved in the defense against parasites and plays a central role in the physiopathology of allergy and asthma [10]. In addition, our results evidenced that either patients with SIRS or SS had median levels of total IgG at diagnosis consistent with hypogammaglobulinemia, attending to the reference values of normality in our laboratory (Table 2). Nonetheless, patients with SS who finally died showed the lowest levels of total IgG.

Human IgG can be subdivided into 4 subclasses, IgG1, $\operatorname{IgG} 2, \operatorname{IgG} 3$ and $\operatorname{IgG} 4$, each encoded by a separate constant (C) region gene and endowed with unique biological and functional properties. Measurement of IgG subclasses revealed that the low levels of total IgG observed in SS patients who died were mostly due to diminution of $\operatorname{IgG1}$, which median levels were in the lower limit of normality (Table 2) [11].

Immunoglobulin $\mathrm{G} 1$ makes up most of the total $\operatorname{IgG}(66 \%)$, followed by $\operatorname{IgG} 2(24 \%), \operatorname{IgG} 3(7 \%)$, and $\operatorname{IgG} 4(3 \%)[12,13]$. In consequence, IgG1 accounts for the major fraction of total $\mathrm{IgG}$, and a decrease in IgG1 normally results in hypogammaglobulinemia [14], which occurs in our study. Immunoglobulin G1 and IgG3 are generally induced in response to protein antigens, whereas IgG2 and IgG4 antibodies are associated with polysaccharide antigens [10]. Immunoglobulin G1 and IgG3 are efficient activators of the classical complement pathway [12]. Activation of the complement cascade is an important means of clearance of opsonized pathogens [10]. In fact, deficiency of IgG1 is often, although not invariably, associated with susceptibility to bacterial infections. However, to our current knowledge, there is no available information on the role of IgG subclasses in sepsis.

Interestingly, comparing patients with SIRS and SS, we found neither significant differences in the levels of the other IgG subclasses nor in the levels of IgA or IgM, although both showed levels of $\operatorname{IgG} 2$ and IgM under normal reference values (Table 2). Our results draw a picture of humoral immunodeficiency associated to the state of SIRS and SS. Although Venet et al [1] had already reported similar results for SS, we have found no available information on endogenous immunoglobulin levels in SIRS.

Correlation analysis supported the potential protective effect of endogenously produced immunoglobulins in SS, as indicated in the inverse association found between immunoglobulin levels and APACHE II score for severity. Univariate Cox regression analysis reinforced the rationale on the protective role of immunoglobulins in SS. In the multivariate analysis, total $\mathrm{IgG}, \operatorname{IgG} 1, \operatorname{IgM}$, and $\operatorname{IgA}$ were independently associated with increased probability of survival, with $\operatorname{IgG} 3$ also showing a protective trend. Immunoglobulin A is critical at protecting mucosal surfaces from toxins, viruses, and bacteria by means of direct 

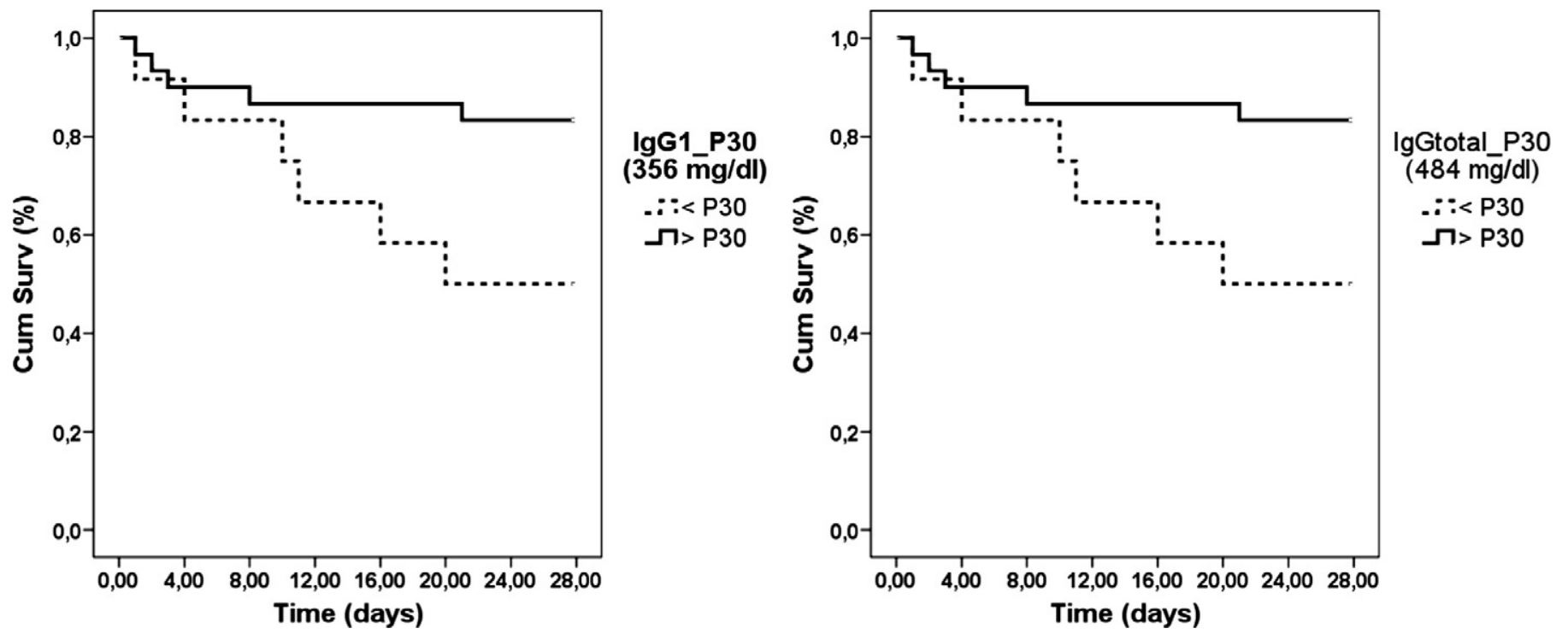

Fig. 1 Kaplan-Meier curves. Deciles from percentile 10 to percentile 90 of immunoglobulins levels at diagnosis were calculated and used to compare survival times in those patients with low or high concentrations of immunoglobulins in plasma. The first decile showing significant differences between groups based upon the log-rank test (Mantel-Haenzel) was used as the cutoff point (percentile 30). Outcome for this analysis was time until death. Time was censored at day 28. Cum Surv indicates cumulative survival. 

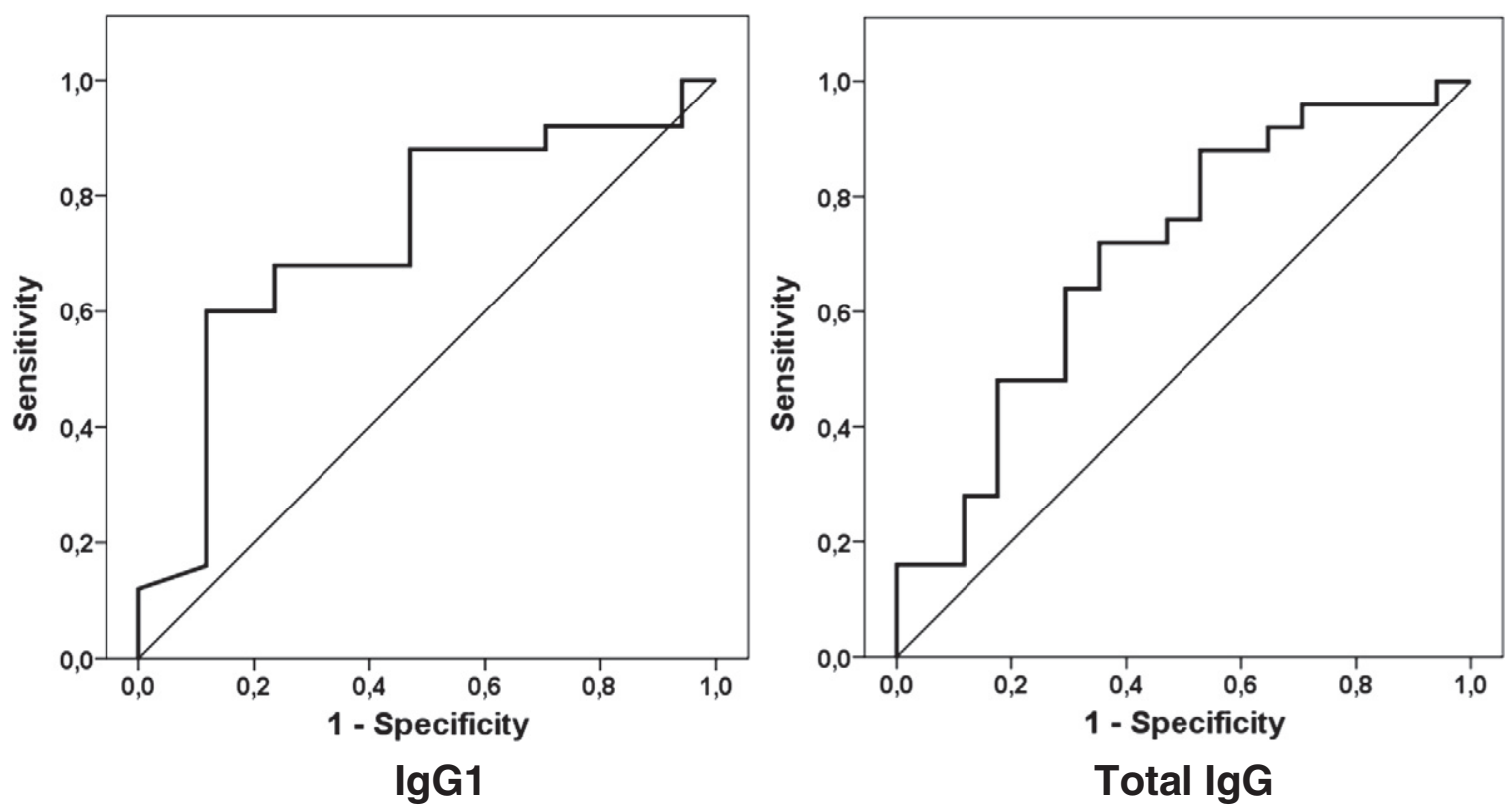

Fig. 2 Receiver operating characteristic curves of immunoglobulin levels at diagnosis predicting survival.

neutralization or prevention of binding to the mucosal surface [10]. Immunoglobulin $\mathrm{M}$ is a pentameric immunoglobulin secreted early in the course of infection. Immunoglobulin $\mathrm{M}$ functions by opsonizing (coating) antigen for destruction and fixing complement [10]. Consequently, low levels of this immunoglobulin could preclude bacterial clearance. Coutinho et al [15] reported noticeable reductions in numbers of IgA and IgM plasma cells in intestinal tissues from patients with intra-abdominal sepsis.

The association between immunoglobulins levels with survival was not dependent on hemodilution, as supported in the multivariate analysis. Otherwise, a subclass/isotype defect may be primary, associated with a genetic defect, or secondary to other diseases, often with an inflammatory component $[11,12]$, or alternatively results as a consequence of the existence of a previous state of immunodeficiency derived from the critical condition with SS patients $[16,17]$.

One limitation of our study was the absence of data on immunoglobulin levels along the disease course in both patients with SIRS and SS. Development of specific responses of antibodies is a major landmark of the adaptive immunity against infection and could strongly influence prognosis. Nonetheless, our study clearly demonstrates that endogenous immunoglobulin levels in the very early stages of SS are associated to disease severity at diagnosis and also with outcomes, consequently supporting their important pathogenic role in this disease. Early evaluation of endogenous immunoglobulin levels in SS could thus represent an opportunity for implementing early medical interventions in those patients with SS at a higher risk for death. This way, a recent meta-analysis indicates that the treatment effect of IVIG on mortality for patients with SS is borderline significant with a large degree of heterogeneity in treatment effect in individual studies [18]. In light of our results in the areas under the receiver operating characteristic and Kaplan Meier analysis, measuring endogenous levels of total $\mathrm{IgG}$ and $\mathrm{IgG} 1$ at diagnosis could present an opportunity to improve the render of clinical assays evaluating IVIG as treatment in SS, helping to better select those patients to be treated. Nonetheless, our study evidenced that, in addition to IgG1, other major endogenous immunoglobulins isotypes and subclasses seem to play a beneficial role in SS, which could explain the higher benefit of substitutive polyclonal immunoglobulins in this disease over those preparations containing only $\operatorname{IgG}$. Further works are warranted to evaluate the potential protective role of endogenous immunoglobulins not only in SS but also in severe sepsis.

Supplementary materials related to this article can be found online at http://dx.doi.org/10.1016/j.jcrc.2012.08.004.

\section{Acknowledgments}

The authors wish to acknowledge Veronica Iglesias for their technical support and Alicia San Jose for assistance with language aspects. This study was possible thanks to the financial support obtained from "Fondo de Investigaciones Sanitarias, FIS -Proyectos de Investigación Sanitaria" (Spain) (PI 10/01362).

\section{References}

[1] Venet F, Gebeile R, Bancel J, et al. Assessment of plasmatic immunoglobulin $\mathrm{G}, \mathrm{A}$ and $\mathrm{M}$ levels in septic shock patients. Int Immunopharmacol 2011;11:2086-90. 
[2] Andaluz-Ojeda D, Iglesias V, Bobillo F, et al. Early natural killer cell counts in blood predict mortality in severe sepsis. Crit Care 2011;15: R243.

[3] Taccone FS, Stordeur P, De Backer D, et al. Gamma-globulin levels in patients with community-acquired septic shock. Shock 2009;32: 379-85.

[4] Laupland KB, Kirkpatrick AW, Delaney A. Polyclonal intravenous immunoglobulin for the treatment of severe sepsis and septic shock in critically ill adults: a systematic review and meta-analysis. Crit Care Med 2007;35:2686-92.

[5] Werdan K, Pilz G, Bujdoso O, et al. Score-based immunoglobulin G therapy of patients with sepsis: the SBITS study. Crit Care Med 2007;35:2693-701.

[6] Kreymann KG, de Heer G, Nierhaus A, et al. Use of polyclonal immunoglobulins as adjunctive therapy for sepsis or septic shock. Crit Care Med 2007;35:2677-85.

[7] Bone RC, Balk RA, Cerra FB, et al. Definitions for sepsis and organ failure and guidelines for the use of innovative therapies in sepsis. The ACCP/SCCM Consensus Conference Committee. American College of Chest Physicians/Society of Critical Care Medicine. 1992. Chest 2009;136:e28.

[8] Lennette EHHW, Shadomy HJ. Manual of clinical microbiology. Washington, DC: American Society for Microbiology; 1985. p. $160-200$.

[9] Ferreira FL, Bota DP, Bross A, et al. Serial evaluation of the SOFA score to predict outcome in critically ill patients. JAMA 2001;286(14): 1754-8.
[10] Schroeder Jr HW, Cavacini L. Structure and function of immunoglobulins. J Allergy Clin Immunol 2010;125:S41-52.

[11] Rose ME, Lang DM: Evaluating and managing hypogammaglobulinemia. Cleve Clin J Med 73:133-137, 140, 143-134, 2006.

[12] Pan Q, Hammarstrom L. Molecular basis of IgG subclass deficiency. Immunol Rev 2000;178:99-110.

[13] Blaese RM WJ: IgG subclass deficiency and specific antibody deficiency. Patient \& Family Handbook for Primary Immunodeficiency Diseases Immune Deficiency Foundation In Towson MD, ed 5153, 2007.

[14] Driessen G, van der Burg M. Educational paper: primary antibody deficiencies. Eur J Pediatr 2011;170:693-702.

[15] Coutinho HB, Robalinho TI, Coutinho VB, et al. Intra-abdominal sepsis: an immunocytochemical study of the small intestine mucosa. J Clin Pathol 1997;50:294-8.

[16] Monneret G, Venet F, Kullberg BJ, et al. ICU-acquired immunosuppression and the risk for secondary fungal infections. Med Mycol 2010;49(Suppl. 1):S17-23

[17] Monneret G, Venet F, Pachot A, et al. Monitoring immune dysfunctions in the septic patient: a new skin for the old ceremony. Mol Med 2008;14:64-78.

[18] Soares MO, Welton NJ, Harrison DA, et al. An evaluation of the feasibility, cost and value of information of a multicentre randomised controlled trial of intravenous immunoglobulin for sepsis (severe sepsis and septic shock): incorporating a systematic review, metaanalysis and value of information analysis. Health Technol Assess 2012;16:1-186 
Supplementary file 1:

\begin{tabular}{|l|c|}
\hline \multicolumn{1}{|c|}{ Microbiological findings } & $\begin{array}{c}\text { Number of } \\
\text { positive } \\
\text { cases }\end{array}$ \\
\hline Gram Positive bacteria- Lung & 5 \\
\hline Gram Positive bacteria- Abdominal & 0 \\
\hline Gram Positive bacteria- Urine & 0 \\
\hline Gram Positive bacteria- Catheter & 1 \\
\hline Gram Positive bacteria- Blood & 6 \\
\hline Gram Positive bacteria- Wound Exudate & 5 \\
\hline Gram Positive bacteria- Peritoneal Liquid & 2 \\
\hline Gram Positive bacteria- Axilla- Pharynx - Rectum & 3 \\
\hline Gram Positive bacteria- Other Location & 3 \\
\hline Gram Negative bacteria- Lung & 7 \\
\hline Gram Negative bacteria- Abdominal & 0 \\
\hline Gram Negative bacteria- Urine & 3 \\
\hline Gram Negative bacteria - Catheter & 1 \\
\hline Gram Negative bacteria- Blood & 5 \\
\hline Gram Negative bacteria- Wound Exudate & 8 \\
\hline Gram Negative bacteria- Peritoneal Liquid & 1 \\
\hline Gram Negative bacteria - Axilla- Pharynx - Rectum & 12 \\
\hline Gram Negative bacteria- Other Location & 8 \\
\hline Fungi- Lung & 1 \\
\hline Fungi- Abdominal & 0 \\
\hline Fungi- Urine & 3 \\
\hline Fungi- Catheter & 0 \\
\hline Fungi- Blood & 0 \\
\hline Fungi- Wound Exudate & 1 \\
\hline Fungi- Peritoneal Liquid & 0 \\
\hline Fungi - Axilla- Pharynx - Rectum & 3 \\
\hline Fungi - Other Location & \\
\hline & \\
\hline
\end{tabular}

